\title{
Primate tarsal bones from Egerkingen, Switzerland, attributable to the middle Eocene adapiform Caenopithecus lemuroides
}

Erik R Seiffert, Loïc Costeur, Doug M Boyer

The middle Eocene species Caenopithecus lemuroides, known solely from the Egerkingen fissure fillings in Switzerland, was the first Paleogene fossil primate to be correctly identified as such (by Ludwig Rütimeyer in 1862), but has long been represented only by fragmentary mandibular and maxillary remains. More recent discoveries of adapiform fossils in other parts of the world have revealed Caenopithecus to be a biogeographic enigma, as it is potentially more closely related to Eocene adapiforms from Africa, Asia, and North America than it is to any known European forms. More anatomical evidence is needed, however, to provide robust tests of such phylogenetic hypotheses. Here we describe and analyze the first postcranial remains that can be attributed to $C$. lemuroides - an astragalus and three calcanei held in the collections of the Naturhistorisches Museum Basel that were likely recovered from Egerkingen over a century ago. Qualitative and multivariate morphometric analyses of these elements suggest that $C$. lemuroides was even more loris-like than European adapines such as Adapis and Leptadapis, and was not simply an adapine with an aberrant dentition. The astragalus of Caenopithecus is similar to that of younger Afradapis from the late Eocene of Egypt, and parsimony and Bayesian phylogenetic analyses that include the new tarsal data strongly support the placement of Afradapis and Caenopithecus as sister taxa to the exclusion of all other known adapiforms, thus implying that dispersal between Europe and Africa occurred during the middle Eocene. The new tarsal evidence, combined with previously known craniodental fossils, allows us to reconstruct $C$. lemuroides as having been an arboreal and highly folivorous 1.5-2.5 kg primate that likely moved slowly and deliberately with little or no capacity for acrobatic leaping, presumably maintaining consistent powerful grasps on branches in both above-branch and inverted postures. 
2 Erik R. Seiffert, ${ }^{1 *}$ Loïc Costeur, ${ }^{2}$ Doug M. Boyer ${ }^{3 *}$

$3 \quad{ }^{1}$ Department of Anatomical Sciences, Stony Brook University, Stony Brook, New York

$4 \quad{ }^{2}$ Department of Geosciences, Naturhistorisches Museum Basel, Basel, Switzerland

$5 \quad{ }^{3}$ Department of Evolutionary Anthropology, Duke University, Durham, North Carolina

6

$7 \quad *$ Correspondence to:

8 Erik R. Seiffert, Department of Anatomical Sciences, Stony Brook University, Stony Brook,

9 New York, 11794-8081, USA. E-mail: erik.seiffert@stonybrook.edu

10 or

11 Doug M. Boyer, Department of Evolutionary Anthropology, Duke University, Durham, North

12 Carolina, 27705, USA. E-mail: douglasmb@gmail.com

13 
Introduction

16 Caenopithecus is a phylogenetically and biogeographically enigmatic adapiform primate whose

17 fossil record is restricted to middle Eocene (Lutetian, $43 \mathrm{Ma}, \mathrm{MP} 13 \mathrm{~b}$ ) fissure fillings in the commune of Egerkingen, Canton Solothurn, northern Switzerland (Godinot 1998; Rütimeyer 1962; Stehlin 1916). Upper molars of the type and only species, Caenopithecus lemuroides, were described by Rütimeyer (1862), and later Stehlin (1916) described parts of the lower dentition, mandible, additional parts of the upper dentition, and the orbital region. These limited remains show that $C$. lemuroides was a relatively large adapiform - having second lower molars that are about the same length as those of the extant lemurids Eulemur fulvus and Prolemur simus (Kay et al. 2004) — and had a fused mandibular symphysis, large canine teeth, very small $\mathrm{P}^{2} / 2$, simple $\mathrm{P}^{3-4 / 3-4}$, quadrate upper molars with distinct hypocones and mesostyles, and narrow lower molars with elongate crests and well-developed metastylids. The maxillary remains of $C$. lemuroides show that the species had a postorbital bar, but no postorbital closure. Analysis of lower molar shearing crests suggests that $C$. lemuroides was a dedicated folivore (Kay et al., 2004). (1916), but are not universally accepted as belonging to that genus — Franzen (1994) identified partial skeletons from the Geiseltal and Messel deposits as belonging to a new species of Caenopithecus (i.e., Caenopithecus "neglectus"), but these are now the type specimens of Godinotia neglecta (Franzen 2000) and Darwinius masillae (Franzen et al. 2009), and Godinot

34 (1988; 1998) has expressed doubt about the presence of Caenopithecus at Bouxwiller, France, that was reported by Jaeger (1971). Stehlin also attributed an astragalus from Egerkingen (NMB Eh 741) to C. lemuroides, but this element is probably that of a non-primate hyaenodontidan

37 'creodont' (see also Decker \& Szalay 1974). 
In an unpublished doctoral dissertation, Dagosto (1986) attributed an astragalus and three calcanei from the original Egerkingen collections held at the Naturhistorisches Museum Basel (NMB) to C. lemuroides and briefly described those elements ${ }^{1}$. Here we expand on Dagosto's earlier work by 1) providing quantitative justification for attribution of these tarsals to $C$. lemuroides, 2) describing and comparing the Egerkingen tarsals in greater detail, notably making comparisons with several specimens that have been discovered since Dagosto's work was completed in 1986; 3) analyzing the more complete specimens using multivariate and other morphometric techniques; and 4) including C. lemuroides in phylogenetic analyses alongside numerous other living and extinct primates. The tarsals of $C$. lemuroides provide important new insights into the locomotor adaptations and relationships of this mysterious primate.

History of study

Rütimeyer (1862) identified Caenopithecus as a primate [and in so doing was the first to correctly identify a fossil primate of Paleogene age (Stehlin, 1916)]; with little comparative material available for study, he [and later Forysth Major (1872)] was impressed by upper molar features that Caenopithecus shared with extant howler monkeys (Alouatta). The identification of Caenopithecus as a primate was subsequently questioned by various authorities (e.g., Delfortrie 1873), but Gervais (1873) considered Caenopithecus to be a synonym of Adapis (see also Flower 1876; Forbes 1894; Schlosser 1887), and Gaudry (1878) argued that Caenopithecus was aligned with lemurs, drawing attention to dental features that the genus shared with extant Hapalemur and Lemur. Stehlin (1916) noted additional features of the lower dentition and mandible that

\footnotetext{
${ }^{1}$ We were unaware of Dr. Dagosto's earlier work at the time that this manuscript was submitted for review, and we thank Dr. D.L. Gebo for bringing this to our attention.
} 
59 Caenopithecus shared with the few additional European adapiforms that were known by the time

60 of his study. With the benefit of an expanding North American fossil record, Stehlin also pointed

61 out dental similarities to Shoshonius and Washakius, which are now considered to be distantly

62 related washakiin omomyiforms. Abel (1931) and Le Gros Clark (1959) believed Caenopithecus

63 to be a tarsioid ${ }^{2}$, and Gregory (1920) later suggested that the genus might be related to indrioid

64 lemurs, but these are minority views; most debates subsequent to the publications of Stehlin

$65(1912,1916)$ have focused on whether Caenopithecus is more closely related to adapines such as

66 Adapis and Leptadapis (e.g., Godinot 1998; Rose et al. 1994; Russell et al. 1967; Simons 1972;

67 Simpson 1940; Szalay \& Delson 1979) or to some "cercamoniine" adapiform such as

68 Europolemur or Protoadapis (Franzen 1994; Gingerich 1977; Remane 1956; Simons 1962;

69 Weigelt 1933). In her unpublished doctoral dissertation, Dagosto (1986) briefly described and

70 figured the tarsals analyzed here, attributed them to C. lemuroides, and concluded that they

71 "support the hypothesis of a close relationship between Adapis, Leptadapis, and Caenopithecus"

72 (p. 198) and that "Adapis, Leptadapis, and Caenopithecus... have abandoned the primitive

73 euprimate emphasis on leaping and have evolved locomotor modes which stress quadrupedal

74 locomotion and climbing" (pp. 201-202).

75 The study of Caenopithecus has been further complicated in recent years by the

76 discovery of several geographically far-flung taxa, such as Aframonius, in the late Eocene of

77 Africa (Simons et al. 1995), and the poorly known Adapoides, in the middle Eocene of Asia

78 (Beard et al. 1994), that have been identified as close relatives of Caenopithecus and placed in

79 Caenopithecinae [a subfamily of the otherwise strictly European Adapidae; Godinot (1998)]. In

80 proposing this group, Godinot (1998) also included the problematic middle Eocene genus

\footnotetext{
${ }^{2}$ It should be noted that Abel's "Tarsioidea" also included taxa that are now considered to be plesiadapiforms (e.g., Paromomys, Carpolestes) or adapiforms (Anchomomys, Periconodon, Pronycticebus). Other adapiforms (Adapis, Pelycodus, Notharctus, Protoadapis) were included in his Lemuroidea.
} 
81 Mahgarita from North America. Membership has since expanded to include late Eocene

82 Afradapis from Egypt (Boyer et al. 2010; Seiffert et al. 2009), and possibly Mescalerolemur

83 (from the middle Eocene of Texas; Kirk \& Williams 2011) and Darwinius (from the middle

84 Eocene of Europe; Franzen et al., 2009; see phylogenetic analysis of Seiffert et al., 2009).

85 Mahgarita and Mescalerolemur are the only non-notharctine adapiforms known from North

86 America, and, like Caenopithecus, their geographic origins remain mysterious (Kirk \& Williams

87 2011). Fleagle (2013) placed all of these taxa, including middle Eocene European Europolemur

88 and Godinotia, into a new family, Caenopithecidae. Here we use the nomen Caenopithecinae and

89 use it to refer to Caenopithecus and its demonstrable near relatives (Afradapis and Aframonius),

90 because the phylogenetic analyses that we present here call into question the monophyly of an

91 assemblage that includes these taxa as well as Mahgarita and Mescalerolemur (see also Kirk \&

92 Williams, 2011). We refer to the clade that includes Adapis and Leptadapis (the monophyly of

93 which is consistently supported by our phylogenetic analyses) as Adapinae.

94 The higher-level affinities of caenopithecines and Mahgarita continues to be debated;

95 authorities have identified some of these species as stem anthropoids or stem haplorhines

96 (Franzen et al. 2009; Rasmussen 1990; Rasmussen 1994; Simons et al. 1995) while others have

97 considered some or all of these species to be most parsimoniously interpreted as stem

98 strepsirrhines (Dagosto \& Gebo 1994; Godinot 1998; Kay et al. 1997; Kirk \& Williams 2011;

99 Maiolino et al. 2012; Marivaux et al. 2013; Ni et al. 2013; Rose et al. 2009; Ross et al. 1998;

100 Seiffert et al. 2009; Seiffert et al. 2005). Until recently, the only evidence that could be brought

101 to bear on this debate was the dental anatomy of these taxa, and the poorly preserved crania of

102 Mahgarita (see for instance the different interpretations of Rasmussen 1990 and Ross 1994), but

103 the recent discovery of an astragalus of Afradapis (Boyer et al., 2010) showed that taxon to be 
104 remarkably strepsirrhine-like in its tarsal morphology, contrasting strongly with that which

105 would be expected along the haplorhine or anthropoid stem lineages (see for instance Boyer \&

106 Seiffert 2013). The astragalus of Afradapis shows several similarities to the astragalus from the

107 Egerkingen collections that we describe here, bolstering the evidence for its attribution to

108 Caenopithecus, which has been placed as the sister taxon of Afradapis in multiple phylogenetic

109 analyses (Boyer \& Seiffert 2013; Boyer et al. 2010; Kirk \& Williams 2011; Marigó et al. in

110 review; Ni et al. 2013; Seiffert et al. 2009). We further test all of these phylogenetic hypotheses

111 by adding the character data from the Egerkingen tarsals to the morphological character matrix

112 that has most recently been employed by Marigó et al. (in review), which we analyze using both

113 parsimony and Bayesian approaches.

114

115 Institutional abbreviations

116 AMNH, American Museum of Natural History, New York, NY, U.S.A.; CM, Carnegie Museum

117 of Natural History, Pittsburgh, Pennsylvania, U.S.A.; DPC, Duke Lemur Center Division of

118 Fossil Primates, Durham, North Carolina, U.S.A.; ESC, Private collection of Mr. Dominique

119 Vidalenc (Escamps locality); GMH, Geiseltalmuseum, Halle, Germany; GU, H.N.B. Garhwal

120 University, Srinagar, Uttarakhand, India; HTB, Hamann-Todd collection, Cleveland Museum of

121 Natural History; IPS, Institut de Paleontologia de Sabadell (= Institut Català de Paleontologia

122 Miquel Crusafont), Spain; ISEM, Institut des Sciences de l'Évolution de Montpellier,

123 Montpellier, France (ISEM-ECA, Escamps locality, ISEM-BFI, La Bouffie locality); IRSNB,

124 Institut Royal des Sciences Naturelles del Belgique, Brussels, Belgium; IVPP, Insitute of

125 Paleontology and Paleoanthropology, Chinese Academy of Sciences, Beijing, China; Ma-PhQ,

126 Muséum d'Histoire Naturelle Victor Brun, Montauban, France; MCZ, Museum of Comparative 
127 Zoology, Harvard University, Cambridge, Massachusetts, U.S.A.; MNHN, Muséum National

128 d'Histoire Naturelle, Paris, France; NMB, Naturhistorisches Museum Basel, Basel, Switzerland;

129 NMNH, Smithsonian Institution National Museum of Natural History, Washington, D.C.,

130 U.S.A.; PMZ, Paleontological Museum of the University of Zürich, Zürich, Switzerland; ROS,

131 Private collection of Mr. Dominique Vidalenc (Rosieres locality); SBU, Stony Brook University,

132 Stony Brook, New York, U.S.A.; SDNHM, San Diego Natural History Museum, San Diego,

133 California, U.S.A.; UCM, University of Colorado Museum of Natural History, Boulder,

134 Colorado, U.S.A.; UCMP, University of California Museum of Paleontology, Berkeley,

135 California, U.S.A.; UF, University of Florida, Florida Museum of Natural History, Gainesville,

136 Florida, U.S.A.; UM, University of Michigan, Ann Arbor, Michigan, U.S.A.; USGS, U.S.

137 Geological Survey, Denver, Colorado, U.S.A.; UNSM, University of Nebraska Science Museum,

138 Lincoln, Nebraska, U.S.A.; USNM, United States National Museum, Smithsonian Institute,

139 Washington D.C,, U.S.A.; UWBM, Burke Museum, Seattle, Washington, U.S.A.; VPL/JU,

140 Vertebrate Palaeontology Laboratory, University of Jammu; YPM, Yale Peabody Museum, Yale

141 University, New Haven, Connecticut, U.S.A.

142

\section{Materials and methods}

144 Attribution

145 The tarsals described here derive from the Egerkingen fissure fills, but provenance is only

146 documented for one specimen, NMB Eh 719, which was recovered from the $\gamma$ (="Gamma")

147 fissure. In her dissertation, Dagosto (1986) stated that all of the specimens are from the $\gamma$ fissure,

148 suggesting that locality information for the specimens was available in 1986 but has since been 
149 lost. On the basis of articular compatibility of the astragalus (NMB En.270) with the calcaneus

150 NMB Eh 719, as well as the similar size, color, preservation, and peculiar morphology of all

151 three calcanei (i.e., NMB Eh 719, En.268, and En.269), we consider it highly probable that all of

152 the tarsals described here belong to the same species, and so are likely to derive from the same

153 fissure that Eh 719 was recovered from (i.e., fissure $\gamma$, where the two relatively large adapiforms

154 C. lemuroides and Leptadapis priscus occur; note that Dagosto (1986) was unaware that remains

155 of L. priscus have also been recovered from fissure $\gamma$, and so thought that the much smaller

156 species Microadapis sciureus was the only other option for attribution). We employ measures of

157 relative abundance (by comparing the number of craniodental specimens attributed to each large

158 adapiform species known from Egerkingen $\gamma$ ) and regressions of dental and tarsal variables (i.e.,

159 astragalar trochlear width and calcaneo-cuboid joint size to $\mathrm{M}_{2}$ size across a sample of living

160 primates) to determine the most probable species attribution. Original scans and digital models of

161 all specimens are available on MorphoSource (www.morphosource.org); a DOI for each

162 specimen is provided in Table 1.

163 We gathered comparative data on tarsal facet size and $\mathrm{M}_{2}$ size from extant and fossil

164 primates (Appendix S1 and S2) in order to determine whether the Egerkingen tarsal bones

165 predict tooth sizes more similar to those of C. lemuroides or L. priscus. To this end, we regressed

166 natural log-transformed lower second molar $\left(\mathrm{M}_{2}\right)$ area (= maximum mesiodistal length

167 multiplied by maximum buccolingual breadth) on natural log-transformed astragalar trochlear

168 width [shown to be highly correlated with body mass in Dagosto and Terranova (1992: their

169 measure "A4")] and calcaneo-cuboid facet area [= cuboid facet length times cuboid facet width,

170 another measure shown to be highly correlated with body mass by Dagosto and Terranova (1992:

171 their "Index 6") and the best calcaneal predictor of body mass found by Yapuncich et al. (2015)]. 
172 Though $\mathrm{M}_{2}$ area may not be as robust a body mass proxy as $\mathrm{M}_{1}$ area (Gingerich et al. 1982), it is

173 a measure that is known in C. lemuroides and L. priscus, and is arguably more removed from

174 functional/evolutionary pressures on tooth size and morphology that affect the adjacent molars.

175 We also estimate the body mass of the Egerkingen primate using the equations derived from 176 regressions of tarsal facet areas on body mass that were recently published by Yapuncich et al. 177 (2015).

178 Our null hypothesis for these analyses was that the Egerkingen tarsals belong to $C$.

179 lemuroides, on the basis of the expression of morphology that would be consistent with that 180 species' demonstrated phylogenetic proximity to A. longicristatus, but not clearly consistent with 181 attribution to a primitive adapine such as L. priscus, whose close relatives (including the alleged 182 congener of L. priscus, Leptadapis magnus) differ in clear and quantifiable ways. If true, the 183 tarsal dimensions (i.e. those of the astragalus NMB En.270 and the best-preserved calcaneus 184 from Egerkingen, NMB Eh 719) should predict an $\mathrm{M}_{2}$ size matching that of teeth identified as 185 belonging to $C$. lemuroides. Our extant sample includes 33 species means, in which all 186 individuals used in computing those means included molar, astragalar, and calcaneal 187 measurements (except for Galagoides demidoff, for which the molar data came from different 188 specimens than those that provided the tarsal data). The sample also includes 30 fossil taxa, of 189 which nine specimens have associated molar and tarsal data (Appendix S2). We also computed $19095 \%$ prediction intervals as the limiting envelope within which the actual molar area must fall to 191 be considered plausibly attributable to the postcranial specimen generating the estimate.

192 Regressions were run in PAST.exe (Hammer et al. 2001). 95\% confidence limits on the 193 prediction interval of tooth size from postcranial element dimensions were generated (using 194 equation 17.29 of Zar 1984). Note that prediction intervals that take into account the Prediction 
195 Standard Error (PSE) of the data (or the 'scatter') around the regression line are more appropriate

196 than a confidence interval based on standard error in the regression parameters (e.g., Chatterjee

$197 \&$ Simonoff 2013). Prediction intervals intuitively must be broad enough to incorporate most of

198 the data points used to construct the regression, whereas confidence intervals based on error in

199 regression parameters typically exclude many more data points used to create the regression,

200 indicating that these limits are not appropriate indicators of whether a given set of (for instance)

201 postcranial and molar dimensions are closely associated.

202 In plotting adapiform $\mathrm{M}_{2}$ area and tarsal measurements among those of other taxa (Fig.

203 1), we observed that larger species (i.e., those at or above "Kay's Threshold" of 500g) tend to

204 have higher residuals. Therefore, instead of expecting the "owner" of NMB En.270 and Eh. 719

205 to have a small residual between its actual value and predicted value, we reasoned that it would

206 more likely to exhibit a residual value close to the average residual value shown by other large

207 adapiforms in the sample. To compare residuals among adapiforms, we first ran a regression that

208 excluded large adapiforms (i.e., ten taxa were excluded from the trochlear width regression, and

209 eight were excluded from the calcaneo-cuboid facet regression). We re-computed adapiform

210 residuals relative to this new line and then compared the values of the $\mathrm{M}_{2}$ area residuals

211 generated by the tarsal specimens under investigation to these populations using one sample t-

212 tests, where the residual values of the tarsal dimensions were treated as the test values.

213 Finally, to address the possibility that the astragalus NMB En.270 and the calcaneus

214 NMB Eh 719 could have come from two different species rather than a single species, we noted

215 that for dentally-associated elements, molar residuals from the calcaneus and astragalus were

216 strongly correlated. To quantify this correlation we converted residuals from the original

217 regressions into z-scores. For each taxon occurring in both regressions $(n=57)$, we computed the 
218 absolute value of the differences between residuals generated from the trochlear width and

219 calcaneo-cuboid joint area regressions. We found these differences to be small in general, and

220 hypothesized that if both tarsals came from a single species, the difference in $\mathrm{M}_{2}$ residuals should

221 be within the $95 \%$ confidence interval of the differences exhibited by the extant sample. If the

222 tarsals came from two different species, there is no way to constrain how much difference should

223 exist between the two sets of residuals when the bones are treated as if they came from a single

224 species. Thus this test can potentially refute the hypothesis that both bones came from a single

225 species (if the difference is outside the observed range), but not that they came from two species.

226

227 Multivariate morphometric analysis of primate astragali

228 In order to quantitatively assess the phenetic affinities of the Egerkingen tarsals, we undertook a

229 principal components analysis of a set of linear and angular measurements taken on digital

230 models of 25 primate and 27 non-primate astragali. The dataset was first developed by Boyer

231 (2009), and later augmented by Boyer et al. (2010) and Chester et al. (2015). The astragalus

232 described here (NMB En.270) lacks most of the head, and is abraded in such a way that not all

233 measurements in the dataset could be taken. From an original set of 18 linear measurements, we

234 were able to take 11 (specifically 2, 4-8, 10-14 from Boyer et al., 2010, some of which (4,

235 "Fibular facet maximum dorsoplantar height"; 5, "Fibular facet proximodistal length"; 7,

236 "Lateral tibial facet maximum mediolateral width"; and 12, "Flexor fibularis groove mediolateral

237 width") were estimated due to abrasion along the lateral margin of the lateral tibial facet (for 4 ,

238 5, and 7), and along the plantar surface of the medial tubercle buttressing the groove for flexor

239 fibularis (for 12). Of six angular measurements, we were able to take three (20-22) (Appendix

240 S3). All linear measurements were converted to shape ratios by dividing each measurement by a 
241 geometric mean (based on 10 measurements - 4-8, 10-13, 15) and then log transforming those

242 ratios. Angular measurements were converted to radians. A principal components analysis of

243 these data was undertaken using the program PAST. See Appendix S3 for the complete dataset.

245 Quantification of flexor fibularis groove depth

246 We used digital models of the astragali of 52 crown strepsirrhine individuals (20 genera,

247 including three subfossil lemuriform genera) and seven adapiform genera to quantify the depth

248 of the flexor fibularis groove along the most anterior extent of its plantar exposure. Astragali

249 were oriented with the plantar surface facing upward and in posterior view, such that the point

250 marking the base of the trough of the flexor fibularis groove was aligned with the point marking

251 the plantar apex of the navicular facet or sustentacular facet (whichever was visible in that view).

252 This cross-sectional view of the flexor fibularis groove was therefore oriented roughly

253 perpendicular to the anteroposteriorly oriented line of action of the flexor fibularis tendon along

254 the plantar surface of the astragalus. In this view, the two peaks formed by 1) the medial tubercle

255 buttressing the groove and 2) the most plantar projection of the anteromedial aspect of the ectal

256 facet provided landmarks for two measurements that were taken simultaneously using the

257 "Measure" tool in the program Geomagic — the linear width of the flexor fibularis groove, and

258 (by clicking "Projection" in Geomagic) the length of the contour between the two points that

259 were used to calculate linear width (which, in Geomagic, is not dependent on orientation but

260 rather is the shortest distance between those two points along the contour). Surfaces with

261 rendering artifacts, such as artificially roughened or "spikey" areas, were smoothed in Geomagic

262 to ensure accuracy of the contour measurement. We used a simple ratio of the contour

263 measurement to the linear width measurement to describe the depth of the groove; species with a 
264 ratio of 1 show no concavity of the groove, while increasing positive departures from that value

265 reflect increasing concavity (and therefore tall walls constraining the passage of the tendon). In

266 species with very little concavity of the groove, the two landmarks could be difficult to place

267 (because there were no obvious "peaks"), but this is not of great concern to us because wherever

268 the two points were placed in such species, the ultimate values for the ratio approached equality;

269 our interest in taking this measurement was to detect marked departures from equality, and to

270 identify taxa that had markedly concave flexor fibularis grooves along the plantar surface of the

271 astragalus.

272

273 Peroneal tubercle position in early fossil primates

274 We took three measurements along the proximodistal long axis of the calcaneus in order to 275 quantify peroneal tubercle position and size across a sample of early fossil primates (1: length of

276 the proximal segment; 2 : distance from the proximal-most aspect of the calcaneal tuber to the

277 distal-most projection of the peroneal tubercle; and 3: distance from the proximal-most aspect of

278 the calcaneal tuber to the midpoint of the peroneal tubercle). The sample includes a total of 100

279 individuals, composed of 51 adapiform specimens [Adapis $(\mathrm{n}=6)$, Asiadapis $(\mathrm{n}=2)$,

280 Caenopithecus $(\mathrm{n}=3)$, Cantius $(\mathrm{n}=16)$, Leptadapis $(\mathrm{n}=8)$, Marcgodinotius $(\mathrm{n}=5)$, Notharctus

$281(\mathrm{n}=7)$, Smilodectes $(\mathrm{n}=4)$ ], 21 omomyiform specimens [Arapahovius $(\mathrm{n}=3)$, Hemiacodon $(\mathrm{n}=1)$,

282 Omomys $(\mathrm{n}=6)$, Ourayia $(\mathrm{n}=1)$, Shoshonius $(\mathrm{n}=1)$, Teilhardina (belgica, $\mathrm{n}=8)$, Tetonius $(\mathrm{n}=1)]$,

283 nine stem anthropoid specimens [Eosimias $(\mathrm{n}=6)$, Parapithecidae $(\mathrm{n}=5)$, Proteopithecus $(\mathrm{n}=1)$,

284 six plesiadapiform specimens [Carpolestes $(\mathrm{n}=1)$, Ignacius $(\mathrm{n}=1)$, Nannodectes $(\mathrm{n}=1)$,

285 Plesiadapis $(\mathrm{n}=3)$ ], three dermopteran specimens [Cynocephalus $(\mathrm{n}=2)$, Galeopterus $(\mathrm{n}=1)$ ], and 286 ten scandentian specimens [Ptilocercus $(\mathrm{n}=3)$, Tupaia $(\mathrm{n}=7)$ ]. 
288 Automated geometric analysis of primate calcanei

289 In order to compare overall shape of the best-preserved calcaneus from Egerkingen (NMB Eh

290 719) with that of other living and extinct primates, we used an automated morphometric

291 procedure that requires no researcher supervision (i.e., no measurements, landmarks or

292 anatomical axes need be supplied for bones included in the comparison) (Boyer et al. 2015). We

293 chose to take this approach in order to minimize the degree to which characterizations of shape

294 affinities are dependent on measurements selected, or researcher observer error or bias. We

295 would opt for this approach with the astragalus as well, but the method cannot be easily

296 implemented for analysis of fragmentary bones at this time. In order to create 3D digital models

297 of calcanei, 159 specimens representing 46 primate genera and 6 non-primate euarchontan

298 genera were Micro-CT or laser scanned and processed in Avizo and Geomagic to create shell-

299 like (i.e., without internal structure) mesh files representing only the external surface of each

300 bone. All surface files are published on www.morphosource.org and can be directly downloaded,

301 though the cleaned, shell-like versions are not necessarily represented (but are available on

302 request). These 3D digital models were then analyzed using the fully automated 3D geometric

303 morphometric algorithm auto3dgm (Boyer et al. 2015), a MATLAB application (available on

304 GitHub). The algorithm is also available as an R-package, which can currently be downloaded at

305 the following URL with documentation and tutorials

306 (www.stat.duke.edu/ sayan/auto3dgm/index.shtml). Components of the method are detailed in

307 Boyer et al. (2015); here we present a brief explanation of the protocol. The analysis down-

308 samples each surface to a uniform number of evenly spread landmarks - in this case 256 points,

309 which it then uses to find pairwise alignments via the Closest Iterative Points algorithm (Besl \& 
310 McKay 1992). We reduce the risk of incorrect alignments by specifying eight initial alignments

311 that represent all combinations of the first three principal axes of variation in the landmark

312 points. 1,200 points were used to represent each bone's surface. The initial set of pairwise

313 distances between bones of the sample is used to define a minimum spanning tree linking all

314 bones. Point correspondences are propagated through this network, allowing proper alignment of

315 disparate shapes. This propagation process results in a final landmark dataset, and revised

316 pairwise distance measures between all surfaces. We then used the Procrustes distance matrix in

317 a Multidimensional Scaling Analysis with the MATLAB function 'mds.m' to condense the

318 variation into two dimensions (the landmark output could also have been analyzed in

319 morphologika $\left.{ }^{2.5}\right)$.

320

321 Phylogenetic analysis

322 We undertook multiple phylogenetic analyses to determine how the new character data from the

323 Egerkingen tarsals influenced previous placements of Caenopithecus and other adapiforms. The

324 phylogenetic analyses presented here build on a morphological character matrix that is based

325 largely on the original work of Kay et al. (1997), Ross et al. (1998) and Seiffert et al. (2003;

326 2004), and which has been successively augmented by Seiffert et al. (2009; 2010; 2005a; 2005b),

327 Boyer et al. (2010), Patel et al. (2012), Boyer and Seiffert (2013), Gladman et al. (2013), and,

328 most recently, Marigó et al. (in review), who added dental and tarsal characters for Anchomomys

329 frontanyensis, a small-bodied adapiform from the middle Eocene of Europe (Moyà-Solà and

330 Köhler, 1993; Moyà-Solà et al., 2011). The matrix (Dataset S1) now includes 391 characters,

331 and, with the addition of Mescalerolemur, a possible caenopithecine from the middle Eocene of 
332 Texas (Kirk \& Williams 2011), a total of 109 taxa. We undertook both parsimony and Bayesian 333 analyses of this character matrix.

334 Two initial parsimony analyses were carried out using PAUP 4.10b10 (Swofford 1998).

335 For both, heuristic searches were run for 10,000 replicates with random addition sequence and

336 the tree bisection and reconnection algorithm. For one of the two parsimony analyses, 256

337 characters whose states could be reasonably arranged into ordered (additive) morphoclines were

338 treated as such. A subset of these ordered characters (209 total) had polymorphisms that were

339 scored as intermediate states rather than scored using standard polymorphic scoring [i.e., (01)].

340 These 209 characters were scaled so that transitions between "fixed" states were equal to a single

341 step. In addition, we employed a molecular scaffold that constrained extant taxa to fit with the

342 prevailing primate phylogeny based on molecular sequence data (specifically, the results of

343 Springer et al. 2012), and we constrained characters encoding premolar loss so that teeth that had

344 previously been lost could not be regained. Another parsimony analysis was run with the

345 molecular scaffold enforced, but with no assumptions about character ordering or premolar re-

346 evolution - i.e., all characters were treated as unordered, with all transitions between states

347 equal to a single step. Equally parsimonious trees recovered by these analyses are summarized

348 here as strict consensus trees, and bootstrap support is provided, based on 1000 pseudoreplicates

349 (also calculated in PAUP).

350 Two Bayesian analyses were carried out using MrBayes 3.2.2 (Ronquist et al. 2012) and

351 that program's Mk model for morphological data. Both analyses were run on the CIPRES server

352 (Miller et al., 2010). The same molecular scaffold as that used in the parsimony analyses was

353 enforced in MrBayes using partial constraints. Analyses were run for 50 million generations,

354 with four chains (three heated, one cold), sampling every 1000 generations. Trees were 
355 summarized as a "halfcompat" consensus (50\% majority-rule consensus) with a relative burn-in

356 (25\% of the samples). One analysis was run with all characters treated as unordered. While it

357 would be ideal to run a Bayesian analysis of the matrix with all 256 characters treated as ordered

358 as in the parsimony analysis described above, unfortunately MrBayes only allows multistate

359 characters to be treated as ordered if they have six or fewer states, and 28 of the ordered

360 characters in the parsimony analysis have $>6$ states. In order to run comparable parsimony and

361 Bayesian analyses with all 256 characters treated as ordered, we removed the intermediate

362 polymorphic states in the matrix and used standard polymorphic scoring. We consider this

363 solution to be far from ideal, because it effectively renders those polymorphisms uninformative

364 for phylogenetic reconstruction, but it is the only clear option that we could find for running

365 comparable analyses while maintaining what we consider to be appropriate character state

366 delimitations (the alternative being to collapse adjacent states into the same state, which would

367 also lead to loss of information). In all of the Bayesian analyses coding was set to "variable" (lset

368 coding=variable), which led to the exclusion of invariant or parsimony uninformative characters.

369 The parsimony analysis of this modified matrix was run in the same way as the other parsimony

370 analyses, as described above. We also run all of the same analyses, with all of the same

371 assumptions, with the Egerkingen tarsals scored as belonging to Leptadapis priscus, the other

372 large adapiform at Egerkingen fissure $\gamma$, in order to determine whether attribution to this taxon

373 (rather than to Caenopithecus) has an impact on phylogenetic relationships among adapiforms.

374

375 Micro-CT scanning

376 The Egerkingen tarsals described here were micro-CT scanned at the American Museum of

377 Natural History's Microscopy and Imaging Facility, using a Phoenix brand v/tome/x s240 micro- 
378 CT scanner. High resolution scan and photographic imagery utilized here are available through

379 MorphoSource.org. Scans of taxa used in comparative analyses and details on scanning facility, 380 scanning resolution and energy settings are also largely available through MorphoSource.org.

381 Additional details are available in appendix tables or supplementary information of Boyer et al. 382 (2013) and Boyer and Seiffert (2013).

384 Results

385 Attribution

On the basis of astragalar trochlear width and calcaneo-cuboid joint surface size relative

to $\mathrm{M}_{2}$ size, the possibility of the Egerkingen primate tarsals being attributable to either Anchomomys cf. pygmaeus or Necrolemur cf. zitteli (both of which have been recovered from Egerkingen $\gamma$ ) can be confidently excluded. Of the remaining possibilities (Caenopithecus lemuroides or the dentally smaller Leptadapis priscus) Stehlin (1916) lists 22 specimens in the

391 Egerkingen $\gamma$ collection of C. lemuroides (an additional six are known from the "Huppersand"),

392 but only two specimens of L. priscus. Using a more conservative metric, the minimum number of

393 C. lemuroides individuals represented in the Egerkingen $\gamma$ collection is six, while the minimum

394 number of L. priscus individuals represented in Egerkingen $\gamma$ collection is two. On the basis of 395 abundance, the most likely attribution is to C. lemuroides. This is particularly true when the 396 number of isolated tarsals is taken in account - i.e., it is much more likely that four isolated 397 tarsals (all likely attributable to a single species) would be derived from the species represented 398 by 22 non-tarsal specimens (C. lemuroides), than to the species represented by only two non399 tarsal specimens (L. priscus). 

determination of 0.94 (trochlear width) and 0.93 (calcaneo-cuboid facet size) (Fig. 1). The $\mathrm{M}_{2}$ area of $C$. lemuroides is within the computed prediction intervals for $\mathrm{M}_{2}$ area generated by both tarsal elements, though it has a high positive residual indicating that, if the tarsals are attributable to C. lemuroides, that species would have relatively small tarsal facets relative to $\mathrm{M}_{2}$ area (Fig. 1). The $\mathrm{M}_{2}$ area of L. priscus also falls within this interval, but with a fairly small and slightly negative residual. On this basis, the tarsals could belong to either species and would apparently be more likely candidates for attribution to L. priscus. residual values of these adapiforms to those of the focal fossils. We found that the residual

410 values of the two candidate owners of the Egerkingen tarsals are both well outside of the $95 \%$ confidence limits on the means of the residual value distributions exhibited by other large adapiforms (Fig. 2). Computing the significance of the difference between the focal fossil residual values and the means for the known associations, we find that, for the astragalus, the

414 probability of attribution to L. priscus is lower (t-test of null hypothesis that the adapiform mean 415 is equal to that of $L$. priscus residual of -0.23 ; adapiform mean is $0.18,95 \%$ C.I. is $0.05-0.30$; t416 value $=7.30 ; p$ (null correct $)=0.00003)$ than to $C$. lemuroides $($ residual of $0.51 ; \mathrm{t}$-value $=-5.94$; $417 p($ null correct $)=0.0001)$. For the calcaneus, the probability of attribution to $C$. lemuroides is 418 slightly lower (t-test of null hypothesis that adapiform mean is equal to the C. lemuroides 419 residual of 0.57 ; adapiform mean is $0.19,95 \%$ C.I. is $0.04-0.33$; $\mathrm{t}$-value $=-5.85 ; p$ (null correct) $420=0.0004)$ than attribution to $L$. priscus (residual of -0.18 ; $\mathrm{t}$-value $5.67 ; p$ (null correct) $=0.0005)$.

421 However, the differences are minimal in both cases, and again we note that NMB Eh 719 and 422 NMB En.270 have strange (but morphologically and metrically compatible) articular surfaces, 
423 arguing against attribution to two different species of different dental size. Nonetheless, these

424 results may lead one to question whether the bones belong to two different taxa.

425 The comparison of absolute values of z-score differences between calcaneal and

426 astragalar regression residuals helps to address the last concern, though it cannot completely

427 resolve it (Fig. 3). Computing this value for 58 taxa (i.e., all those species with data available for

428 both bones in the original regression, including those of adapines), we find the average

429 difference between z-score converted residuals is about 0.6 standard deviation units, with a

430 standard deviation of 0.42 units, and a full range from $0.017-1.96$. Whether both fossils are

431 treated as C. lemuroides, or both are treated as L. priscus, the residual differences do not reject

432 the hypothesis that these bones belong to a single taxon. It also leads to the expectation that if, in

433 fact, one bone represents $C$. lemuroides and the other represents $L$. priscus, then these animals

434 would have had very similarly-sized tarsals overall, despite smaller teeth in the latter.

435 The last relevant observation emerging from these analyses is that the residual values of

436 putative close relatives of Caenopithecus [Europolemur klatti (Thalmann 1994) and Afradapis

437 (Seiffert et al. 2009)] are not only positive, but are well above the general adapiform means (Fig.

438 2). The closest relatives of L. priscus in the sample are the adapines Adapis parisiensis and

439 Leptadapis magnus. For the astragalus, both of those taxa still exhibit a positive residual in

440 contrast to the $L$. priscus attribution, and A. parisiensis exhibits a value greater than the

441 adapiform mean. For the calcaneus, Adapis also has a positive residual, though it is on the same

442 side of the adapiform mean as the L. priscus residual. L. magnus has a slightly negative residual,

443 putting it in closer proximity to the L. priscus residual. Higher than average positive residuals are

444 therefore expected for caenopithecine tarsal-dental comparisons (meaning that caenopithecines

445 are expected to have larger $\mathrm{M}_{2} \mathrm{~s}$ relative to tarsal size than the average adapiform), while neutral 
446 to somewhat positive residuals (that are slightly below the average for adapiforms) are expected

447 for adapine tarsal-dental comparisons. This makes sense given what is known about the

448 folivorous caenopithecine Afradapis (Seiffert et al., 2009, 2010) because primate folivores are

449 expected to have relatively large postcanine teeth relative to body mass (e.g., Kay 1975; Scott

450 2011). Previous analyses of shearing quotients indicate that Caenopithecus was very likely

451 folivorous (Kay et al. 2004), and we obtained the same result (Appendix S4, Figure S1; see

452 dental topographic variables for Caenopithecus in Table 3) using the dental topographic

453 comparative framework employed by Seiffert et al. (2010) (though we note that Caenopithecus

454 plots close to Prolemur simus, which was grouped with folivores in our analysis but is

455 technically a bamboo specialist). As stated above, primate species with folivorous/fibrous diets

456 are expected to have relatively large teeth, and thus large positive residuals of tooth size from

457 tarsal size. Of the candidate species that the tarsals might belong to, C. lemuroides residuals meet

458 this expectation, but $L$. priscus does not meet the expectation of neutral to slightly positive

459 residuals based on the data available from other adapines.

460 Finally, on the basis of the overall morphological pattern, NMB En.270 is more similar to

461 the astragalus of the caenopithecine Afradapis than it is to those of adapines. C. lemuroides has

462 been placed as the sister taxon of Afradapis to the exclusion of all other living and extinct

463 primates in the phylogenetic analysis of Seiffert et al. (2009) (and all later analyses that

464 augmented that matrix), as well as in analysis of a larger character matrix that was independently

465 constructed by Ni et al. (2013). More details on these similarities are presented below. The

466 morphology of NMB En.270 is therefore certainly phylogenetically consistent with attribution to

467 C. lemuroides, given what is known about its currently recognized sister taxon. L. priscus has

468 been placed as the sister taxon to L. magnus and Adapis based on dental data (Marigó et al., in 
469 review), and the latter taxa also show a number of similar morphological features of the

470 astragalus and calcaneus. If the Egerkingen tarsals belonged to L. priscus, we would expect the

471 morphology to reflect an antecedent condition, or similar specializations, to those of Adapis or

472 Leptadapis; instead the tarsal specimens exhibit some unusual specializations that are not 473 expressed in these taxa.

474 In light of all the foregoing - i.e., on the combined basis of abundance, size (including 475 the higher than average positive residuals for the Caenopithecus tarsal-dental comparisons, 476 which fit expectations for a folivorous caenopithecine, but not an adapine), and morphology 477 we consider the most parsimonious attribution of the Egerkingen tarsals to be to C. lemuroides 478 rather than L. priscus.

479

480 Body mass estimates

481 Using the prediction equations published by Yapuncich et al. (2015) astragalar ectal facet area 482 (AEFa) and calcaneal ectal facet area (CEFa) from NMB En.270 and NMB Eh 719, respectively, 483 returned mean estimates of $1663 \mathrm{~g}(\mathrm{AEFa} ; 95 \% \mathrm{PI}=659-4196 \mathrm{~g})$ and $2217 \mathrm{~g}(\mathrm{CEFa} ; 95 \% \mathrm{PI}=$ 484 1098-4476g) using their "strepsirrhine" equation; 2023g (AEFa; 95\% PI = 342-11984g) and $4852104 \mathrm{~g}(\mathrm{CEFa} ; 95 \% \mathrm{PI}=609-7268 \mathrm{~g})$ using their "lorisiform" equation; and 2962g (CEFa; 95\% $486 \mathrm{PI}=1392-6305 \mathrm{~g})$ and $1964 \mathrm{~g}(\mathrm{AEFa} ; 95 \% \mathrm{PI}=556-6929 \mathrm{~g})$ using their "lorisid" equation. 487 Description of the Caenopithecus tarsals Astragalus (NMB En.270, Fig. 4). The astragalus is largely complete, but is abraded along the 490 lateral trochlear rim, the most proximal and medial aspect of the body (the medial tubercle 
491 buttressing the groove for the flexor fibularis tendon), and probably (but less clearly) the most

492 distal and lateral aspect of the ectal facet and fibular facets, where those two facets typically

493 meet. The specimen is also missing most of the head and the navicular facet.

494 In medial view the astragalar body is dorsoplantarly tall, with a medial trochlear rim that

495 has a small radius of curvature (i.e., it is tightly curved for its proximodistal length). The lateral

496 tibial facet (trochlea) bears a shallow sulcus between the medial and lateral rims, which are of

497 about the same height in proximal view. In dorsal view, the lateral tibial facet has a fairly straight

498 medial border along the body (i.e., excluding the distal extension that is confluent with the

499 medial tibial facet), but the lateral border is rounded and tapers strongly toward the proximal and

500 medial aspect of the body; the lateral tibial facet is thus distinctly " $\mathrm{v}$ "-shaped in proximal view,

501 and the proximal tapering of the facet allows for a capacious groove for the tendon of the flexor

502 fibularis muscle, which is situated lateral to the lateral tibial facet, as in all known adapiforms

503 and crown strepsirrhines (Beard et al. 1988). Unlike most other primates, this groove extends

504 well onto the plantar aspect of the body and is buttressed laterally by a thick and laterally

505 projecting flange, which also supports the most proximal aspect of the ectal facet, and

506 presumably served as an attachment site for the posterior astragalo-fibular ligament. There is no

507 hint of a posterior astragalar shelf or a superior astragalar foramen.

508 The fibular facet is proximodistally convex and quite large, covering most of the lateral

509 aspect of the astragalar body in lateral view. The fibular facet slopes laterally from the lateral

510 tibial facet at an angle of $112^{\circ}$ (using the measurement protocol described by Boyer and Seiffert,

511 2013). The medial tibial facet is large, taking up more than half of the medial surface of the

512 astragalar body and extending all the way to its plantar surface, as in many other "prosimian"

513 primates (Boyer et al. 2015). The facet continues distally, becoming dorsoplantarly shorter as it 
514 curves onto the medial surface of the astragalar neck. There is a dorsoplantarly tall but shallow

515 bean-shaped fossa distal to the medial tibial facet, presumably for attachment of the posterior

516 tibioastragalar portion of the deltoid ligament. The articular area of the medial tibial facet

517 measures $25.7 \mathrm{~mm}^{2}$. The medial tubercle buttressing the groove for the flexor fibularis tendon is

518 abraded proximally, but the plantar border of the medial wall of the body clearly extends far

519 plantarly as a protruding ridge, which terminates just distal to the most proximal extension of the

520 sustentacular facet. This plantar projection forms the medial half of the deep trochlear groove for

521 the flexor fibular tendon as it passes plantarly around the astragalus, and clearly contributes to

522 the perception that the astragalar body is tall.

523 We estimate that the astragalar neck meets the body at approximately a $33^{\circ}$ angle.

524 Judging from the shape of the astragalar neck along its broken surface, the navicular facet likely

525 would have been mediolaterally quite broad relative to its dorsoplantar height. A small part of

526 the navicular facet is preserved on the lateral aspect of the neck, revealing that that part of the

527 facet, at least, was clearly convex. On the plantar surface, the proximal part of the sustentacular

528 facet is preserved, and is strikingly convex, with articular surface extending medially and

529 laterally away from the plantar apex of the facet. There is no concave extension of the

530 sustentacular facet along its proximal margin, as occurs in some primates. The facet's

531 proximolateral border is well-defined, but the proximomedial border is not, sloping gradually

532 toward the sulcus that separates the facet from the plantar ridge on the body's medial wall. An

533 elongate tubercle is present on the dorsal surface of the neck, presumably for attachment of the

534 astragalar-ectocuneiform ligament.

535 The ectal facet is roughly rectangular in plantar view, with a laterally projecting proximal

536 part where the facet extends out onto the lateral tubercle for the flexor fibularis groove. The 
537 medial margin of the ectal facet is well-defined and projects plantarly, forming the lateral wall of

538 the deep flexor fibularis groove. The area of the ectal facet is $20.6 \mathrm{~mm}^{2}$. See Table 2 for

539 astragalar measurements taken on the specimen that follow the methods of Gebo et al. (2001).

540

541 Calcanei [NMB Eh 719 (Fig. 5), NMB En.268 (Fig. 6), and NMB En.269 (Fig. 7)]. Three

542 primate calcanei have been identified in the Egerkingen $\gamma$ collections. As already discussed, the

543 three calcanei are of approximately the same size and, despite some differences, conform to a

544 unique morphological pattern. Unless otherwise mentioned, the following description is based

545 largely on NMB Eh 719, which is both the best-preserved calcaneus, and the only specimen that

546 is known to be from fissure $\gamma$ based on available records (Fig. 5). Of the other two calcanei,

547 NMB En.268 (Fig. 6) is missing the medial part of the sustentaculum and has a large crack

548 passing mediolaterally through the sustentaculum and ectal facet, leading to displacement of the

549 two halves of the bone relative to each other; it is also missing most of the cortical bone on the

550 lateral surface of the calcaneal tuber. The medial aspect of the sustentaculum of NMB En.269

551 (Fig. 7) is also missing, and the bone is badly abraded all along the medial and plantar surface,

552 including the cuboid facet. In dorsal view, most of the lateral part of the ectal facet of NMB

553 En.269 is missing, and the proximal aspect of the calcaneal tuber is badly damaged.

554 The distal segment of NMB Eh 719 makes up approximately $37 \%$ of total calcaneal

555 length and is not dorsally "flexed" relative to the proximal segment (see Gladman et al. 2013).

556 The cuboid facet of NMB Eh 719 is damaged along its dorsomedial and plantar surface, but it is

557 clear that the articular surface is "fan"-shaped, with a long axis that is oriented obliquely with

558 respect to the dorso-plantar axis of the calcaneal body. There is a distinct concavity along the

559 medial and plantar surface of the facet for articulation with a proximally projecting process of 
560 the cuboid. Medial and plantar to this articular pit is a proximodistally elongate distal calcaneal

561 tubercle (best developed in NMB Eh 719 and NMB En.269). The cuboid facet and its margins

562 are best preserved on NMB En.268, and this specimen confirms that the sustentacular facet does

563 not extend to the distal end of the calcaneus, that there is no secondary sustentacular facet, and

564 that there is no facet for the navicular distal to the sustentacular facet. At its broadest point (i.e.,

565 at the most medial projection of the sustentacular shelf), NMB Eh 719 is about $48 \%$ as wide as

566 the calcaneus is long. The sustentaculum does not have a deep groove for the passage of the

567 flexor fibularis tendon, but rather is quite flat - particularly that of NMB Eh 719, but somewhat

568 less so in NMB En.268. This condition is surely correlated with the dorsolateral orientation of

569 the entire sustentacular shelf, which is best appreciated in distal view (Figs. 5D, 6D, 7D). In

570 dorsal view the sustentacular facet of NMB Eh 719 is proximodistally elongate, bean-shaped,

571 and bears a gentle lateral concavity; it tapers distally and plantarly to meet the body of the

572 calcaneus (the facet is, however, broken along its proximal and medial margin). The proximal

573 margin of the sustentaculum does not bear a convex articular surface for a proximal extension of

574 the astragalar sustentacular facet, as occurs in some other Paleogene primates. The ectal facet is

575 about $55 \%$ as wide as it is long, and tapers proximally but remains quite broad distally. The facet

576 is tightly curved in all specimens, though on NMB En.268 this condition is obscured somewhat

577 by breakage and displacement of the distal part of the facet. The dorsal surface of the facet does

578 not project out laterally above the lateral border of the calcaneus, as occurs in some primates that

579 consequently bear a concave surface inferolateral to the ectal facet. The peroneal tubercle is

580 placed at approximately the distal margin of the ectal facet, is longer (proximodistally) than it is

581 high (dorsoplantarly), and does not project far laterally; it is not elongate and shelf-like as in

582 some other Paleogene primates. The lateral wall of the distal segment in C. lemuroides appears 
583 to be medially oriented with respect to the proximal segment, but this might also be interpreted

584 as a consequence of medial bowing of the calcaneal tuber with respect to the distal segment. The

585 calcaneal tuber bears distinct rugosities not only along the dorsal surface but also along the

586 medial margin, further contributing to its medially bowed appearance. See Table 2 for calcaneal

587 measurements taken on the specimens that follow the methods of Gebo et al. (2001).

588

589 Comparisons with other strepsirrhine astragali

590 Given Caenopithecus' well-supported phylogenetic placement among "adapiforms" — an

591 assemblage of fossil primates that are basally diverging within the order and that may or may not

592 be paraphyletic with respect to crown strepsirrhines (see phylogenetic results), we restrict our

593 comparisons largely to these taxa, specifically adapines (Dagosto 1983; Decker \& Szalay 1974),

594 notharctines (Gebo 1988; Gebo et al. 1991), asiadapines (Rose et al., 2009), Anchomomys

595 (Moyà-Solà and Köhler, 1993; Moyà-Solà et al., 2011; Marigó et al., in review), Azibius

596 (Marivaux et al. 2011), and Djebelemur (Marivaux et al. 2013). We also make comparisons

597 based on figures of isolated specimens that have been attributed to Europolemur klatti

598 (Thalmann 1994) and figures and half-casts of specimens that have been attributed to

599 Kyitchaungia takaii (Beard et al., 2007) from the middle Eocene of Germany and Burma,

600 respectively. Beard et al. (2007) consider Kyitchaungia to be a sivaladapid; if correct, the

601 specimens might be the only known tarsal elements from that clade (though we note that, on the

602 basis of our comparisons of $\mathrm{M}_{2}$ size to tarsal dimensions, these specimens could also be

603 attributable to the amphipithecid Myanmarpithecus yarshensis - a possibility that Beard et al.

604 (2007) did not explicitly consider). Here we make comparisons with the astragalus (NMMP 59)

605 and best-preserved calcaneus (NMMP 58) that Beard et al. (2007) attribute to Kyitchaungia. We 
606 also make comparisons with the distal calcaneus that is part of the problematic partial skeleton

607 NMMP 20, from the late middle Eocene of Myanmar; this partial skeleton is either that of an

608 amphipithecid, as originally suggested on the basis of the dental remains known from

609 Sabapondaung kyitchaung locality (Ciochon et al., 2001), or is a sivaladapid (dental remains of

610 which have not been found at the locality; Beard et al., 2007). In addition, we discuss similarities

611 that the Caenopithecus tarsals share with those of lorisids, the subfossil indrioid Babakotia, and

612 some other extant strepsirrhines, largely because of their importance for functional interpretation.

613 Note that the same comparisons would also be appropriate if the Egerkingen tarsals actually

614 belong to L. priscus.

615 Caenopithecus shows a unique mix of astragalar features, some of which are seen in

616 Adapis and Afradapis, and others of which are more similar to conditions seen in Leptadapis and

617 notharctines. The astragalar body is relatively tall (dorsoplantarly) when compared with those of

618 Adapis (Fig. 8E), Afradapis (Fig. 8G), lorises (Fig. 9E and F), and Babakotia (Fig. 9G). The

619 plantar aspect of the proximal portion of the astragalar body is not preserved in Adapoides (Fig.

$6208 \mathrm{H}$ ), but the remaining morphology suggests that the astragalar body was probably fairly low,

621 perhaps as in Afradapis. Among other stem strepsirrhines, relatively tall astragalar bodies are

622 also seen in Leptadapis (Fig. 8D), notharctines such as Cantius (Fig. 8B), asiadapines (Fig. 8C),

623 Anchomomys, Azibius, Djebelemur (Fig. 8A), and NMMP 59. The height of Babakotia's

624 astragalar body in medial view is exaggerated by its tall plantarly-projecting medial process

625 buttressing the groove for the tendon of flexor fibularis (Fig. 9G).

626 The very well-defined triangular proximal extension of the lateral tibial facet is most like

627 those of Afradapis and Babakotia (Figs. 8G, 9H). Other living and extinct strepsirrhines have

628 facets that taper posteriorly, but they are not so distinctly set off from the flexor fibularis groove. 
629 In Caenopithecus that groove is deeply excavated and extends onto the plantar aspect of the

630 body, as in adapines (Fig. 8D and E), Afradapis (Fig. 8G), Babakotia (Fig. 9G), lorises (Fig. 9E

631 and F), and, to a lesser extent, Varecia (Fig. 9D). In Afradapis, Caenopithecus, Babakotia, and

632 some lorises, the proximomedial margin of the ectal facet projects distinctly plantar to the

633 groove, forming its lateral wall. The plantar ridge forming the medial wall of this groove in

634 Caenopithecus is also well-developed in Leptadapis (see MNHN QU 11001, Fig. 8D) and

635 Babakotia, but is not as distinct in Adapis and Afradapis. This plantar projection clearly

636 contributes to the perception that Caenopithecus and Leptadapis have tall astragalar bodies, but

637 in medial view the neck and medial tibial facet of Caenopithecus are actually more similar to

638 those of Afradapis, aside from the strongly projecting plantar ridge.

639 The medial tibial facet of Caenopithecus is dorsoplantarly deep as in all other

640 adapiforms, but specifically resembles that of Afradapis in becoming dorsoplantarly shorter as it

641 curves onto the medial surface of the astragalar neck; this similarity is surely also due to the

642 relatively long astragalar necks of Afradapis and Caenopithecus when compared to those of

643 adapines. The $\ln$ of the square root of medial tibial facet area relative to ectal facet area is 0.11 ,

644 which is higher than that of any Paleogene primate. The only extant and subfossil primates that

645 equal or exceed this value (i.e., that have an equal, or higher, ratio of medial tibial facet area

646 relative to ectal facet area) are indriids, some lemurids, galagids, some lorisids (Arctocebus and

647 Nycticebus), and Palaeopropithecus.

648 The complete absence of a posterior trochlear shelf also characterizes Adapis, Adapoides,

649 Afradapis, Babakotia, and lorises; such "shelves" are present, to varying degrees, in notharctines,

650 Anchomomys, Djebelemur, and some extant strepsirrhines, and Beard et al. (2007) suggest that

651 one was probably present on NMMP 59. In medial view Leptadapis appears to bear a posterior 
652 trochlear shelf, but this posterior bulge is composed solely of the plantarly projecting ridge

653 buttressing the flexor fibular groove, and there is no shelf extending across the proximal and

654 plantar aspect of the body as in some other adapiforms and crown strepsirrhines. The absence of

655 a superior astragalar foramen differs from the condition in Afradapis, Leptadapis, and some

656 specimens of Adapis; this foramen also occurs variably in lorisids, but not in any other extant

657 primates of which we are aware.

658 The fibular facet angle of $112^{\circ}$ is slightly higher than those that have been calculated for

659 Leptadapis $\left(104-109^{\circ}, n=3\right)$, but is within the range of Adapis $\left(106-114^{\circ}, n=8\right)$ and Babakotia

$660\left(98-125^{\circ}, n=3\right)$, close to that of Djebelemur $\left(113^{\circ}\right)$, and lower than that of the single Afradapis

661 specimen that is currently known $\left(116^{\circ}\right)$ (Boyer \& Seiffert, 2013). Other adapiforms have lower

662 values, for instance basal Cantius $\left(94^{\circ}-103^{\circ}\right)$, Pelycodus $\left(96^{\circ}-108^{\circ}\right)$, Asiadapis $\left(100^{\circ}\right)$,

663 Marcgodinotius $\left(106^{\circ}-110^{\circ}\right)$, and Anchomomys $\left(105-111^{\circ}\right)$.

664 The astragalar neck meets the body at approximately a $33^{\circ}$ angle, similar to that of

665 Afradapis and the values reported by Gebo et al. (2001) for Adapis and Leptadapis, but higher

666 than the values that they reported for notharctines aside from Notharctus tenebrosus $\left(35^{\circ}\right)$.

667 Among smaller stem strepsirrhines, astragalar neck angle is also relatively low $-29^{\circ}$ in

668 Asiadapis, 20-32 $2^{\circ}$ in Marcgodinotius, $19^{\circ}$ in Anchomomys, $17-18^{\circ}$ in Azibius, $20^{\circ}$ in Djebelemur,

669 and $26^{\circ}$ in NMMP 59. The possible Europolemur klatti specimen (CeIV-2852) also appears to

670 have a low neck angle, certainly lower than those of Afradapis or Caenopithecus. Lorises and

671 Babakotia have particularly high neck angles.

672 The elongate tubercle on the dorsal surface of the neck for the astragalar-ectocuneiform

673 ligament is also well-developed in Adapoides, Afradapis, Babakotia, lorises, many notharctines,

674 and apparently on Europolemur, but is not clearly expressed to the same degree in adapines. 
In many omomyiforms, asiadapines, adapines, and Adapoides there is a concave proximal

676

677

678

679

680

681

682

683

684

685

686

687

688

689

690

691

692

693

694

695

696

697

extension of the sustentacular facet that would form a sort of locking mechanism with a

posteriorly convex proximal extension of the sustentacular facet on the calcaneus (Boyer et al., 2010); in contrast, there is no distinct articular surface for such a proximal extension in either

Caenopithecus or Afradapis. Caenopithecus is fairly unique among adapiforms in having a strongly mediolaterally convex proximal portion of the sustentacular facet.

Multivariate morphometric analysis of primate astragali

Along principal component one (which explains $39.4 \%$ of the variance) Caenopithecus falls close to Afradapis, and, among extant primates sampled, overlaps solely with the morphospace occupied by lorisids (Fig. 10). Among non-primates, Caenopithecus' PC1 score is close to that of some Cynocephalus individuals, as well as the extinct carpolestid Carpolestes and paromomyid Ignacius. The strongest loadings along this axis are for variables 12 (flexor fibularis groove width), 20 (angle between fibular facet and medial tibial facet), and 21 (angle between medial and lateral tibial facets), all of which are positive. The positions of Caenopithecus, Afradapis, adapines, Babakotia, and lorisids along PC1 reflect the fact that, relative to other crown primates, they have broad flexor fibularis grooves, high (obtuse) angles between the fibular facet and the medial tibial facet, and low (acute) angles between the medial and lateral tibial facets. Principal component 2 explains $17.7 \%$ of the variance and does not clearly separate extant primates along functional lines; this component is dominated by a strong positive loading for variable 13 (flexor fibularis groove proximodistal length). Again, Caenopithecus overlaps with the adapine-caenopithecine and lorisid morphospaces along this axis (but also that of many other primates and non-primates). Overall, among extant primates that might guide functional 
698 interpretation, the clearest phenetic affinities along the principal two axes are with the cautious

699 and slow-climbing lorisids. Importantly, though, on the far negative range of the lorisid

700 morphospace there is near-overlap with the extant large-bodied acrobatic leaper Propithecus,

701 presumably reflecting the fact that the reduced sample of variables that can be measured on the

702 Caenopithecus astragalus does not adequately capture all of the functionally-informative

703 morphology provided by this element (though we note that Propithecus is also capable of hind

704 limb suspension in addition to acrobatic leaping).

705

706 Flexor fibularis groove depth

707 Quantification of flexor fibularis groove depth among living and extinct strepsirrhines revealed 708 that most extant species have ratios of flexor fibularis groove contour length to flexor fibularis 709 groove linear width of 1 or only slightly higher, indicating that there is very little concavity of 710 the groove along the plantar surface of the astragalus (Fig. 11, Table 4). This is universally

711 characteristic of the particularly acrobatic grasp-leaping strepsirrhines, such as the galagids

712 Galagoides and Otolemur, the lemurid Hapalemur, the lepilemurid Lepilemur, and the indriids

713 Indri and Propithecus, but is also seen in extant lemurs with more generalized locomotor

714 behavior. The major departures from ratios of 1 are seen in Cheirogaleus, Varecia, and

715 particularly lorises, which have some of the highest values among extant taxa (of which

716 Nycticebus and Perodicticus have the highest). The highest values among strepsirrhines,

717 however, were found among the subfossil forms Babakotia (ratio of 1.73) and Megaladapis

718 (mean ratio of 2.05). Archaeolemur also had a relatively high value when compared with those 719 of most extant lemurs (mean of 1.1, close to that of Varecia). Among Eocene adapiforms, the

720 phylogenetically basal taxa Asiadapis, Marcgodinotius, and Notharctus had values close to 1 , 
721 while Afradapis and Caenopithecus both had values of 1.22, which is higher than the values of

722 all extant strepsirrhines aside from those of some lorises (and note that the value for

723 Caenopithecus is a minimum estimate, due to damage to the medial plantar ridge buttressing the

724 groove). The adapines Adapis and Leptadapis had intermediate values, with means of 1.05 and

7251.10 , respectively.

726

727 Comparisons with other strepsirrhine calcanei

728 In terms of overall morphology and proportions, the calcanei of $C$. lemuroides are similar to

729 those of Adapis and Leptadapis in having mediolaterally broad ectal facets (relative to

730 proximodistal length), well-developed distal calcaneal tubercles, and "fan"-shaped (rather than

731 strictly ovoid) facets for the articulating cuboid. This gestalt similarity to adapines is further

732 supported by automated geometric analysis of calcanei from multiple living and extinct primates

733 (see below). The C. lemuroides calcanei also show some striking specializations that, as a

734 complex, clearly set them apart not only from adapines but all other adapiforms — including

735 features such as tightly curved ectal facets that project dorsal to the calcaneal tubers, a convex

736 lateral border of the calcaneus, and sustentacular shelves that are dorsolaterally inclined relative

737 to the mediolateral plane of the ectal facets' dorsal apices. Outside of adapiforms, some of these

738 features can be found among lorises and Babakotia, and these probable convergences help to

739 guide our functional inferences.

$740 \quad$ Relative elongation of the distal calcaneal segment in Caenopithecus (37\% of total

741 calcaneal length in NMB Eh 719) is intermediate between the very foreshortened condition

742 exhibited by adapines (27-34\%) and the values seen in the relatively elongate notharctines (38-

743 45\%), asiadapines (39-44\%), and NMMP 58 [48\%, Beard et. al., (2007)]; Anchomomys is unique 
744 among stem strepsirrhines in having even longer distal segments (51-53\%). The value for NMB

745 Eh 719 matches that which was reported for Europolemur by Gebo et al. (2001). The variable

746 "ResB" of Boyer et al. (2013), which is the residual from a regression of absolute distal calcaneal

747 segment length on estimated body mass across primates, is -0.16 . Among Paleogene primates,

748 this residual is higher than those exhibited by asiadapines and adapines, but lower than those of

749 notharctines, Anchomomys, and all omomyiforms. Caenopithecus' value is lower than those of

750 all extant lemuriforms and galagids, but higher than those of lorisids (see Table 1 of Boyer et al.,

751 2013). Among subfossil lemurs, Mesopropithecus has a much higher "Res B" residual,

752 Megaladapis and Pachylemur have slightly higher residuals, while Archaeolemur, Babakotia,

753 and Palaeopropithecus have much lower residuals.

754 The position of the peroneal tubercle in Caenopithecus is also intermediate between the

755 relative placements in adapines and other adapiforms, although Asiadapis shows a similar pattern

756 (Fig. 12A, Table 5). Europolemur klatti (GMH XXXII-196) has a somewhat proximally-placed

757 peroneal tubercle - clearly proximal to the distal terminus of the ectal facet, and therefore more

758 adapine-like than Caenopithecus. NMMP 20 and NMMP 58 have also been interpreted as having

759 adapine-like positions of the peroneal tubercle (Ciochon et al., 2001; Beard et al., 2007). The

760 peroneal tubercles of adapines are particularly well-developed and protrude markedly directly

761 plantar to the apex of the ectal facet; they are so different from those of other adapiforms in their

762 robust construction that Decker and Szalay (1974) even questioned their homology with those of

763 their relatives. In strong contrast, the peroneal tubercles of Caenopithecus have proximal and

764 distal borders that grade gradually into the body of the calcaneus.

765 The width/length ratio of the ectal facet of NMB Eh 719 (55) is more similar to those of

766 adapines than notharctines (means of which, reported by Gebo et al. (2001), range from 45-52, 
767 but with ranges extending to 60 in Notharctus pugnax). The value of 64 reported for NMMP 58

768 would be particularly high for an adapiform, with similar values only seen in Adapis. The value

769 of Anchomomys frontanyensis is only slightly lower than that of Caenopithecus (52, Marigó et

770 al., in review), while, based on the values reported by Thalmann (1994), the index for

771 Europolemur klatti is particularly low (41.8), at the low end of the notharctine range.

772 The cuboid facets of Caenopithecus are similar to those of adapines in being fan-shaped,

773 but the long axes of the facets in the former are more dorsoplantarly oriented than the latter (Fig.

774 12). A similarly dorsoplantar orientation of the cuboid facet appears to be present in NMMP 20

775 (Ciochon et al., 2001) and NMMP 58 (Beard et al., 2007), and, among crown strepsirrhines, in

776 lorisids and Babakotia (Fig. 13). Notharctines, asiadapines, and Anchomomys have cuboid facets

777 whose long axes are oriented more mediolaterally than dorsoplantarly.

778 The well-developed distal calcaneal tubercles of Caenopithecus (particularly notable in

779 NMB Eh 719 and NMB En.269) are similar to those of adapines, which typically (but not

780 consistently) have better-developed tubercles than notharctines such as Cantius and Notharctus.

781 Anchomomys, Marcgodinotius, and NMMP 58 also have relatively small distal calcaneal

782 tubercles.

783 The dorsolateral inclination of the sustentacular facet in Caenopithecus is - when

784 judged relative to the mediolateral plane of the ectal facet - also seen in basal adapiforms such

785 as Cantius and Marcgodinotius; other adapiforms, including adapines and more basal taxa such

786 as Asiadapis, show a larger angle between the mediolateral planes of the ectal and sustentacular

787 facets.

788 The strong medial bowing of the calcaneal tuber in Caenopithecus, combined with its

789 lack of development of any lateral flaring, appears to be unique among adapiforms, but among 
790 extant primates is seen in lorisids (Fig. 13). The preserved portion of the calcaneal tuber of

791 NMMP 58 appears to be bowed medially, but the most proximal portion of the tuber is damaged.

792

793 Automated geometric analysis of primate calcanei

794 The multidimensional scaling (MDS) plot from the auto3dgm analysis (Fig. 14; see Datasets S3

795 and S4 for 3D coordinates and MDS coordinates, respectively) appears to capture a mix of

796 phylogenetic and functional signals. The first axis is probably related in large part to major

797 differences in distal calcaneal elongation, with the relatively elongate calcanei of tarsiers,

798 galagids, Microcebus, and omomyiforms having strongly positive scores, and the relatively

799 foreshortened calcanei of non-primate euarchontans, hominoids, and cercopithecoids having

800 strongly negative scores. Several basal extinct primate clades, such as Notharctinae, Adapinae,

801 Asiadapinae, and Eosimiidae occupy a central zone along the first axis, presumably reflecting in

802 part their intermediate levels of distal calcaneal elongation. Caenopithecus (NMB Eh 719) falls

803 into a unique part of the primate calcaneal morphospace, showing no overlap with any other

804 living or extinct taxon, but falling about mid-way between the polygons encompassing

805 Dermoptera, Lorisidae, and Adapinae; Babakotia also falls into this part of the MDS plot, but is

806 in an even more extreme position, actually falling outside of the morphospace encompassing all

807 other known living and extinct primates. Non-cheirogaleid, non-lepilemurid lemuriforms show

808 considerable cohesion along the first axis despite variation in locomotor style, presumably

809 reflecting strong phylogenetic signal in calcaneal morphology; the same can be said of

810 platyrrhines as a whole. Lorisids fall within the lemuriform morphospace along the first axis, but,

811 along with Babakotia, some adapines, and Caenopithecus, have strongly positive scores along

812 the second axis. Overall, as with the multivariate analysis of the astragalus, Caenopithecus 
813 appears to occupy a calcaneal morphospace that is best interpreted as being related to cautious

814 slow climbing, considerable pedal mobility, and possibly hind limb suspension. The proximity of

815 Caenopithecus to adapines is consistent with its phylogenetic placement (see below), while its

816 more positive score along the second axis (relative to most adapines) might reflect an increased

817 emphasis on slow and cautious climbing, and possibly hind limb suspension, when compared to

818 its adapine relatives. Such a scenario is also consistent with the functional interpretation that has

819 been put forth for the closely related caenopithecine Afradapis, and the possible caenopithecine

820 Adapoides, on the basis of their astragalar morphology, which is very loris-like (Boyer et al.

821 2010). We further explore the functional implications of Caenopithecus' tarsal morphology

822 below.

823

824 Phylogenetic analysis

825 Parsimony analysis of the character matrix with 256 of 291 characters ordered, transitions

826 between fixed and polymorphic states weighted as a half-step, premolar re-acquisition not

827 allowed, and with the molecular scaffold enforced recovered two trees of 4330.5 steps

828 (consistency index excluding uninformative characters $(\mathrm{CI})=0.1605$, retention index $(\mathrm{RI})=$

8290.5646 , rescaled consistency index $(\mathrm{RC})=0.0914$, Fig. 15$)$. The only differences between the

830 current result and that of Marigó et al. (in review, who provided the most recent modification of

831 the matrix used here) are 1) the placement of the clade (Europolemur dunaifi, (Aframonius,

832 (Afradapis, Caenopithecus))) as the sister taxon of Adapinae to the exclusion of Microadapis

833 (and all other adapiforms), 2) the placement of taxa previously situated as basal caenopithecines

834 (Europolemur klatti and Mahgarita stevensi) as members of a (Europolemur klatti, (Darwinius,

835 (Mahgarita, Mescalerolemur))) clade, and 3) notharctines (represented by Cantius) and the 
836 "cercamoniines" Pronycticebus and Protoadapis are consecutive sister taxa of a clade containing

837 all of the aforementioned taxa. None of these relationships are well-supported - only the

838 Adapinae (bootstrap value of 93), Adapis parisiensis + Leptadapis magnus (91), and Afradapis +

839 Caenopithecus (70) clades are supported by bootstrap values higher than 50.

840 Parsimony analysis with all characters unordered and equally weighted, but constrained

841 by the molecular scaffold, led to the recovery of 342 equally parsimonious trees of length 4638

$842(\mathrm{CI}=0.2218, \mathrm{RI}=0.4950, \mathrm{RCI}=0.1104)($ Fig. 16A). In contrast to the results from the analysis

843 with some characters ordered and scaled, the sister taxon of Adapinae was found to be a

844 (Microadapis, (Pronycticebus + Protoadapis)) clade rather than Caenopithecinae; an Afradapis-

845 Caenopithecus clade was placed as a more basal sister group of that clade, alongside Aframonius

846 and E. dunaifi, followed more distantly by Magharita. Darwinius, Djebelemur, E. klatti,

847 Mescalerolemur, a European anchomomyin clade, and an African "Anchomomys" milleri +

848 Azibiidae clade were all placed in an unresolved polytomy, higher up the strepsirrhine stem

849 lineage than notharctines, asiadapines, and sivaladapids, but branching off at the same node as

850 adapines, caenopithecines, and (Microadapis, (Pronycticebus + Protoadapis)).

851 Both Bayesian phylogenetic analyses presented here reached convergence, judging from

852 very low $(<0.01)$ average standard deviations of split frequencies in the last generations sampled.

853 The "halfcompat" consensus derived from Bayesian analysis with all characters unordered (Fig.

854 16B) provides more resolution than the comparable parsimony analysis, but few higher-level

855 relationships among adapiforms are well-supported aside from Adapinae [posterior probability

856 ( $\mathrm{PP}=100)]$, Afradapis + Caenopithecus (97), Pronycticebus + Protoadapis (99), Sivaladapidae

857 (100), and Asiadapinae (100). This analysis differs from both parsimony analyses in placing an

858 Afradapis-Caenopithecus clade as the sister group of Adapinae to the exclusion of Aframonius, 
859 though with only very weak support. Darwinius, E. dunaifi, and Mahgarita are placed in an

860 unresolved polytomy outside of that clade, followed more distantly by E. klatti. One of the more

861 notable implications of this topology is that, given parsimony optimization, it unequivocally

862 requires re-acquisition of the upper and lower first premolar, and re-evolution of a double-rooted

863 upper and lower second premolar (i.e., from a single-rooted condition), along the stem leading to

864 Adapinae. Also notable in this context is the placement of the possible caenopithecine

865 Mescalerolemur as a sister taxon of Anchomomyini, far from Mahgarita. We suspect that this

866 result is incorrect, given that Mescalerolemur and Mahgarita are such geographically and

867 temporally unique records in the primate fossil record (and share a number of striking

868 morphological apomorphies), but it is nevertheless interesting that the older and arguably more

869 primitive Mescalerolemur is placed closer to crown strepsirrhines than caenopithecines,

870 adapines, and non-anchomomyin "cercamoniines", similar to the results recovered by Kirk \&

871 Williams (2011) for Mescalerolemur + Mahgarita. Outside of Strepsirrhini, is also notable that,

872 within Haplorhini, results are radically different from those in the parsimony analyses in

873 supporting a "strict tarsier-anthropoid clade" (i.e., tarsiers join anthropoids to the exclusion of all

874 omomyiforms) rather than a monophyletic Tarsiiformes (tarsiers + omomyiforms).

875 Parsimony and Bayesian analysis of the matrix with standard polymorphic scoring

876 (which reduced the total number of states for each of the 256 multistate characters that were

877 ordered in the parsimony analysis, thereby allowing them to be treated as ordered in MrBayes)

878 resulted in some differences from the parsimony results in Figs. 15 and 16A, and the Bayesian

879 results in Fig. 16B, but none that impacted the placement of Caenopithecus close to Afradapis,

880 and, more distantly, Adapinae (Figs. 17A, B). In the parsimony analysis with standard

881 polymorphic scoring (783 equally parsimonious trees of length 3796; CI excluding 
882 uninformative characters $=0.1771, \mathrm{RI}=0.5919, \mathrm{RCI}=0.1059)$, the only changes among stem

883 strepsirrhines were outside of Adapidae, specifically 1) the joining of Darwinius and

884 Europolemur klatti as a sister clade of Mahgarita + Mescalerolemur (rather than being

885 paraphyletic with respect to Mahgarita + Mescalerolemur), 2) recovery of a Pronycticebus +

886 Protoadapis clade as sister of the clade containing Adapidae, Darwinius, E. klatti, Mahgarita,

887 and Mescalerolemur (rather than being paraphyletic with respect to that clade), 3) recovery of a

888 clade containing European Anchomomys species and movement of African "Anchomomys"

889 milleri to a sister taxon relationship with Djebelemur, and 4) placement of Mazateronodon as the

890 sister taxon of a ((Plesiopithecus, (“A.” milleri, Djebelemur)), crown Strepsirrhini) clade.

891 The Bayesian analysis with 256 characters ordered showed more differences from the

892 results based entirely on unordered characters, but again Afradapis was placed as the sister taxon

893 of Caenopithecus, and, with Aframonius, all caenopithecines were placed as sister taxa of

894 Adapinae, but with higher support (posterior probability of 79 versus 66). There was also

895 moderate support $(\mathrm{PP}=72)$ for placement of $E$. dunaifi as the sister taxon of that clade. There was

896 no support for a clade containing all stem and crown strepsirrhines to the exclusion of

897 asiadapines, notharctines, and Donrussellia (support by a PP of 90 in the analysis with all

898 characters unordered); instead sivaladapids, asiadapines, and a (Microadapis (Pronycticebus,

899 Protoadapis)) clade were placed in a basal polytomy, with only notharctines and Donrussellia

900 being placed more basally. The anchomomyin clade broke down into a polytomy with azibiids,

901 and Mescalerolemur was again separated from Mahgarita and placed as a sister of a clade

902 containing anchomomyins, azibiids, djebelemurids, Plesiopithecus, and crown strepsirrhines.

903 When the same phylogenetic analyses are run with the Egerkingen tarsals scored as

904 Leptadapis priscus rather than as Caenopithecus, the results of some analyses were different, 
905 though not radically so. Under parsimony (with 256 characters ordered, transitions between fixed 906 and polymorphic states weighted as a half-step, premolar re-acquisition not allowed, and with the

907 molecular scaffold enforced) Caenopithecus still formed a clade with Afradapis, but

908 caenopithecines as a whole were not placed as the closest sister taxa of Adapinae; rather, the

909 sister group of the "core" caenopithecines (i.e., an (Aframonius, (Afradapis, Caenopithecus)) was

910 a clade containing Darwinius and E. dunaifi. Mescalerolemur and Mahgarita together formed

911 the sister group of that larger clade, and all of those taxa were joined more basally by E. klatti,

912 while Microadapis was placed as the sister taxon of Adapinae. When all characters were treated

913 as unordered, parsimony analysis placed adapines as the sister taxon of a (Microadapis,

914 (Pronycticebus, Protoadapis)) clade, and caenopithecines (broadly defined) were paraphyletic

915 with respect to that larger clade. Under Bayesian inference, the support for the paraphyly of

916 caenopithecines with respect to adapines disappeared, and there was only very weak support

917 (0.51 posterior probability) for an (Aframonius, (Afradapis, Caenopithecus)) clade, and no

918 support (i.e., posterior probability of $<50$ ) for a caenopithecine-adapine clade. With the change to

919 the treatment of polymorphic characters (i.e., use of "standard" polymorphic scoring), the same

920 strict consensus and "halfcompat" topologies were retrieved regardless of whether the

921 Egerkingen tarsals were attributed to L. priscus or Caenopithecus.

922

923 Discussion and conclusions

924 Functional considerations

925 In her doctoral dissertation, Dagosto argued that "Adapis parisiensis, Leptadapis magnus,

926 and Caenopithecus lemuroides have features of the upper ankle joint and foot proportions which

927 strongly suggest that quadrupedal slow climbing was the dominant form of locomotion" 
928 (Dagosto, 1986, p. 333). Our analyses lend additional support to this hypothesis, and our

929 functional interpretation is broadly consistent with that of Dagosto (1986).

930 It has been argued that several features of the strepsirrhine hind limb, including astragalar

931 features such as laterally flaring fibular facets and laterally placed grooves for the tendon of

932 flexor fibularis, reflect an ancestral dependence on the use of inverted and abducted foot postures

933 on inclined and vertical small-diameter supports (Gebo 2011). Some features of the

934 Caenopithecus tarsals suggest that, relative to other adapiforms, C. lemuroides' tarsus may have

935 been held in particularly inverted postures. For instance, if the fibular facet angle faithfully

936 reflects pedal inversion (Gebo, 2011; Boyer and Seiffert, 2013), then Caenopithecus' high value

937 alone would suggest that this taxon might have had more inverted foot postures than any other

938 Paleogene primate aside from Afradapis, Cantius nuniensis, and Djebelemur [though the ranges

939 of Adapis parisiensis and Notharctus tenebrosus also encompass values as high as that of

940 Caenopithecus, see Boyer and Seiffert (2013 and Boyer et al. (2015)]. Boyer et al. (2015) have

941 also recently argued that the ratio of medial tibial facet (MTF) area to ectal facet (EF) area

942 provides another quantitative proxy for pedal inversion in fossil primates, and Caenopithecus'

943 ratio of 0.11 is higher than that of any other adapiform. Among extant primates, Caenopithecus'

944 value is higher than those of cheirogaleids, Lepilemur, Daubentonia, and even some lorises, but

945 is equaled or exceeded by leaping galagids, indriids, and lemurids. Boyer et al. (2015) argued

946 that the high MTF/EF area ratios of the latter strepsirrhines might reflect increased loading of the

947 MTF due to acrobatic grasp-leaping, i.e., increased loading relative to more generalized (less

948 acrobatic) ancestors whose feet were already more habitually inverted than those of other, non-

949 strepsirrhine primates, and thus already had high MTF/EF area ratios. 
$951 \mathrm{MTF} / \mathrm{EF}$ area ratios as in Caenopithecus, it could be argued that the latter's values reflect

952 acrobatic leaping as well as pedal inversion. However we consider this to be less likely than a

953 dependence on slow and cautious climbing, and possibly hind limb suspension, when other loris-

954 like features of Caenopithecus' tarsals are taken into account, such as its high astragalar neck

955 angle, inferred presence (based on neck width) of a broad astragalar head, a curved distal

956 projection of the medial tibial facet that extends onto the astragalar neck, and a deeply excavated

957 groove for the tendon of flexor fibularis on the plantar surface of the body (which, at least among

958 extant strepsirrhines, is deepest in species that are known to habitually engage in hindlimb

959 suspension). Calcaneal features seen in Caenopithecus that are likely related to increased pedal

960 inversion and overall mobility rather than acrobatic grasp-leaping include the dorsoplantarly

961 oriented long axis of the cuboid facet, projection of the ectal facet dorsal to the calcaneal tuber

962 (rather than being level to it), the dorsolateral inclination of the sustentacular shelf, and the

963 convexity of the lateral border of the calcaneal body and (correlated) medial bowing of the

964 calcaneal tuber. Furthermore, the distal calcaneus of Caenopithecus is less elongate (relative to

965 body mass) than are the calcanei of acrobatic lemuriforms with high MTF/EF ratios. Finally, in

966 our morphometric analyses the tarsals of Caenopithecus show no close phenetic affinities to

967 those of extant leaping primates, and instead appear to be most consistent with a somewhat loris-

968 like complex derived from a generalized adapiform Bauplan that combined both notharctine-like 969 and adapine-like features.

970 The trochlea-like groove for the tendon of flexor fibularis (the medial wall of which is

971 highly abraded on NMB En.270, but obviously quite prominent, see Fig. 18, feature 2)

972 presumably served to prevent medial slippage of that tendon and maintain its line of action while 
973 the foot was held in diverse inverted postures, including those that would have been required by

974 hind limb suspension. The strong medial buttressing of this groove via a bony plantar projection

975 might have been particularly important for Caenopithecus because, unlike most other primates,

976 the plantar groove guiding the passage of the flexor fibularis tendon along the plantar surface of

977 the calcaneal sustentaculum was poorly developed, as might be expected given the dorsolateral

978 inclination of the sustentacular shelf. The plantar projection on the medial aspect of the

979 astragalar body might, then, represent a compensatory feature that maintained a tunnel-like

980 passage for the tendon. The continuation of this trochlear passage for the flexor fibularis tendon

981 onto the plantar surface of the astragalus could have been particularly important for the

982 maintenance of strong pedal grasps when the foot was held in extreme plantarflexion (as would

983 occur during hind limb suspension), as this groove and its associated ligaments would have

984 formed — and maintained the integrity of — the so-called "tarsal tunnel" (e.g., Keck, 1962), a

985 structure that, in the case of suspensory species that habitually hold the foot in extreme

986 plantarflexion, might also prevent plantar bowstringing of the flexor fibularis tendon. This

987 inference is supported by the presence of a similarly deep plantar exposure of the flexor fibularis

988 groove in occasionally or habitually suspensory euarchontans such as Cynocephalus, subfossil

989 palaeopropithecid "sloth lemurs", lorises, and even in the occasionally suspensory lemurid

990 Varecia variegata (Meldrum et al., 1997), a species whose flexor fibularis grooves are

991 comparatively more shallow than the former taxa, but are nevertheless larger and deeper than

992 those of its close lemurid relatives that rarely, if ever, engage in hind limb suspension (Fig. 11).

993 All of these species also resemble Caenopithecus in lacking the distinct posterior trochlear shelf

994 that is seen various Paleogene primates (e.g., notharctine adapiforms and microchoerine

995 omomyiforms) whose postcranial morphology suggests an increased capacity for leaping; the 
996 absence of such a shelf-like projection along the proximal border of the lateral tibial facet

997 presumably would have allowed for increased plantarflexion relative to those taxa that have a

998 shelf. A prominent medial wall of the flexor fibularis groove that is similar to that of

999 Caenopithecus is also present in Babakotia (Fig. 9H). In extant lorises the same function is

1000 achieved in a slightly different manner; rather than having a mediolaterally restricted plantar

1001 projection, instead the lateral tibial facet (=trochlear articular surface) is mediolaterally broad

1002 and its entire surface projects plantar to the flexor fibularis groove (Figs. 9E, F), providing a

1003 structurally somewhat different (but functionally similar) strong medial buttress for a similarly

1004 trochlear groove - again presumably preventing medial slippage and bowstringing of the flexor

1005 fibularis tendon, and maintaining the line of action of the tendon during strong pedal grasping

1006 and hind limb suspension. Quantification of flexor fibularis groove depth demonstrates that

1007 Afradapis and Caenopithecus are both loris-like in this feature (Fig. 11), while Babakotia and

1008 Megaladapis show the same pattern but take it to an extreme, with values that are much higher

1009 than those of any other strepsirrhines. Though Varecia isn't the only lemurid that engages in hind

1010 limb suspension [and it should be noted that occasional use of hind limb suspension is not at all

1011 uncommon among primates (e.g., Meldrum et al., 1997)], it does so more frequently, and its high

1012 values relative to its lemurid relatives might also be explained as a correlate of this behavioral

1013 pattern. The high value of Cheirogaleus medius is interesting given evidence from that species'

1014 axial skeleton for a more loris-like dorso-stable Bauplan than other cheirogaleids (including

1015 Cheirogaleus major) (Granatosky et al. 2014). The high value of the terrestrial subfossil form

1016 Archaeolemur is more difficult to explain and requires further investigation, though it does not

1017 approach the magnitude seen in Afradapis and Caenopithecus. In summary, the pronounced

1018 height of the astragalar body in Caenopithecus — which is often associated with leaping 
1019 propensities in primates - seems more likely to be a correlate of the plantar projection that

1020 buttresses the flexor fibularis groove, while at the same time being accentuated by the absence of

1021 the posterior shelf. We interpret these correlated features as two aspects of a morphological

1022 pattern that more likely facilitated inversion, increased capacity for plantarflexion, and possibly

1023 hind limb suspension in this species.

1024 The dorsoplantar orientation of the long axis of the cuboid facet (and correlated medial 1025 placement of the cuboid pivot) is also seen in slow-moving lorises and palaeopropithecids, and 1026 suggests that the articulating cuboid would have been held in such a position that the navicular 1027 articulation was more dorsally oriented than in those taxa that have cuboid facets whose "pits" 1028 are situated along the plantar margin of the facet. The dorsolateral inclination of the calcaneal 1029 sustentacular facet might represent a structural mechanism that would have restricted movement 1030 of the astragalar neck such that, in the most stable positions allowed by the articulating ectal and 1031 sustentacular facets, the long (roughly mediolateral) axis of the astragalar neck and head would 1032 have been held in an inverted position. A similar dorsolateral orientation of the sustentaculum, 1033 with no plantar groove, is also seen in Babakotia (Fig. 13E). The tightly curved calcaneal ectal 1034 facet of Caenopithecus nevertheless appears to provide an extensive surface for articulation of 1035 the astragalar ectal facet, thereby allowing for considerable mobility in the proximodistal plane 1036 and corresponding potential for inversion (when positioned relatively proximally) and eversion 1037 (when positioned relatively distally) of the calcaneus with respect to the astragalus (Fig. 19, and 1038 see Decker \& Szalay, 1974) (though this assessment is based on articulation with NMB En.270, 1039 which probably does not belong to the same individual, see Fig. 19). This capacity for eversion is 1040 interesting given the strikingly convex shape of the proximal portion of the sustentacular facet of 1041 Caenopithecus (Fig 16A), which is fairly unique among adapiforms (see the relatively flat 
1042 sustentacular facets of Adapis and Asiadapis, Figs. 18C, D) and rare among extant primates.

1043 Given that the calcaneal sustentacular facet is relatively flat (mediolaterally), the convexity of the

1044 articulating astragalar sustentacular facet, and the medioplantar orientation of the medial

1045 extension of that facet, suggests a mechanism by which the astragalus might be capable of

1046 slipping into a more or less "locked" (but not particularly stable) position when the calcaneus is

1047 everted relative to the astragalus (Fig. 19B, D, E, H). Such everted positions greatly reduce the

1048 overlap of the articulating sustentacular facets, however, and furthermore lead to a corresponding

1049 separation of the head of the astragalus from the distal calcaneus (and, presumably, correlated

1050 separation of the navicular from the cuboid), suggesting to us that these foot postures are

1051 unlikely to have been used habitually. It is conceivable that such postures might have been

1052 employed during quadrumanous bridging behaviors, for instance when one foot maintains a

1053 strong grasp on an inclined support, but becomes increasingly everted as the body turns away

1054 from that support to grasp a nearby branch with the other limbs. A similar medioplantar

1055 extension of the astragalar sustentacular facet is also seen in lorisids, lending some support to

1056 that interpretation, but in these taxa the facets are not nearly as convex as that of Caenopithecus.

1057 Among living primates, projection of the ectal facet dorsal to the calcaneal tuber is seen

1058 in generally slow-moving species such as lorisids, whereas leaping species that depend on

1059 powerful propulsion via the triceps surae musculature (such as tarsiers; Gebo, 1987), tend to

1060 have calcaneal tubers that project dorsally to approximately the same level as the most dorsal

1061 surface of the ectal facet. The development of rugosities along the medial margin of the calcaneal

1062 tuberosity on NMB Eh 719 suggests that the calcaneal tendon might have had strong insertions

1063 along both the dorsal and medial surfaces of the tuber, as might be required if the calcaneus as a

1064 whole was typically held in an inverted position with respect to the tibia. The medial curvature, 
1065 and moderately developed plantar projection, of the calcaneal tuber would also be expected to

1066 have increased the mechanical advantage of the superficial head of the flexor digitorum brevis

1067 muscle, which is important for species that engage in hind limb suspension because such an

1068 arrangement allows for strong digital flexion in diverse foot postures, notably those that might

1069 reduce the contractile potential of flexor fibularis (Sarmiento 1983). A distinctly convex lateral

1070 border of the calcaneus is also seen (though to a greater degree) in lorisids, whereas dedicated

1071 leapers tend to have calcaneal tubers and distal segments whose long axes are roughly parallel.

1072 The mediolateral curvature of the calcaneal body in primates with more inverted feet might be

1073 functionally similar to dorsoplantar curvature of the calcaneal body in primates that have more

1074 everted feet; i.e., due to inversion, the medial surface of the tuber becomes functionally

1075 equivalent (in terms of the line of action of the triceps surae musculature) to the dorsal surface of

1076 the tuber in taxa with more everted feet.

1077 Finally, we note that Caenopithecus has a particularly well-developed tubercle on the

1078 lateral surface of the astragalar neck for the astragalar-ectocuneiform ligament. This ligament

1079 tubercle is also well-developed in lorises, highly suspensory sloth lemurs such as Babakotia and

1080 Palaeopropithecus, the loris-like caenopithecine Afradapis, and the loris-like possible

1081 caenopithecine Adapoides, but is not clearly expressed to the same extent in adapines or grasp-

1082 leaping lemuriforms. We infer that the large tubercle reflects the existence of a particularly large

1083 astragalar-ectocuneiform ligament, and hypothesize that such an enlarged ligament might have

1084 been one of several ligamentous features that served (at least in part) to keep the astragalus

1085 closely anchored to the surrounding tarsals when the compressive load of the tibia on the

1086 astragalus was released - as would be expected to occur during hind limb suspension. Such a

1087 morphological adaptation would undoutedly be a more energy-efficient mechanism for 
1088 maintaining articular integrity of the tarsals in habitually suspensory postures than to depend on

1089 muscles and their associated tendons. This interpretation calls into question whether Notharctus

1090 might have also utilized hind limb suspensory behaviors to a significant degree because it (but

1091 not Cantius) exhibits a tubercle that is developed to the same extent as that of Caenopithecus.

1092 In summary, when all of the evidence presented here is taken into account, we consider it

1093 most likely that Caenopithecus had a tarsus that was habitually held in strong inversion, and that

1094 this species was capable of strong pedal grasping in a diversity of postures, as is typical of slow-

1095 moving primates that simultaneously use all four limbs to navigate arboreal settings in which

1096 branches are small relative to hand and foot size (such as terminal branches). We do not detect

1097 any compelling morphological evidence for habitual leaping or acrobatic grasp-leaping in

1098 Caenopithecus' tarsals, but we do consider their morphology to be consistent with the use of

1099 hind limb suspension. Jenkins and McClearn (1984) pointed out that hind limb reversal of the

1100 sort that is required for hind limb suspension is accomplished in placental mammals via cruro-

1101 astragalar plantarflexion, subtalar inversion, and transverse tarsal supination, all of which we

1102 consider to have been possible in Caenopithecus and facilitated particularly well by its

1103 morphology. Inverted postures might be further indicated by a long and deep plantar exposure of

1104 the flexor fibularis groove, the development of the large tubercle for the astragalar-

1105 ectocuneiform ligament, and by the correlation of such extreme postures with slow climbing as

1106 suggested by the existence in Caenopithecus of relatively small tarsal facets (in this case

1107 estimated relative to tooth size - though admittedly this could also relate to a folivorous diet (and

1108 relatively large molars) as suggested above).

1109

1110 Lifestyle, phylogenetic position, and biogeographic origin of Caenopithecus 
If we are correct in attributing the Egerkingen tarsals to Caenopithecus lemuroides, then

1112 members of this species can now be reconstructed as having been folivorous slow climbers that

1113 were approximately $1.5-2.5 \mathrm{~kg}$ in body mass. We consider it unlikely that $C$. lemuroides

1114 individuals were adept leapers, and more probable that members of this species consistently

1115 maintained powerful grasps on branches as they moved through their arboreal habitats. We also

1116 consider it possible, based in part on the form-function correlation that we propose for the depth

1117 of the flexor fibularis groove on the plantar surface of the astragalus, that $C$. lemuroides might

1118 have regularly engaged in hind limb suspensory postures, though more evidence from the other

1119 bones of the hind limb is certainly needed to fully test that hypothesis. Regardless of whether the

1120 inference of hind limb suspension is correct, the reconstruction of $C$. lemuroides as a folivorous

1121 and slow climbing species suggests that the best extant primate analogues might be found among

1122 howler monkeys (Alouatta), although all known living and extinct alouattines are considerably

1123 larger than C. lemuroides (ranging in size from $\sim 4$ to $11.5 \mathrm{~kg}$; Smith \& Jungers, 1997). The

1124 combination of folivory and slow climbing arguably also fits with what might be predicted for

1125 the adaptive profile of basal "stem" members of the lemuriform indrioid palaeopropithecid clade,

1126 prior to their acquisition of extreme specializations for quadrumanual under-branch suspension.

1127 The acquisition of such a lifestyle in distantly related lineages that presumably shared a common

1128 ancestor with distinctively strepsirrhine ankle morphology (Gebo, 2011; Boyer and Seiffert,

1129 2013) may help to explain tarsal similarities that are shared by C. lemuroides and Babakotia.

1130 Most of our phylogenetic analyses place Caenopithecus close to adapines to the exclusion

1131 of other non-caenopithecine adapiforms, but importantly the new tarsal evidence shows that

1132 Caenopithecus is not just a dentally aberrant adapid with an adapine-like postcranium; instead,

1133 Caenopithecus appears to be an adaptively unique member of Europe's middle Eocene primate 
1134 fauna. The biogeographic underpinnings of the adapiform diversity seen in the middle Eocene of

1135 Europe remain mysterious. Godinot (1998) argued that Caenopithecus and Adapinae were likely

1136 immigrant taxa that arrived in Europe independently during the middle Eocene, possibly from

1137 Asia, but simple parsimony reconstructions of continental biogeography onto the trees derived

1138 from our phylogenetic analyses all unambiguously imply that the last common ancestor of

1139 caenopithecines and adapines was already present in Europe. Nevertheless, a key taxon in

1140 Godinot's scenario was middle Eocene Adapoides from the Shanghuang fissure fillings in China

1141 (Beard et al., 1994), which was not included in our phylogenetic analyses because undescribed

1142 material of that taxon announced in an abstract (Coster et al., 2012) indicates that teeth

1143 previously assigned to another adapiform in the Shanghuang fauna actually belong to Adapoides;

1144 we await explicit clarification on this matter before integrating Adapoides into phylogenetic

1145 analysis. Admittedly, the new observations (and expanded sample of Adapoides noted by Coster

1146 et al.) could have an important impact on our understanding of the biogeographic origins of

1147 adapines and caenopithecines.

1148 The "core" caenopithecines (Aframonius, Afradapis, and Caenopithecus) present another

1149 biogeographic puzzle — depending on the assumptions and methods employed there were either

1150 1) two unambiguously independent caenopithecine dispersals from Europe to account for the

1151 presence of Aframonius and Afradapis in Africa (i.e., on the two "allcompat" trees derived from

1152 the Bayesian analyses, and on that derived from parsimony analysis with all characters

1153 unordered), or 2) ambiguity, with two independent dispersals to Africa or back-migration of

1154 Caenopithecus to Europe being equally parsimonious (i.e., on the remaining trees). The

1155 biogeographic scenario is further complicated by the fact that the middle Eocene

1156 "caenopithecids" Mescalerolemur and Mahgarita from west Texas - which are unique records 
1157 in North America, and arguably the most biogeographically anomalous adapiforms — do not

1158 form a clade in our Bayesian analyses, or in our parsimony analyses when characters are treated

1159 as unordered (these taxa do form a clade in our parsimony analyses, when some characters are

1160 treated as ordered). In our opinion, the separation of these genera (and the independent

1161 colonizations of North America required by such a result) is almost certainly erroneus and more

1162 likely reflects the in situ acquisition of caenopithecine-like convergences in Mahgarita (e.g.,

1163 mandibular symphyseal fusion, enlarged upper molar hypocones, acquisition of an enlarged $\mathrm{P}^{3}$

1164 protocone) from a Mescalerolemur-like form that more closely resembled anchomomyins or

1165 djebelemurids. The placement of Mescalerolemur as a close relative of crown strepsirrhines to

1166 the exclusion of non-anchomomyin adapiforms in our Bayesian analyses is similar to the

1167 placement retrieved by Kirk \& Williams (2011) for a combined Mescalerolemur-Mahgarita

1168 clade when those authors employed a previous version of the matrix used here in their parsimony

1169 analyses (but notably with a reduced taxon set outside of Strepsirrhini). The divergent

1170 placements of Mescalerolemur and Mahgarita in some of our phylogenetic analyses clearly

1171 reveals the potential for parallel acquisition of the aforementioned caenopithecine-like features

1172 from more generalized small-bodied ancestors, and suggests that much more fossil evidence is

1173 needed from Afro-Arabia, Asia, Europe, and North America to tease apart the phylogenetic and

1174 biogeographic history of this group. Tarsals of Mescalerolemur or Mahgarita could provide

1175 particularly decisive evidence, given that Adapoides, Afradapis, and Caenopithecus are all

1176 known to have somewhat loris-like astragali (Gebo et al., 2001; Boyer et al., 2010) that differ

1177 markedly from those known for notharctids, djebelemurids, anchomomyins, and Europolemur.

1178 Finally, we note that middle Eocene localities in Europe have now yielded primate and

1179 non-primate species whose adaptive profiles closely resemble those that might have been present 
1180 among Madagascar's lemuriforms in the later Oligocene and early Miocene, when non-

1181 daubentoniid clades were likely diversifying (Springer et al., 2012; Kistler et al., 2015). As

1182 discussed earlier, as slow moving folivores, caenopithecines might have resembled basal

1183 palaeopropithecids, while adapines and Europolemur-like forms were presumably more like

1184 basal lemurids in their lifestyles; anchomomyin stem strepsirrhines and microchoerine

1185 omomyiforms were cheirogaleid-like in being small-bodied insectivorous or omnivorous species

1186 capable of leaping (Dagosto and Schmid, 1996; Marigó et al., in review); and the non-primate

1187 apatemyids appear to have occupied a niche similar to that of extant Daubentonia (e.g.,

1188 Koenigswald, 1990). A similar pattern might have existed slightly later in the middle Paleogene

1189 of Afro-Arabia, with the caenopithecine Afradapis occupying a basal palaeopropithecid-like

1190 niche, djebelemurids and basal lorisiforms occupying cheirogaleid-like niches, and

1191 plesiopithecids (based solely on craniodental evidence) possibly being somewhat Daubentonia-

1192 like (Godinot, 2006, 2010). Afro-Arabia clearly differs from both Europe and (presumably)

1193 Madagascar, however, in having a diverse anthropoid fauna through the later Paleogene. The

1194 extent to which dispersal and/or endemic common ancestry shaped the similar adaptive

1195 composition of primate communities on these landmasses (which were largely isolated and thus

1196 biogeographically filtered during the later Paleogene) is a complex puzzle that will provide

1197 fascinating insight on primate evolutionary history as it is gradually pieced together by future

1198 work.

1199

1200 Acknowledgements

1201 We thank the Academic Editor Brian Kraatz, as well as Daniel Gebo, Laurent Marivaux, and one

1202 anonymous reviewer for their helpful comments on the manuscript. ERS thanks Marcelo 
1203 Sánchez-Villagra for coordinating travel to Switzerland in 2011, which ultimately led to the re1204 identification of the Caenopithecus tarsals in the NMB collections. DMB's travel to Basel, and 1205 scanning of comparative tarsal material, was funded by the U.S. National Science Foundation 1206 award BCS 1317525 (formerly BCS 1125507) to DMB and ERS. We thank the following 1207 curators, collections managers, and colleagues for access to comparative material: K. Beard 1208 (University of Kansas); P. Chatrath, G. Gunnell, E. Simons (Duke University); S. Chester 1209 (Hunter College); H. Covert and T. Culver (University of Colorado); E. Delson, W. Harcourt1210 Smith (Lehman College); N. Duncan, J. Galkin, J. Meng, R. O’Leary, I. Rutzky, N. Simmons, 1211 and E. Westwig (American Museum of Natural History); R. Dunn (Des Moines University); D.

1212 Gebo (Northern Illinois University); M. Godinot (Ecole Pratique des Hautes Etudes); P. Holroyd 1213 (University of California Museum of Paleontology); L. Marivaux (Institut des Sciences de 1214 l'Évolution de Montpellier); L. Tallman (Grand Valley State University); P. Gingerich 1215 (University of Michigan); K. Rose (Johns Hopkins University); C. Sidor (Burke Museum); T. 1216 Smith (Royal Belgian Institute of Natural Sciences); and A. Su (Cleveland State University). 1217 Inclusion of dental material and analyses of it were supported by BCS 1304045 to DMB and E. 1218 M. St. Clair. We thank J. Puente for running initial versions of the auto3dgm and T. Gao for 1219 helping establish a user friendly version of the MATLAB code for auto3dgm. We thank Justin 1220 Gladman for taking photographs of the tarsal material and helping with some early versions of 1221 analyses.

1222

1223

1224 References

1225 
1226

1227

1228

1229

1230

1231

1232

1233

1234

1235

1236

1237

1238

1239

1240

1241

1242

1243

1244

1245

1246

1247

1248

Abel O. 1931. Die Stellung des Menschen im Rahmen der Wirbeltiere. Jena: Gustav Fischer, 398.

Beard KC, Dagosto M, Gebo DL, and Godinot M. 1988. Interrelationships among primate higher taxa. Nature 331:712-714.

Beard KC, Qi T, Dawson MR, Wang B, and Li C. 1994. A diverse new primate fauna from middle Eocene fissure-fillings in southeastern China. Nature 368:604-609.

Beard KC, Marivaux L, Tun ST, Soe AN, Chaimanee Y, Htoon W, Marandat B, Aung HH, and Jaeger J-J. 2007. New sivaladapid primates from the Eocene Pondaung Formation of Myanmar and the anthropoid status of Amphipithecidae. Bulletin of the Carnegie Museum of Natural History 39:67-76.

Besl PJ, and McKay ND. 1992. A method for registration of 3-D shapes. IEEE Transactions on Pattern Analysis and Machine Intelligence 14:239-256.

Boyer DM. 2009. New Cranial and Postcranial Remains of Late Paleocene Plesiadapidae ("Plesiadapiformes," Mammalia) from North America and Europe: Description and Evolutionary Implications. Ph.D. Dissertation, Stony Brook University.

Boyer DM, and Seiffert ER. 2013. Patterns of astragalar fibular facet orientation in extant and fossil primates and their evolutionary implications. American Journal of Physical Anthropology 151:420-447.

Boyer DM, Seiffert ER, and Simons EL. 2010. Astragalar morphology of Afradapis, a large adapiform primate from the earliest late Eocene of Egypt. American Journal of Physical Anthropology 143:383-402.

Boyer DM, Seiffert ER, Gladman JT, and Bloch JI. 2013. Evolution and allometry of calcaneal elongation in living and extinct primates. PLOS ONE 8:e67792. 
1249 Boyer DM, Puente J, Gladman JT, Glynn C, Mukherjee S, Yapuncich GS, and Daubechies I.

1250

1251

1252

1253

1254

1255

1256

1257

1258

1259

1260

1261

1262

1263

1264

1265

1266

1267

1268

1269

1270 2015. A new fully automated approach for aligning and comparing shapes. The Anatomical Record 298:249-276.

Boyer DM, Yapuncich GS, Butler JE, Dunn RH, and Seiffert ER. 2015. Evolution of postural diversity in primates as reflected by the size and shape of the medial tibial facet of the talus. American Journal of Physical Anthropology. DOI: 10.1002/ajpa.22702.

Chatterjee S, and Simonoff JS. 2013. Handbook of Regression Analysis. Hoboken: John Wiley \& Sons.

Chester SGB, Bloch JI, Boyer DM, and Clemens WA. 2015. Oldest known euarchontan postcrania and affinities of Paleocene Purgatorius to Primates. Proceedings of the National Academy of Sciences, USA 112:1487-1492.

Ciochon RL, Gingerich PD, Gunnell GF, and Simons EL. 2001. Primate postcrania from the late middle Eocene of Myanmar. Proceedings of the National Academy of Sciences, USA 98:7672-7677.

Coster P, Ni X, and Beard KC. 2012. The middle Eocene adapiform primates from the Shanghuang fissure fillings, Jiangsu Province, People's Republic of China. Journal of Vertebrate Paleontology 32:81.

Dagosto M. 1983. Postcranium of Adapis parisiensis and Leptadapis magnus (Adapiformes, Primates). Folia Primatologica 41:49-101.

Dagosto M, and Terranova CJ. 1992. Estimating the body size of Eocene primates: A comparison of results from dental and postcranial variables. International Journal of Primatology 13:307-344. 
1271 Dagosto M, and Gebo DL. 1994. Postcranial anatomy and the origin of the Anthropoidea. In:

1272 Fleagle JG, and Kay RF, eds. Anthropoid Origins. New York: Plenum Press, 567-593.

1273 Dagosto M, and Schmid P. 1996. Proximal femoral anatomy of omomyiform primates. Journal 1274 of Human Evolution 30:29-56.

1275 Decker RL, and Szalay FS. 1974. Origins and function of the pes in the Eocene Adapidae 1276 (Lemuriformes, Primates). In: Jenkins FAJ, ed. Primate Locomotion. New York: $1277 \quad$ Academic Press, 261-291.

1278 Delfortrie M. 1873. Un singe de la famille des lémuriens dans les phosphates de chaux 1279 quaternaires du Département du Lot. Actes de la Société linnéenne de Bordeaux 29:87-

1280 95.

1281 Fleagle JG. 2013. Primate Adaptation and Evolution, Third Edition. New York: Academic Press. 1282 Flower WH. 1876. Extinct Lemurina. Annals and Magazine of Natural History 17:323-328. 1283 Forbes HO. 1894. A Hand-Book to the Primates, Volume I. London: W.H. Allen \& Co., Ltd. 1284 Forsyth Major CJ. 1872. Note on some fossil monkeys found in Italy, preceded by a review of 1285 1286 the fossil Quadrumana in general. Annals and Magazine of Natural History, Fourth Series 10:13-166.

1287 Franzen JL. 1994. The Messel primates and anthropoid origins. In: Fleagle JG, and Kay RF, eds. 1288 Anthropoid Origins. New York: Plenum Press, 99-122.

1289 Franzen JL. 2000. Der sechste Messel-primate (Mammalia, Primates, Notharctidae, 1290 Cercamoniinae). Senckenbergiana Lethaea 80:289-303.

1291 Franzen JL, Gingerich PD, Habersetzer J, Hurum JH, von Koenigswald W, and Smith BH. 2009. 1292 Complete primate skeleton from the middle Eocene of Messel in Germany: morphology 1293 and paleobiology. PLoS ONE 4:e5723. 
1294 Gaudry A. 1878. Les enchaînements du monde animal dans les temps géologiques: mammifères 1295 tertiaires. Paris: Librairie Hachette et Cie.

1296 Gebo DL. 1987. Functional anatomy of the tarsier foot. American Journal of Physical $1297 \quad$ Anthropology 73:9-31.

1298 Gebo DL. 1988. Foot morphology and locomotor adaptation in Eocene primates. Folia $1299 \quad$ Primatologica 50:3-41.

1300 Gebo DL. 2011. Vertical clinging and leaping revisited: vertical support use as the ancestral 1301 1302 condition of strepsirrhine primates. American Journal of Physical Anthropology 146:323335.

1303 Gebo DL, Dagosto M, and Rose KD. 1991. Foot morphology and evolution in early Eocene 1304 Cantius. American Journal of Physical Anthropology 86:51-73.

1305 Gebo DL, Dagosto M, Beard KC, and Qi T. 2001. Middle Eocene primate tarsals from China: 1306 implications for haplorhine evolution. American Journal of Physical Anthropology $1307 \quad 116: 88-107$.

1308 Gervais P. 1873. Remarques au sujet du genre Palaeolemur (Adapis). Journal de Zoologie II $1309 \quad 2: 421-426$.

1310 Gingerich PD. 1977. New species of Eocene primates and the phylogeny of European Adapidae. $1311 \quad$ Folia Primatologica 28:60-80.

1312 Gingerich PD, Smith BH, and Rosenberg KR. 1982. Allometric scaling in the dentition of 1313 primates and prediction of body weight from tooth size in fossils. American Journal of $1314 \quad$ Physical Anthropology 58:81-100. 
1315 Gladman JT, Boyer DM, Simons EL, and Seiffert ER. 2013. A calcaneus attributable to the 1316 primitive late Eocene anthropoid Proteopithecus sylviae: Phenetic affinities and phylogenetic implications. American Journal of Physical Anthropology 151:372-397.

1318 Godinot M. 1988. Les primates adapidés de Bouxwiller (Eocène Moyen, Alsace) et leur apport à la compréhension de la faune de Messel et à l'évolution des Anchomomyini. Courier Forschungsinstitut Senckenberg 107:383-407.

1321 Godinot M. 1998. A summary of adapiform systematics and phylogeny. Folia Primatologica 69 (suppl. 1):218-249.

1323 Godinot M. 2006. Lemuriform origins as viewed from the fossil record. Folia Primatologica 1324 77:446-464.

1325 Godinot M. 2010. Paleogene prosimians. In: Werdelin L, and Sanders WJ, eds. Cenozoic 1326 Mammals of Africa. Berkeley: University of California Press, 319-331.

1327 Granatosky MC, Lemelin P, Chester SGB, Pampush JD, and Schmitt D. 2014. Functional and 1328 evolutionary aspects of axial stability in euarchontans and other mammals. Journal of Morphology 275: 313-327.

Gregory WK. 1920. On the structure and relations of Notharctus, an American Eocene primate.

1334 Jaeger J-J. 1971. La faune de mammifères du Lutétien de Bouxwiller (Bas-Rhin) et sa 1335 contribution à l'élaboration de l'échelle des zones biochronologiques de l'Eocène Memoirs of the American Museum of Natural History 3:49-243.

Hammer Ø, Harper DAT, and Ryan PD. 2001. PAST: Paleontological Statistics Software Package for Education and Data Analysis. Palaeontologia Electronica 4:9 pp. Européen. Bulletin du Service de la carte géologique d'Alsace et de Lorraine 24:93-105. 
1337 Jenkins FA, Jr., and McClearn D. 1984. Mechanisms of hind foot reversal in climbing mammals. $1338 \quad$ Journal of Morphology 182:197-219.

1339 Kay RF. 1975. Functional adaptations of primate molar teeth. American Journal of Physical $1340 \quad$ Anthropology 43:195-215.

1341 Kay RF, Ross C, and Williams BA. 1997. Anthropoid origins. Science 275:797-804.

1342 Kay RF, Schmitt D, Vinyard CJ, Perry JMG, Shigehara N, Takai M, and Egi N. 2004. The 1343 paleobiology of Amphipithecidae, south Asian late Eocene primates. Journal of Human $1344 \quad$ Evolution $46: 3-24$.

1345 Keck C. 1962. The tarsal-tunnel syndrome. Journal of Bone and Joint Surgery 44: 180-182.

1346 Kirk EC, and Williams BA. 2011. New adapiform primate of Old World affinities from the 1347 Devil's Graveyard Formation of Texas. Journal of Human Evolution 61:156-168.

1348 Kistler L, Ratan A, Godfrey LR, Crowley BE, Hughes CE, Lei R, Cui Y, Wood ML, Muldoon KM, Andriamialison H, McGraw JJ, Tomsho LP, Schuster SC, Miller W, Louis EE, Yoder AD, Malhi RS, and Perry GH. 2015. Comparative and population mitogenomic

1353 Koenigswald Wv. 1990. Die Paläobiologie der Apatemyiden (Insectivora s.l.) und die analyses of Madagascar's extinct, giant 'subfossil' lemurs. Journal of Human Evolution 79: $45-54$

1355 Ausdeutung der Skelettfunde von Heterohyus nanus aus dem Mitteleozän von Messel bei Darmstadt. Palaeontographica Abteilung A 210.

1356 Le Gros Clark WE. 1959. The Antecedents of Man. An Introduction to the Evolution of the 1357 Primates. Edinburgh: The University Press. 
1358 Maiolino S, Boyer DM, Bloch JI, Gilbert CC, and Groenke J. 2012. Evidence for a grooming

1359

1360

1361

1362

1363

1364

1365

1366

1367

1368

1369

1370

1371

1372

1373

1374

1375

1376

1377

1378

1379

claw in a North American adapiform primate: implications for anthropoid origins. PLoS ONE 7:e29135.

Marigó J, Roig I, Seiffert ER, Moyà-Solà S, and Boyer DM. in review. Astragalar and calcaneal morphology of the middle Eocene primate Anchomomys frontanyensis (Anchomomyini): implications for early primate evolution. Journal of Human Evolution.

Marivaux L, Tabuce R, Lebrun R, Ravel A, Adaci M, Mahboubi M, and Bensalah M. 2011.

Talar morphology of azibiids, strepsirhine-related primates from the Eocene of Algeria:

Phylogenetic affinities and locomotor adaptation. Journal of Human Evolution 61:447457.

Marivaux L, Ramdarshan A, Essid E, Marzougui W, Ammar HK, Lebrun R, Marandat B, Merzeraud G, Tabuce R, and Vianey-Liaud M. 2013. Djebelemur, a tiny pre-toothcombed primate from the Eocene of Tunisia: A glimpse into the origin of crown strepsirhines. PLoS ONE 8:21.

Meldrum DJ, Dagosto M, and White J. 1997. Hindlimb suspension and hind foot reversal in Varecia variegata and other arboreal mammals. American Journal of Physical Anthropology 103:85-102.

Miller MA, Pfeiffer W, and Schwartz T. 2010. Creating the CIPRES Science Gateway for inference of large phylogenetic trees. In Proceedings of the Gateway Computing Environments Workshop (GCE), 14 Nov. 2010, New Orleans, LA, pp 1-8.

Moyà-Solà S, and Köhler M. 1993. Middle Bartonian locality with Anchomomys (Adapidae, Primates) in the Spanish Pyrenees: Preliminary report. Folia Primatologica 60: 158-163. 
1380 Moyà-Solà S., Köhler M., Alba DM, and Roig I. 2011. Calcaneal proportions in primates and 1381 locomotor inferences in Anchomomys and other Paleogene Euprimates. Swiss Journal of

1383 Ni XJ, Gebo DL, Dagosto M, Meng J, Tafforeau P, Flynn JJ, and Beard KC. 2013. The oldest 1384 known primate skeleton and early haplorhine evolution. Nature 498:60-64.

1385 Patel BA, Seiffert ER, Boyer DM, Jacobs RL, St. Clair EM, and Simons EL. 2012. New primate 1386 first metatarsals from the Paleogene of Egypt and the origin of the anthropoid big toe. 1387 Journal of Human Evolution 63:99-120.

1388 Rasmussen DT. 1990. The phylogenetic position of Mahgarita stevensi: Protoanthropoid or 1389 lemuroid? International Journal of Primatology 11:439-469.

1390 Rasmussen DT. 1994. The different meanings of a tarsioid-anthropoid clade and a new model of 1391 anthropoid origins. In: Fleagle JG, and Kay RF, eds. Anthropoid Origins. New York: Plenum Press, 335-360.

Remane A. 1956. Paläontologie und Evolution der Primaten. Besonders Nicht-Hominoiden. In: Hofer H, Schultz AH, and Starck D, editors. Primatologia. Basel: Karger. p 268-378.

Ronquist F, Teslenko M, van der Mark P, Ayres DL, Darling A, Höhna S, Larget B, Liu L, Suchard MA, and Huelsenbeck JP. 2012. MrBayes 3.2: efficient Bayesian phylogenetic inference and model choice across a large model space. Systematic Biology 61:539-542.

Rose KD, Godinot M, and Bown TM. 1994. The early radiation of Euprimates and the initial diversification of the Omomyidae. In: Fleagle JG, and Kay RF, eds. Anthropoid Origins. New York: Plenum Press, 1-27.

Ross C, Williams B, and Kay RF. 1998. Phylogenetic analysis of anthropoid relationships. Journal of Human Evolution 35:221-306. 
1403 Rose KD, Rana RS, Sahni A, Kumar K, Missiaen P, Singh L, and Smith T. 2009. Early Eocene 1404 primates from Gujarat, India. Journal of Human Evolution 56:366-404.

1405 Russell DE, Louis P, and Savage DE. 1967. Primates of the French early Eocene. University of 1406 California Publications in Geological Sciences 73:1-46.

1407 Rütimeyer L. 1862. Eocäne Säugethiere aus dem Gebiet des schweizerischen Jura. Neue Denkschriften der Allgemeinen Schweizerischen Gesellschaft für die Gesammten

Sarmiento EE. 1983. The significance of the heel process in anthropoids. International Journal Naturwissenschaften 19:1-98.

\section{2} of Primatology 4:127-152.

Schlosser M. 1887. Die Affen, Lemuren, Chiropteren, Insectivoren, Marsupialier, Creodonten und Carnivoren des europäischen Tertiärs und deren Beziehungen zu ihren lebenden und fossilen aussereuropäischen Verwandten. Beiträge zur Paläontologie von ÖsterreichUngarns und des Orients 6:1-224.

Scott JE. 2011. Folivory, frugivory, and postcanine size in the Cercopithecoidea revisited. American Journal of Physical Anthropology 146:20-27.

Seiffert ER, Simons EL, and Attia Y. 2003. Fossil evidence for an ancient divergence of lorises and galagos. Nature 422:421-424.

Seiffert ER, Simons EL, and Simons CVM. 2004. Phylogenetic, biogeographic, and adaptive implications of new fossil evidence bearing on crown anthropoid origins and early stem catarrhine evolution. In: Ross CF, and Kay RF, eds. Anthropoid Origins: New Visions. New York: Kluwer Academic Press, 157-181. 
1424 Seiffert ER, Simons EL, Clyde WC, Rossie JB, Attia Y, Bown TM, Chatrath P, and Mathison M.

1425

1426

1427

1428

1429

1430

1431

1432

1433

1434

1435

1436

1437

1438

1439

1440

1441

1442

1443

1444 2005. Basal anthropoids from Egypt and the antiquity of Africa's higher primate radiation. Science 310:300-304.

Seiffert ER, Perry JMG, Simons EL, and Boyer DM. 2009. Convergent evolution of anthropoidlike adaptations in Eocene adapiform primates. Nature 461:1118-1121.

Seiffert ER, Simons EL, Boyer DM, Perry JMG, Ryan TM, and Sallam HM. 2010. A fossil primate of uncertain affinities from the earliest late Eocene of Egypt. Proceedings of the National Academy of Sciences, USA 107:9712-9717.

Simons EL. 1962. A new primate genus, Cantius, and a revision of some allied European lemuroids. Bulletin of the British Museum of Natural History (Geology) 7:1-36.

Simons EL. 1972. Primate Evolution. New York: Macmillan.

Simons EL, Rasmussen DT, and Gingerich PD. 1995. New cercamoniine adapid from Fayum, Egypt. Journal of Human Evolution 29:577-589.

Simpson GG. 1940. Studies on the earliest primates. Bulletin of the American Museum of Natural History 77:185-212.

Smith RJ, and Jungers WL. 1997. Body mass in comparative primatology. Journal of Human Evolution 32:523-559.

Springer MS, Meredith RW, Gatesy J, Emerling CA, Park J, Rabosky DL, Stadler T, Steiner C, Ryder OA, Janečka JE, Fisher CA, and Murphy WJ. 2012. Macroevolutionary dynamics and historical biogeography of primate diversification inferred from a species supermatrix. PLoS ONE 7:e49521. 
1445 Stehlin HG. 1912. Die Säugetiere des schweizerischen Eocaens. Critischer Catalog der 1446 Materialen. Siebenter Teil, erste Hälfte: Adapis. Abhandlung der Schweizerischen 1447 Paläontologischen Gesellschaft 37:1165-1298.

1448 Stehlin HG. 1916. Die Säugetiere des schweizerischen Eocaens. Critischer Catalog der 1449 Materialen. Siebenter Teil, zweite Hälfte: Caenopithecus - Necrolemur-Microchoerus Nannopithex - Anchomomys - Periconodon - Amphichiromys - Heterochiromys Nachträge zu Adapis - Schlussbetrachtungen zu den Primaten. Abhandlung der Schweizerischen Paläontologischen Gesellschaft 41:1299-1552.

Swofford DL. 1998. PAUP* Phylogenetic Analysis Using Parsimony (*and Other Methods), Version 4. Sunderland, MA: Sinauer Associates.

Szalay FS, and Delson E. 1979. Evolutionary History of the Primates. New York: Academic Press.

Thalmann U. 1994. Die Primaten aus dem eozänen Geiseltal bei Halle/Saale (Deutschland). Courier Forschungsinstitut Senckenberg 175:1-161.

1459 Weigelt J. 1933. Neue Primaten aus der mitteleozänen (oberlutetischen) Braunkohle des Geiseltals (geborgen 1932 in den Gruben Cecilie und Leonhardt). Nova Acta Leopoldina 1:7-156.

1462 Winchester JM, Boyer DM, St. Clair EM, Gosselin-Ildari A, Cooke SB, and Ledogar J. 2014. Dental topography of platyrrhines and prosimians: Convergence and contrasts. American Journal of Physical Anthropology 153: 29-44.

Yapuncich GS, Gladman JT, and Boyer DM. 2015. Estimating euarchontan body mass: A comparison of tarsal and dental variables. American Journal of Physical Anthropology DOI: 10.1002/ajpa.22735. 
1468 Zar JH. 1984. Biostatistical Analysis. Englewood Cliffs: Prentice Hall. 
$1470 \quad$ Figure captions

1471

1472 Figure 1. Regression of tooth size on tarsal facet size. Above, regression of the natural log of

1473 lower second molar area (length times width) on the natural log of calcaneo-cuboid facet area

1474 (length times width), with data from 51 living and extinct primates and seven non-primate

1475 euarchontans (raw data are provided in Appendices S1 and S2). Solid circles = extant non-

1476 primate euarchontans; open squares $=$ plesiadapiforms; solid squares $=$ tarsiers and extinct

1477 omomyiforms; open triangles $=$ extinct adapiforms; open circles $=$ extant lemuriforms; " $\mathrm{x} "=$

1478 extant galagids; open diamonds = extant lorises; “+” = natural log of calcaneo-cuboid facet area

1479 of NMB Eh.719 plotted relative to the natural log of second lower molar size of Leptadapis

1480 priscus; “+” enclosed in a diamond = natural log of the calcaneo-cuboid facet area of NMB

1481 Eh.719 plotted relative to the natural log of second lower molar size of Caenopithecus

1482 lemuroides. See figure for regression equation and $\mathrm{r}^{2}$. Below, regression of the natural $\log$ of

1483 lower second molar area (length times width) on the natural log of astragalar trochlear width,

1484 with data from 63 living and extinct primates and seven non-primate euarchontans. Symbols as

1485 above; "+" = natural log of the trochlear width of NMB En.270 plotted relative to the natural log

1486 of second lower molar size of Leptadapis priscus; “+” enclosed in a diamond = natural log of

1487 trochlear width of NMB En.270 plotted relative to the natural log of second lower molar size of

1488 Caenopithecus lemuroides. See figure for regression equation and $\mathrm{r}^{2}$. Note that the extant pen-

1489 tailed tree shrew Ptilocercus shows a tooth-tarsal scaling relationship that differs from that of

1490 living and extinct primates; for this reason it was excluded from the regression equation.

1491 Figure 2. Residuals for the natural $\log$ of $\mathrm{M}_{2}$ area of adapiforms following recalculation of

1492 regression of the natural $\log$ of $\mathrm{M}_{2}$ area on tarsal facet area (calcaneocuboid facet area and 
1493 trochlear width) excluding those adapiform species (raw data are provided in Appendices S1 and 1494 S2). Note that Caenopithecus lemuroides ("Cl") and Leptadapis priscus ("Lp") have predicted 1495 values for the natural $\log$ of lower second molar area that fall outside of the $95 \%$ confidence 1496 interval on the mean for both calcaneocuboid facet area (above) and trochlear width (below).

1497 Other abbreviations: "Ap" = Adapis parisiensis, "Al" = Afradapis longicristatus, "Ca" = Cantius 1498 abditus, "Cm" = Cantius mckennai, "Cr" = Cantius ralstoni, "Ct" = Cantius trigonodus, "Ek" = 1499 Europolemur klatti, "Nt" = Notharctus tenebrosus, "Lm" = Leptadapis magnus, "Sg" = 1500 Smilodectes gracilis. See figure for regression equations.

1501 Figure 3. Box plot of z-score-standardized differences in residuals. Values plotted are the 1502 absolute difference between the z-score-standardized residual of $\mathrm{m} 2$ size to astragalus size and 1503 the residual of $\mathrm{m} 2$ size to calcaneus size of a given taxon. We noticed that for most taxa, the $\mathrm{m} 2$ 1504 residual generated by the calcaneus was proportional to the $\mathrm{m} 2$ residual generated by the 1505 astragalus. The comparative sample includes all specimens for which both astragali and calcanei 1506 could be compared with tooth size (both fossil and extant) for a total $n=57$ species. As in other 1507 plots, the diamond enclosed cross uses the molar measurements of Caenopithecus, while the 1508 regular cross uses those of Leptadapis priscus. Because the fossils under scrutiny plot in the 1509 observed range, this test does not refute the hypothesis that both bones belong to a single species.

1510 Figure 4. Stereopair images of NMB En.270, left astragalus from Egerkingen (probably fissure $\gamma$ ) 1511 attributed here to Caenopithecus lemuroides. A) proximal, B) distal, C) medial, D) lateral, E) 1512 dorsal, and F) plantar views. 
1513 Figure 5. Stereopair images of NMB Eh 719, right calcaneus from Egerkingen fissure $\gamma$,

1514 attributed here to Caenopithecus lemuroides. A) dorsal, B) distal, C) lateral, D) medial, and E)

1515 plantar views.

1516 Figure 6. Stereopair images of NMB En.268, right calcaneus from Egerkingen (probably fissure $1517 \gamma$ ) attributed here to Caenopithecus lemuroides. In A) dorsal, B) distal, C) lateral, D) medial, and 1518 E) plantar views.

1519 Figure 7. Stereopair images of NMB En.269, left calcaneus from Egerkingen (probably fissure $\gamma$ ) 1520 attributed here to Caenopithecus lemuroides. In A) dorsal, B) distal, C) lateral, D) medial, and E) 1521 plantar views.

1522 Figure 8. Astragali of other fossil strepsirrhines compared to NMB En.270, attributed here to 1523 Caenopithecus lemuroides. A) Djebelemur martinezi (CBI-1-545), from the early or middle 1524 Eocene of Tunisia; B) Cantius trigonodus (USGS 21832), from the early Eocene of the U.S.A.; 1525 C) Asiadapis cambayensis (GU 747), from the early Eocene of India; D) Leptadapis magnus 1526 (MNHN QU 11001), from the late Eocene of France; E) Adapis parisiensis (ECA 1379), from 1527 the late Eocene of France; F) Caenopithecus lemuroides (NMB En.270, reversed); G) Afradapis 1528 longicristatus (DPC 21445C), from the late Eocene of Egypt; H) Adapoides troglodytes (IVPP 1529 V13016, reversed), from the middle Eocene of China. Views in, from left to right, dorsal, 1530 plantar, proximal, lateral, distal, and medial views. Scale bars are equal to $1 \mathrm{~mm}$.

1531 Figure 9. Astragali of extant and subfossil strepsirrhines compared to NMB En.270, attributed 1532 here to Caenopithecus lemuroides. A) Microcebus murinus (AMNH 174430); B) Hapalemur 1533 griseus (AMNH 170680); C) Daubentonia madagascariensis (AMNH 119694); D) Varecia 1534 variegata (AMNH 201384); E) Perodicticus potto (AMNH 184579); F) Nycticebus coucang 
1535 (AMNH 212953); G) Babakotia radofilai (DPC 11000); H) Caenopithecus lemuroides (NMB

1536 En.270, reversed). Views in, from left to right, dorsal, plantar, proximal, lateral, distal, and

1537 medial views. Scale bars are equal to $1 \mathrm{~mm}$.

1538 Figure 10. Principal components analysis of astragalar shape variables and angles (raw data are

1539 provided in Appendix S3). First two principal component axes, accounting for $57.1 \%$ of the

1540 overall variance, based on the reduced dataset of 15 astragalar measurements that could be taken

1541 on NMB En.270 (loadings for each variable on PC1 and PC2 are provided in the lower right

1542 hand corner). Note that Caenopithecus (NMB En.270) falls close to Afradapis, and to adapines

1543 and lorisids. The suspensory subfossil palaeopropithecid "sloth lemur" Babakotia expands the

1544 crown primate morphospace considerably, driven largely by extreme expression of features that

1545 also influence Caenopithecus's positive score on PC1 - i.e., a particularly long and wide flexor

1546 fibularis groove (variables 12 and 13) and a high angle between the medial tibial facet and

1547 fibular facet (variable 20).

1548 Figure 11. Quantification of flexor fibularis groove depth on the plantar surface of the astragalus.

1549 Inset image shows the orientation of the astragalus for simultaneous measurement of linear width

1550 of the flexor fibularis groove, and the contour measure of the groove (taken in Geomagic). As

1551 noted in the main text, astragali were oriented with the plantar surface facing upward and in

1552 posterior view, such that the point marking the base of the trough of the flexor fibularis groove

1553 was aligned with the point marking the plantar apex of the navicular facet or sustentacular facet

1554 (whichever was visible in that view). Boxplots show variation within species in the ratio of the

1555 contour measurement to the linear measurement; higher numbers are found in taxa species with

1556 deeper flexor fibularis grooves (raw data are provided in Table 4). Note that the values for

1557 Babakotia and Megaladapis are so extreme that they fall far outside of the figured range. 
1558 Figure 12. Peroneal tubercle position in living and extinct primates, and comparisons of the 1559 Caenopithecus calcaneus NMB Eh 719 with those of other adapiforms. A) Box and whisker

1560 plots of [(natural log of proximal segment length) - (natural log of the position of peroneal

1561 tubercle midpoint)] measured on the calcanei of 50 Eocene adapiforms, 21 Eocene

1562 omomyiforms, four Eocene stem anthropoids, five Oligocene parapithecids, five Paleocene

1563 plesiadapiforms, and 15 extant non-primate euarchontans (raw data are provided in Table 5).

1564 Note that the range of Caenopithecus (including all three Caenopithecus calcanei) is intermediate

1565 between those of adapines and other adapiforms, but the broad range is largely driven by a single

1566 specimen. B) Calcanei of various adapiforms scaled to the same approximate proximal segment

1567 length, illustrating differences in peroneal tubercle position (peroneal tubercles are delimited by

1568 opaque overlays). Also note the very short distal calcaneal segments of Adapis and Leptadapis

1569 relative to those of Caenopithecus and other adapiforms, and the different shapes and

1570 orientations of the long axes of the cuboid facets in distal view (margins of the cuboid facets are

1571 also delimited by opaque overlays). Scale bar $=10 \mathrm{~mm}$.

1572 Figure 13. Calcanei of extant and subfossil strepsirrhines compared to NMB Eh 719, attributed

1573 here to Caenopithecus lemuroides. A) Varecia variegata (AMNH 201384); B) Daubentonia

1574 madagascariensis (AMNH 185643); C) Perodicticus potto (AMNH 184597); D) Nycticebus

1575 coucang (AMNH 102027); E) Babakotia radofilai (DPC 11818); F) Caenopithecus lemuroides

1576 (NMB Eh 719). Views in, from left to right, medial, dorsal, lateral, and plantar; and, on the far

1577 right, proximal (above) and distal (below). Scale bars are equal to $5 \mathrm{~mm}$.

1578 Figure 14. Multidimensional scaling plot derived from automated geometric morphometric

1579 analysis of euarchontan calcanei, based on 1200 points. The position of Caenopithecus

1580 lemuroides (based on NMB Eh 719) is marked by a white star enclosed in a red circle. 
1581 Abbreviations: "Asiad." = Asiadapinae; "Daub." = Daubentonia; "Noth." = Notharctinae;

1582 "Proteo." = Proteopithecus.

1583 Figure 15. Phylogenetic analysis with some multistate characters ordered. Strict consensus of

1584 two equally parsimonious trees of length 4330.5 recovered following parsimony analysis $(10,000$

1585 heuristic search replicates) of the 291 character matrix in PAUP* 4.10b, with 256 of the

1586 characters ordered and transitions between "fixed" and "polymorphic" states in ordered

1587 morphoclines weighted as 0.5 . See text for tree statistics; numbers above or below branches are

1588 bootstrap values, following 1000 pseudoreplicates. Relationships among extant species were

1589 constrained by a molecular "scaffold" following Springer et al. (2012). Matrix is provided as

1590 Dataset S1.

1591 Figure 16. Phylogenetic analysis with all characters unordered. A) Strict consensus of 342

1592 equally parsimonious trees of length 4638 following parsimony analysis $(10,000$ heuristic search

1593 replicates) of the 291 character matrix in PAUP* 4.10b, with all characters unordered and

1594 equally weighted. See text for tree statistics; numbers above or below branches are bootstrap

1595 values, following 1000 pseudoreplicates. Relationships among extant species were constrained

1596 by a molecular "scaffold" following Springer et al. (2012), using partial constraints in MrBayes.

1597 Note that, unlike the consensus tree with some characters ordered and scaled, adapines form a

1598 clade with Microadapis, Pronycticebus, and Protoadapis rather than with any caenopithecine,

1599 though Caenopithecus still forms a clade with Afradapis to the exclusion of all other species. B)

1600 "Halfcompat" (majority-rule) consensus tree following 50 million MCMC generations in

1601 MrBayes (first 25\% discarded as "burn-in"). Numbers above or below branches are posterior

1602 probabilities. Relationships among extant species were constrained by a molecular "scaffold"

1603 following Springer et al. (2012). Note that caenopithecines are paraphyletic with respect to 
1604 adapines given this topology, unambiguously implying re-acquisition of the upper and lower first 1605 premolar in the latter clade.

1606 Figure 17. Phylogenetic analysis with standard polymorphic scoring and 256 multistate

1607 characters treated as ordered. A) Strict consensus of 783 equally parsimonious trees of length

16083796 following parsimony analysis (10,000 heuristic search replicates) of the 291 character

1609 matrix in PAUP* 4.10b, with all characters equally weighted, "standard" scoring of

1610 polymorphisms, and 256 multistate characters treated as ordered. See text for tree statistics;

1611 numbers above or below branches are bootstrap values, following 1000 pseudoreplicates.

1612 Relationships among extant species were constrained by a molecular "scaffold" following

1613 Springer et al. (2012), using partial constraints in MrBayes. B) "Halfcompat" (majority-rule)

1614 consensus tree following 50 million MCMC generations of the same matrix in MrBayes (first

$161525 \%$ discarded as "burn-in"). Numbers above or below branches are posterior probabilities.

1616 Relationships among extant species were constrained by a molecular "scaffold" following

1617 Springer et al. (2012). Note that, as in the Bayesian analysis of unordered characters

1618 caenopithecines are paraphyletic with respect to adapines given this topology, unambiguously

1619 implying (given parsimony optimization) re-acquisition of the upper and lower first premolar in

1620 the latter clade.

1621 Figure 18. Sustentacular facet morphology and flexor fibularis groove depth in Caenopithecus

1622 and other adapiforms. Stereopairs of A) Caenopithecus (NMB En.270, reversed); B) Afradapis

1623 (DPC 21445C, reversed); C) Adapis (ECA 7377); and Asiadapis (GU 747) in distal view,

1624 showing 1) the laterally expanded convexity of the sustentacular facet in Afradapis and

1625 particularly Caenopithecus, and 2) the deep flexor fibularis grooves of Afradapis and

1626 Caenopithecus when compared with Adapis and Asiadapis. 
1627 Figure 19. Articulation of the unassociated Caenopithecus astragalus NMB En.270 and and

1628 calcaneus NMB Eh 719 in inversion and eversion. Articulated astragalus and calcaneus in A)

1629 lateral view, inverted; B) lateral view, everted; C) medial view, inverted; D) medial view,

1630 everted; E) dorsal view, inverted; F) dorsal view, everted; G) distal view, inverted; H) distal

1631 view, everted. In each unique view, from top to bottom the astragalus is rendered as solid (e.g.,

$1632 \mathrm{~A}_{1}$ ), translucent (e.g., $\mathrm{A}_{2}$ ), or is not shown (e.g., $\mathrm{A}_{3}$ ).

1633 Table 1. DOIs and MorphoSource ID numbers for scans and digital models of the Egerkingen 1634 tarsals.

1635 Table 2. Measurements of the Egerkingen tarsals, following Gebo et al. (2001).

1636 Table 3. Relief index (RFI) and orientation patch count (OPC) values for $\mathrm{P}_{4}$ and $\mathrm{M}_{2}$ of

1637 Caenopithecus lemuroides.

1638 Table 4. Ratios of flexor fibularis groove contour measures versus flexor fibularis groove linear 1639 width in living and extinct strepsirrhines.

1640 Table 5. Measurements of peroneal tubercle position and size taken on calcanei of living and 1641 extinct euarchontans. "ProxL" = length of the proximal segment; "DistPT" = distance from the 1642 proximal-most aspect of the calcaneal tuber to the distal-most projection of the peroneal tubercle;

1643 "MidPT" = distance from the proximal-most aspect of the calcaneal tuber to the midpoint of the 1644 peroneal tubercle; “(3-1)” = MidPT - ProxL; “(2-1)” = DistPT - ProxL; “[(2-3) - 1]” = [(DistPT1645 MidPT) - ProxL].

1647 Supplemental information captions 
1648 Appendix S1. Measurements on tarsal facets and lower second molars of extant and subfossil 1649 euarchontans that were used in regression analyses.

1650 Appendix S2. Measurements on tarsal facets and lower second molars of Paleogene 1651 euarchontans that were used in regression analyses.

1652 Appendix S3. Raw measurements and angular measurements, originally published by Boyer et 1653 al. (2010) and augmented by Chester et al. (2015), taken on living and extinct euarchontans that 1654 were converted to shape variables and radians for principal components analysis. Asterisks 1655 indicate which of the measurements were estimated on NMB En.270 due to abrasion or damage. 1656 More detailed explanations of how measurements are taken on digital models can be found in 1657 Boyer et al. (2010).

1658 Appendix S4. Data from dental topography analysis of Caenopithecus, Afradapis, and 109 1659 individuals from 21 extant "prosimian" genera. Values are provided for the input variables $\mathrm{M}_{2}$ 1660 Relief Index (RFI), $\mathrm{M}_{2}$ Orientation Patch Count (OPC), and $\mathrm{M}_{1}$ area (length $\mathrm{x}$ width; note that 1661 the same $M_{1}$ area (i.e., the mean $M_{1}$ area of all $M_{1}$ s associated with $M_{2} s$ ) is used for each $M_{2}$ of 1662 Afradapis and Caenopithecus, because associated $\mathrm{M}_{1} \mathrm{~s}$ were not available for each $\mathrm{M}_{2}$ analyzed);

1663 the dietary classification for extant taxa ("Actual group"); the group predicted by the 1664 discriminant function analysis ("Predicted group (highest prob.)"); probability of classification 1665 into the group predicted by the discriminant function analysis ("Probability"); next-best 1666 classification predicted by the discriminant function analysis ("Second highest group");

1667 probability of the next-best classification predicted by the discriminant function analysis

1668 ("Probability (Second highest group)"); and the discriminant function scores for the first three 1669 discriminant axes ("DF1", "DF2", "DF3"). Results are based on a stepwise discriminant function 
1670 analysis (using the Mahalanobis distance method) run in SPSS v. 22; because Box's M test was

1671 significant, classifications were based on the group covariance matrices of the canonical

1672 discriminant functions, not the original variables. $93.6 \%$ of the original grouped cases were

1673 classified correctly. See Winchester et al. (2014) for a recent summary of the RFI and OPC

1674 methods and their efficacy.

1675 Figure S1. Plot of the first two discriminant functions based on RFI, OPC, and $\mathrm{M}_{1}$ area.

1676 Individuals from each dietary category are enclosed by ellipses that include $95 \%$ confidence

1677 intervals (calculated in PAST, Hammer et al. 2001). Note that two specimens of Afradapis had

1678 the same RFI and OPC values and plot at the same points along DF1 and DF2. Raw data are

1679 provided in Appendix S4.

1680 Dataset S1. Character-taxon matrix employed in the parsimony analysis with some multistate

1681 characters ordered and scaled. Transitions between "fixed" states are equal to a single step

1682 (weights are provided in the PAUP block). Note that a constraint tree with the following

1683 topology must be enforced to obtain the results presented here: (Tupaia glis, ((()(Saimiri

1684 sciureus,Aotus trivirgatus),Alouatta seniculus),(Allenopithecus nigroviridis,Pan

1685 troglodytes)),Tarsius bancanus),((Propithecus spp.,((Cheirogaleus major,Microcebus

1686 murinus),Lepilemur mustelinus),(Lemur catta,Varecia variegata $)),((($ Loris

1687 tardigradus,Nycticebus coucang),(Arctocebus calabarensis,Perodicticus potto)),(Galagoides

1688 demidoff,(Galago moholi,Otolemur crassicaudatus)))))). The tree is provided as Dataset S2.

1689 Dataset S2. Constraint tree used in the parsimony analyses (also enforced as partial constraints in 1690 MrBayes). 
1691 Dataset S3. 3D coordinates for specimens analyzed in the automated geometric analysis of 1692 calcanei.

1693 Dataset S4. Multidimensional Scaling coordinates derived from the automated geometric 1694 analysis of calcanei. 


\section{Table 1 (on next page)}

DOIs and MorphoSource ID numbers for scans and digital models of the Egerkingen tarsals 
DOI

doi:10.17602/M2/M5397

doi:10.17602/M2/M5398

doi:10.17602/M2/M5399

doi:10.17602/M2/M5400

doi:10.17602/M2/M5401

doi:10.17602/M2/M5402

doi:10.17602/M2/M5403

doi:10.17602/M2/M5404

\section{Morphosource ID}

M5963-5397

M5963-5398

M5964-5399

M5964-5400

M5965-5401

M5965-5402

M5966-5403

M5966-5404
File name

NMB-En-270_M5963-5397.zip

NMB-En-270_M5963-5398.ply

NMB-Eh-719_M5964-5399.zip

NMB-Eh-719_M5964-5400.ply

NMB-En-268_M5965-5401.zip

NMB-En-268_M5965-5402.ply

NMB-En-269_M5966-5403.zip

NMB-En-269_M5966-5404.ply

\section{File type}

Zipped tiff stack

Smoothed mesh file

Zipped tiff stack

Smoothed mesh file

Zipped tiff stack

Smoothed mesh file

Zipped tiff stack

Smoothed mesh file

\section{Specimen number}

NMB En.270

NMB En.270

NMB Eh 719

NMB Eh 719

NMB En.268

NMB En.268

NMB En.269

NMB En.269

\section{Element}

Left astragalus

Left astragalus

Right calcaneus

Right calcaneus

Right calcaneus

Right calcaneus

Left calcaneus

Left calcaneus 


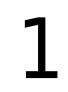

Regression of tooth size on tarsal facet size

Above, regression of the natural log of lower second molar area (length times width) on the natural log of calcaneo-cuboid facet area (length times width), with data from 51 living and extinct primates and seven non-primate euarchontans. Solid circles $=$ extant non-primate euarchontans; open squares $=$ plesiadapiforms; solid squares $=$ tarsiers and extinct omomyiforms; open triangles = extinct adapiforms; open circles = extant lemuriforms; " $\mathrm{x}$ " = extant galagids; open diamonds = extant lorises; " + " = natural log of calcaneo-cuboid facet area of NMB Eh.719 plotted relative to the natural log of second lower molar size of Leptadapis priscus; "+" enclosed in a diamond = natural log of the calcaneo-cuboid facet area of NMB Eh.719 plotted relative to the natural log of second lower molar size of Caenopithecus lemuroides. See figure for regression equation and $r^{2}$. Below, regression of the natural log of lower second molar area (length times width) on the natural log of astragalar trochlear width, with data from 63 living and extinct primates and seven non-primate euarchontans. Symbols as above; "+" = natural log of the trochlear width of NMB En.270 plotted relative to the natural log of second lower molar size of Leptadapis priscus; "+" enclosed in a diamond $=$ natural log of trochlear width of NMB En. 270 plotted relative to the natural log of second lower molar size of Caenopithecus lemuroides. See figure for regression equation and $\mathrm{r}^{2}$. Note that the extant pen-tailed tree shrew Ptilocercus shows a tooth-tarsal scaling relationship that differs from that of living and extinct primates; for this reason it was excluded from the regression equation. 

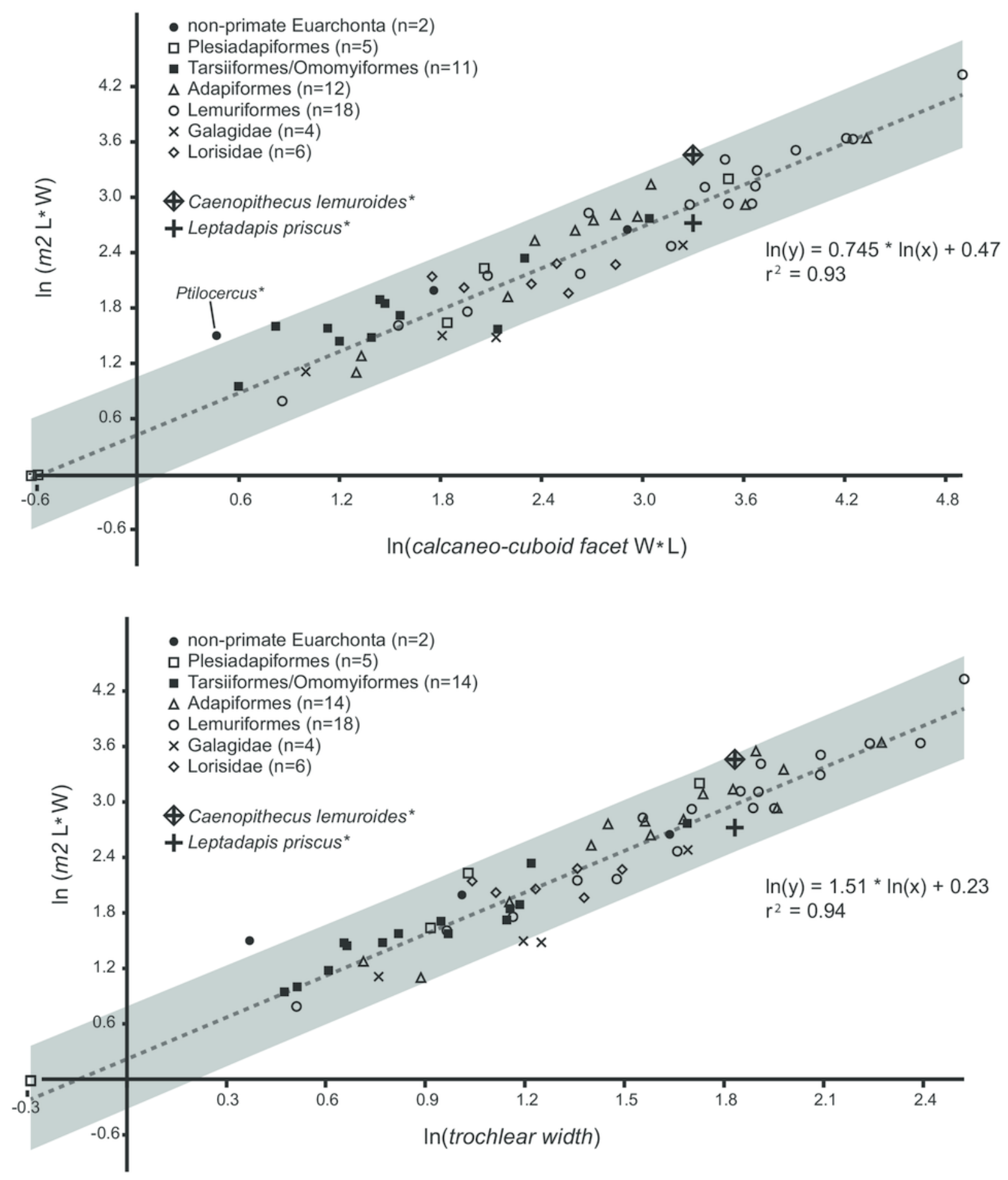
2

Residuals for the natural $\log$ of $\mathrm{M}_{2}$ area of adapiforms following recalculation of regression of the natural log of $\mathrm{M}_{2}$ area on tarsal facet area excluding those adapiform species.

Note that Caenopithecus lemuroides ("Cl") and Leptadapis priscus ("Lp") have predicted values for the natural log of lower second molar area that fall outside of the $95 \%$ confidence interval on the mean for both calcaneocuboid facet area (above) and trochlear width (below). Other abbreviations: "Ap" = Adapis parisiensis, "Al" = Afradapis longicristatus, "Ca" = Cantius abditus, "Cm" = Cantius mckennai, "Cr" = Cantius ralstoni, "Ct" = Cantius trigonodus, "Ek" = Europolemur klatti, "Nt" = Notharctus tenebrosus, "Lm" = Leptadapis magnus, "Sg" = Smilodectes gracilis. See figure for regression equations.

Calcaneo-cuboid facet size residuals

line: $\ln (y)=0.738 * \ln (x)+0.461$

$n$ for regression: 49

$n$ for adapiforms withheld: 9

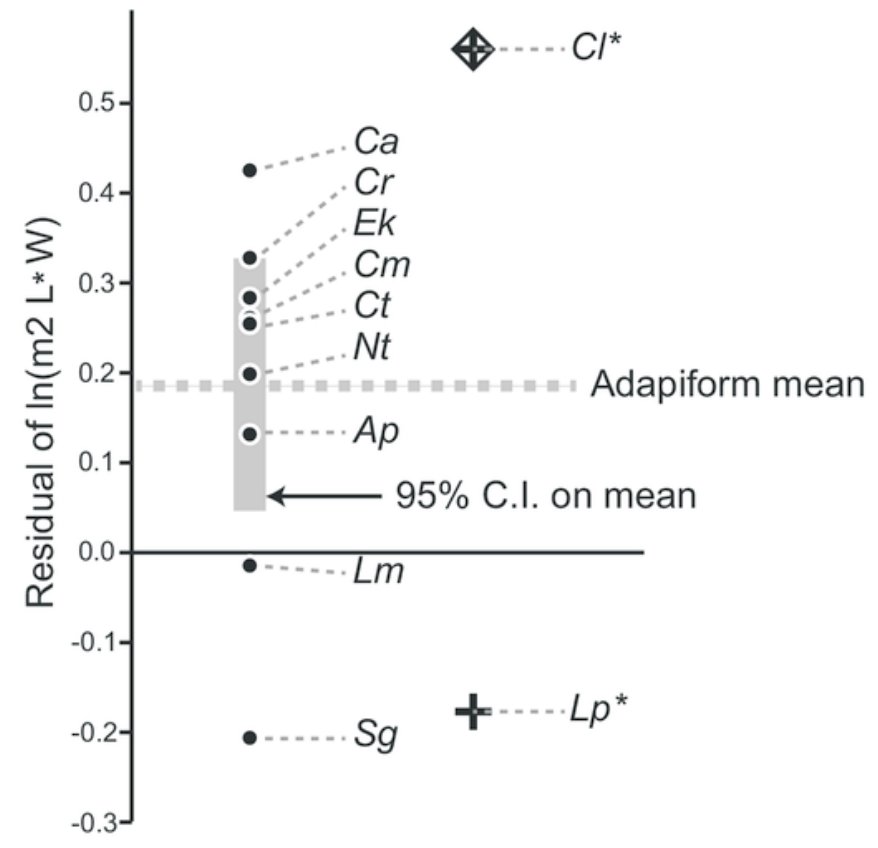

\section{Trochlear width residuals}
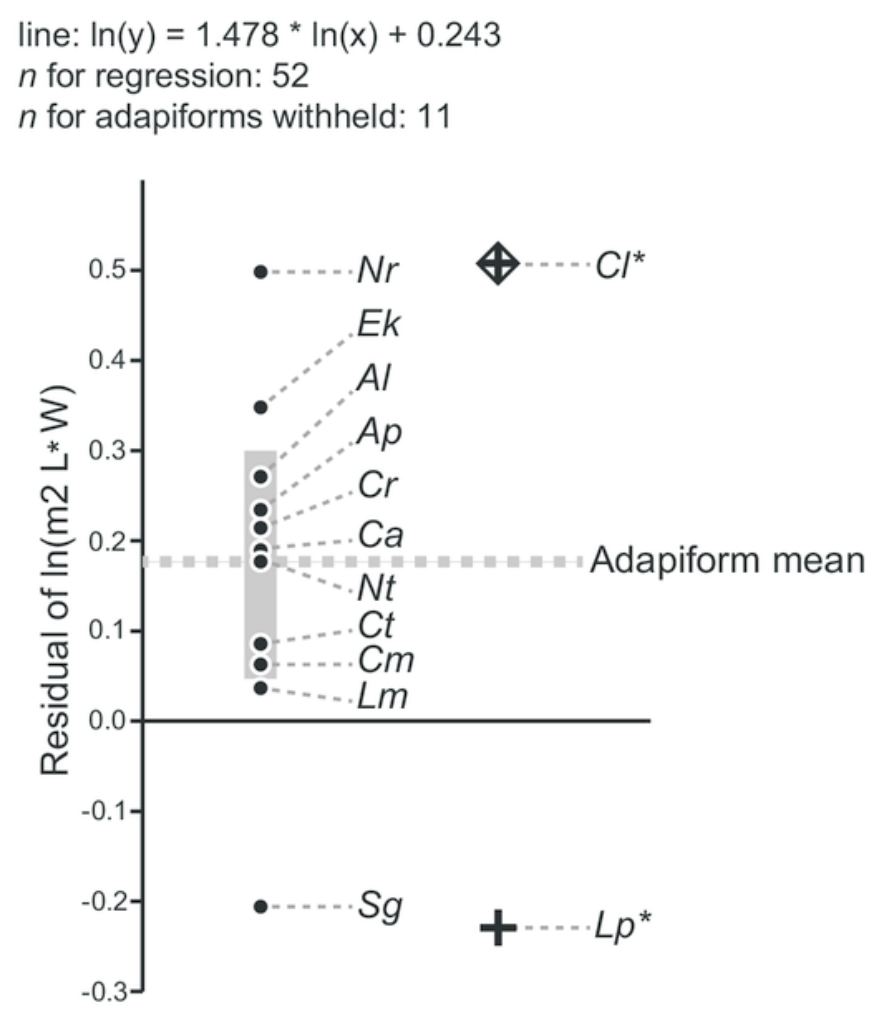


\section{3}

Box plot of z-score-standardized differences in residuals.

Values plotted are the absolute difference between the z-score-standardized residual of $\mathrm{m} 2$ size to astragalus size and the residual of $\mathrm{m} 2$ size to calcaneus size of a given taxon. We noticed that for most taxa, the $\mathrm{m} 2$ residual generated by the calcaneus was proportional to the $\mathrm{m} 2$ residual generated by the astragalus. The comparative sample includes all specimens for which both astragali and calcanei could be compared with tooth size (both fossil and extant) for a total $n=57$ species. As in other plots, the diamond enclosed cross uses the molar measurements of Caenopithecus, while the regular cross uses those of Leptadapis priscus. Because the fossils under scrutiny plot in the observed range, this test does not refute the hypothesis that both bones belong to a single species. 


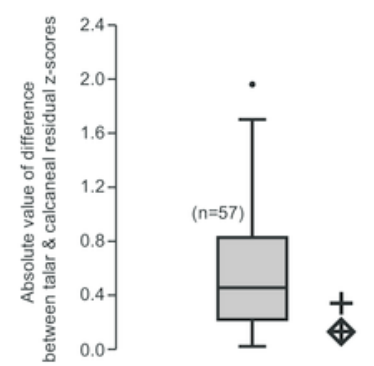


4

Stereopair images of NMB En.270, left astragalus from Egerkingen (probably fissure $\gamma$ ) attributed here to Caenopithecus lemuroides.

A) proximal, B) distal, C) medial, D) lateral, E) dorsal, and F) plantar views. 



\section{Table 2 (on next page)}

Measurements of the Egerkingen tarsals, following Gebo et al. (2001). 


\begin{tabular}{lccc}
\hline & NMB En.268 & NMB En.269 & NMB Eh.719 \\
\hline "Calcaneal length" (CalL) & 22.25 & 20.74 \\
"Distal calcaneal length" (DistL) & & 7.76 \\
"Posterior calcaneal facet length" (PcfL, & & 7.54 & 6.87 \\
= ectal facet of this study) & & 3.77 \\
"Posterior calcaneal facet width" (PcfW) & 2.61 & 6.24 \\
"Heel length" (HeelL) & 8.98 & 10.11 \\
"Calcaneal width" (CalW) & & 4.17 \\
"Calcaneocuboid height" (CubHt) & & 6.51 \\
"Calcaneocuboid width" (CubW) & & 0.49 \\
CalW/CalL & & 0.37 \\
DistL/CalL & & 0.33 \\
PcfL/CalL & & 0.30 \\
HeelL/CalL & & 1.10 \\
PcfL/HeelL & 0.40 & 0.55 \\
PcfW/PcfL & & 1.56 \\
CubW/CubHt & &
\end{tabular}

NMB En.270

\begin{tabular}{lc}
\hline $\begin{array}{l}\text { "Talar neck angle" (TNECKANGLE, in } \\
\text { degrees, estimated) }\end{array}$ & 33 \\
"Trochlear length" (TRL) & 9.33 \\
"Midtrochlear width" (MTRW) & 6.25 \\
"Talar width" (TW) & 9.28 \\
MTRW/TRL & 0.67
\end{tabular}




\section{Table 3(on next page)}

Relief index (RFI) and orientation patch count (OPC) values for $\mathrm{P}_{4}$ and $\mathrm{M}_{2}$ of Caenopithecus lemuroides. 


$\begin{array}{llccccc}\text { Specimen } & \text { Species } & \text { Locus } & \text { 2D area } & \text { 3D area } & \text { RFI } & \text { OPC } \\ \text { NMB no number } & \text { Caenopithecus lemuroides } & \mathrm{p} 4 & 15.77 & 43.18 & 0.50 & 35.50 \\ \text { NMB no number } & \text { Caenopithecus lemuroides } & \mathrm{m} 2 & 25.96 & 67.60 & 0.48 & 68.00 \\ \text { NMB Eh 396 } & \text { Caenopithecus lemuroides } & \mathrm{m} 2 & 25.89 & 67.24 & 0.48 & 54.13 \\ \text { NMB Eh 735 } & \text { Caenopithecus lemuroides } & \mathrm{m} 2 & 26.05 & 71.03 & 0.50 & 62.63 \\ \text { NMB Eh 600 } & \text { Caenopithecus lemuroides } & \mathrm{p} 4 & 16.10 & 38.86 & 0.44 & 28.63 \\ \text { NMB Eh 597 } & \text { Caenopithecus lemuroides } & \mathrm{p} 4 & 14.59 & 41.40 & 0.52 & 36.88 \\ \text { NMB Eh 597 } & \text { Caenopithecus lemuroides } & \mathrm{m} 2 & 25.24 & 68.45 & 0.50 & 56.25\end{array}$




\section{5}

Stereopair images of NMB Eh 719, right calcaneus from Egerkingen fissure $\gamma$, attributed here to Caenopithecus lemuroides.
A) dorsal, B) distal, C) lateral, D) medial, and E) plantar views. 

6

Stereopair images of NMB En.268, right calcaneus from Egerkingen (probably fissure $\gamma$ ) attributed here to Caenopithecus lemuroides.

In A) dorsal, B) distal, C) lateral, D) medial, and E) plantar views. 



\section{7}

Stereopair images of NMB En.269, left calcaneus from Egerkingen (probably fissure $\gamma$ ) attributed here to Caenopithecus lemuroides.

In A) dorsal, B) distal, C) lateral, D) medial, and E) plantar views. 

8

Astragali of other fossil strepsirrhines compared to NMB En.270, attributed here to Caenopithecus lemuroides.
A) Djebelemur martinezi (CBI-1-545), from the early or middle Eocene of Tunisia; B) Cantius trigonodus (USGS 21832), from the early Eocene of the U.S.A.; C) Asiadapis cambayensis (GU 747), from the early Eocene of India; D) Leptadapis magnus (MNHN QU 11001), from the late Eocene of France; E) Adapis parisiensis (ECA 1379), from the late Eocene of France; F) Caenopithecus lemuroides (NMB En.270, reversed); G) Afradapis longicristatus (DPC 21445C), from the late Eocene of Egypt; H) Adapoides troglodytes (IVPP V13016, reversed), from the middle Eocene of China. Views in, from left to right, dorsal, plantar, proximal, lateral, distal, and medial views. Scale bars are equal to $1 \mathrm{~mm}$. 

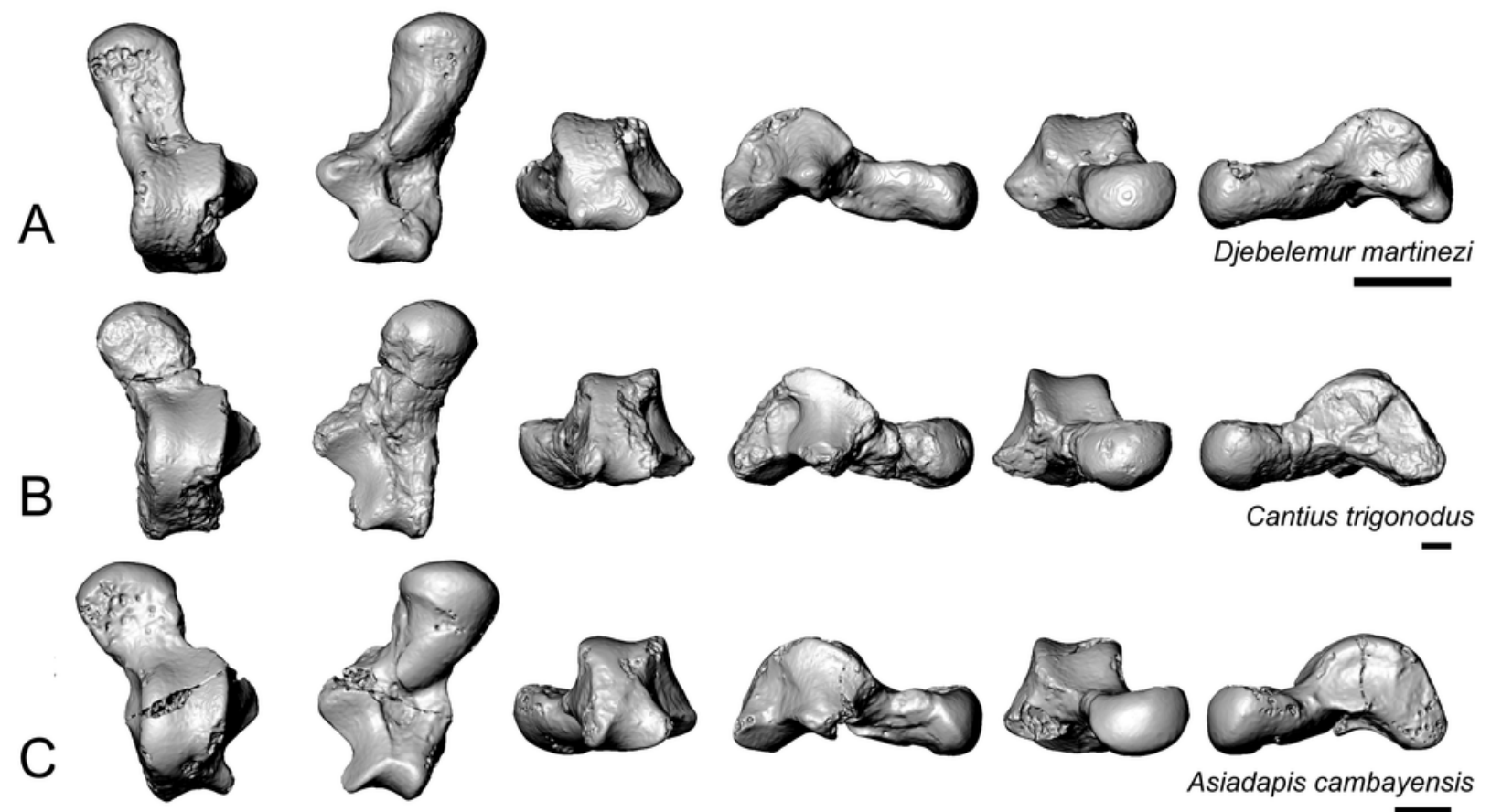

Asiadapis cambayensis

D
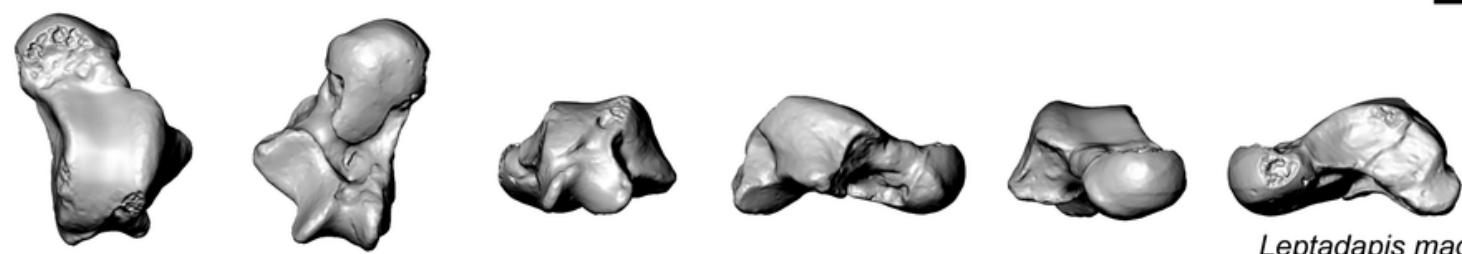

Leptadapis magnus
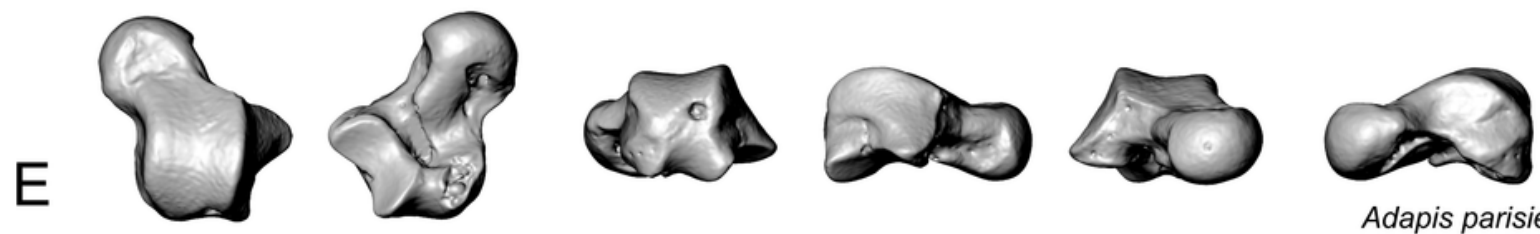

Adapis parisiensis
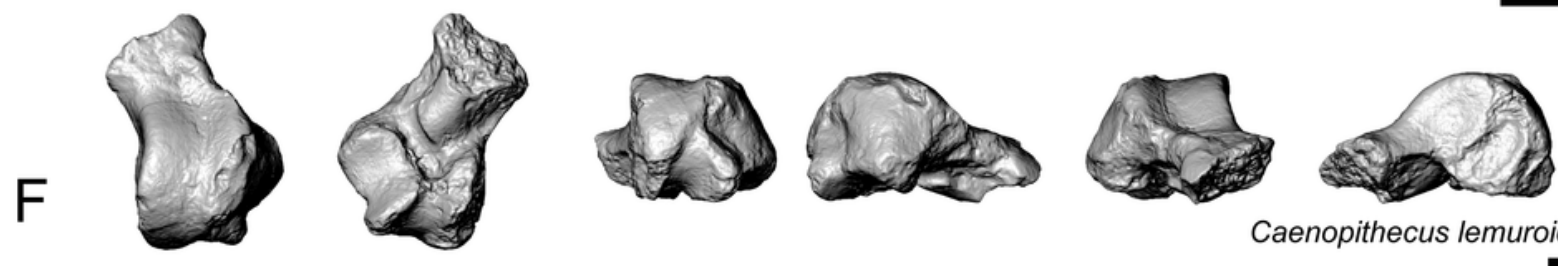

Caenopithecus lemuroides
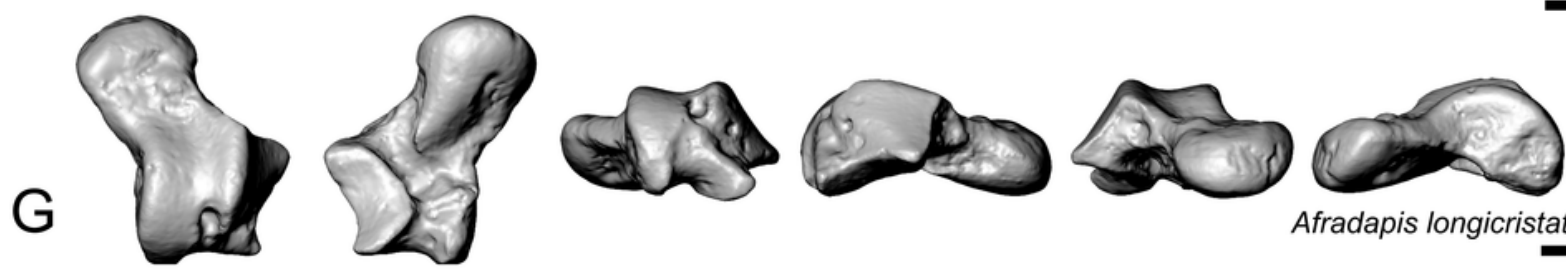

Afradapis longicristatus

$\mathrm{H}$
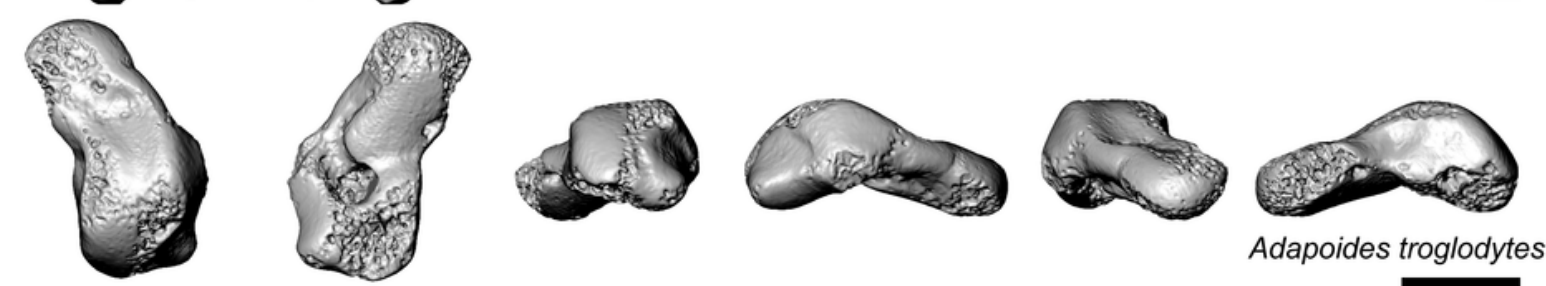
9

Astragali of extant and subfossil strepsirrhines compared to NMB En.270, attributed here to Caenopithecus lemuroides.
A) Microcebus murinus (AMNH 174430); B) Hapalemur griseus (AMNH 170680); C)
Daubentonia madagascariensis (AMNH 119694); D) Varecia variegata (AMNH 201384); E) Perodicticus potto (AMNH 184579); F) Nycticebus coucang (AMNH 212953); G) Babakotia radofilai (DPC 11000); H) Caenopithecus lemuroides (NMB En.270, reversed). Views in, from left to right, dorsal, plantar, proximal, lateral, distal, and medial views. Scale bars are equal to $1 \mathrm{~mm}$. 

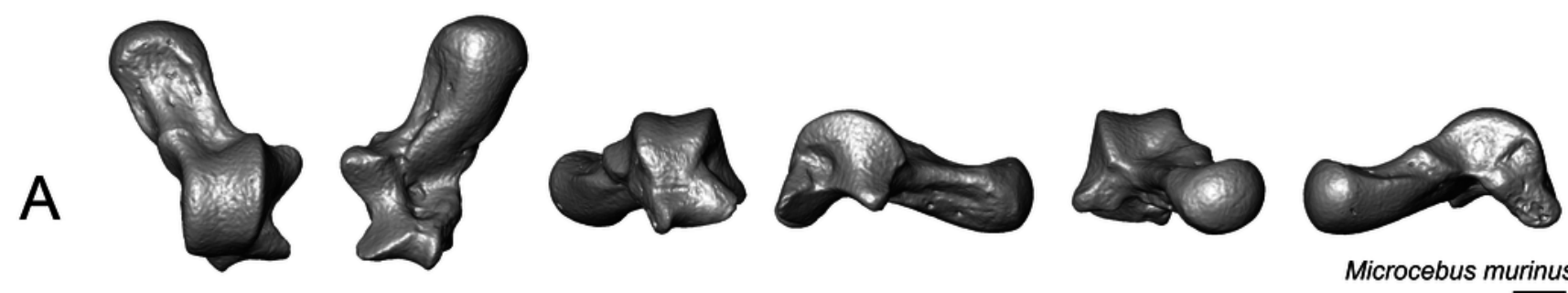

Microcebus murinus
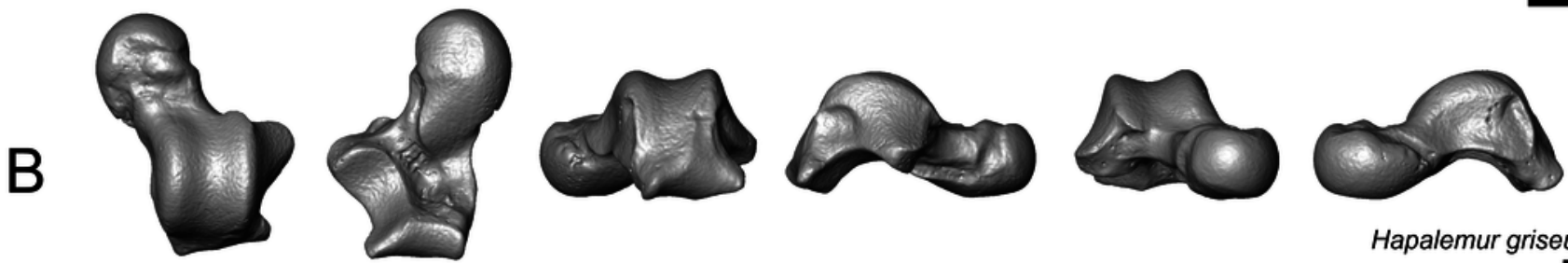

Hapalemur griseus
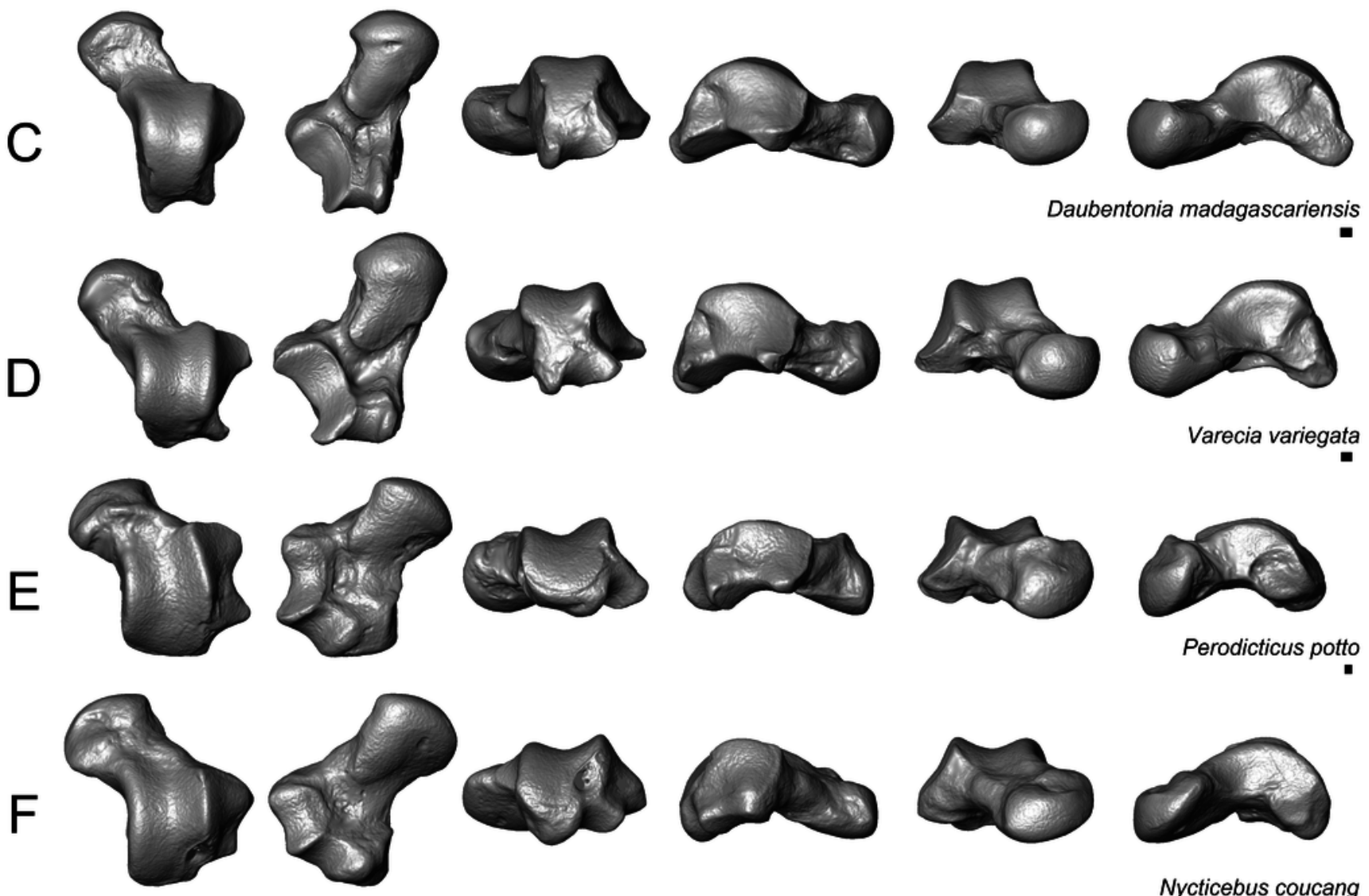

Nycticebus coucang
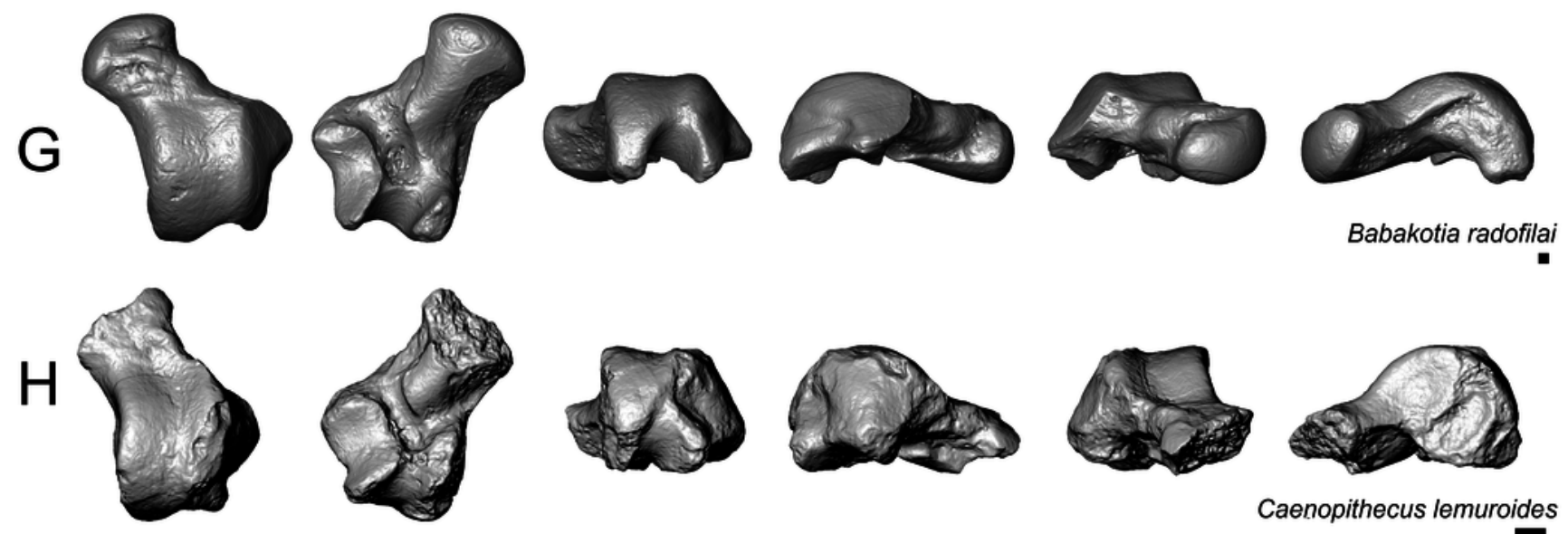
Principal components analysis of astragalar shape variables and angles.

First two principal component axes, accounting for $57.1 \%$ of the overall variance, based on the reduced dataset of 15 astragalar measurements that could be taken on NMB En.270 (loadings for each variable on PC1 and PC2 are provided in the lower right hand corner). Note that Caenopithecus falls close to Afradapis, and to adapines and lorisids. The suspensory subfossil palaeopropithecid "sloth lemur" Babakotia expands the crown primate morphospace considerably, driven largely by extreme expression of features that also influence Caenopithecus's positive score on PC1 -- i.e., a particularly long and wide flexor fibularis groove (variables 12 and 13) and a high angle between the medial tibial facet and fibular facet (variable 20).

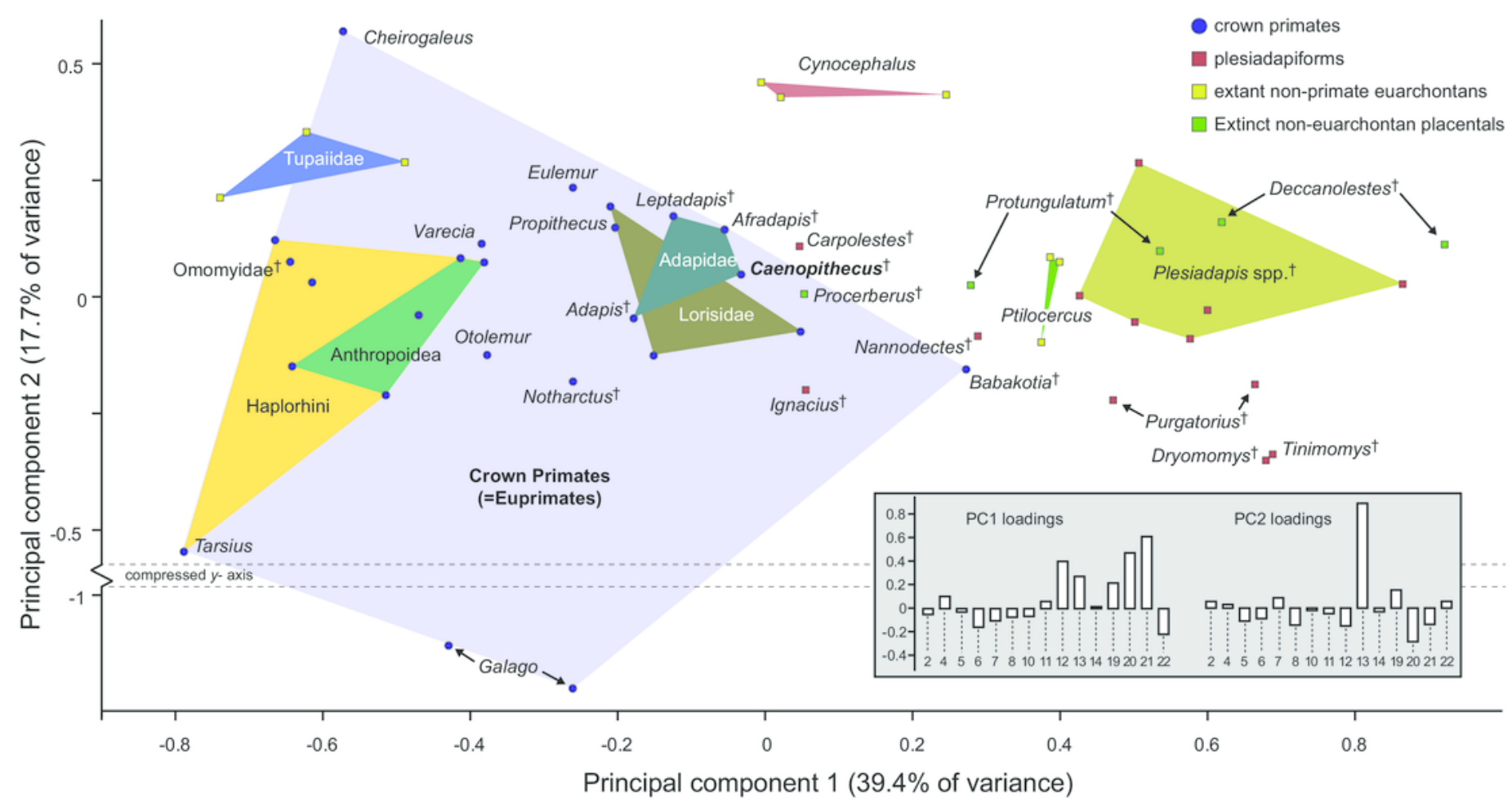


11

Quantification of flexor fibularis groove depth on the plantar surface of the astragalus.

Inset image shows the orientation of the astragalus for simultaneous measurement of linear width of the flexor fibularis groove, and the contour measure of the groove (taken in Geomagic). As noted in the main text, astragali were oriented with the plantar surface facing upward and in posterior view, such that the point marking the base of the trough of the flexor fibularis groove was aligned with the point marking the plantar apex of the navicular facet or sustentacular facet (whichever was visible in that view). Boxplots show variation within species in the ratio of the contour measurement to the linear measurement; higher numbers are found in taxa species with deeper flexor fibularis grooves. Note that the values for Babakotia and Megaladapis are so extreme that they fall far outside of the figured range. 


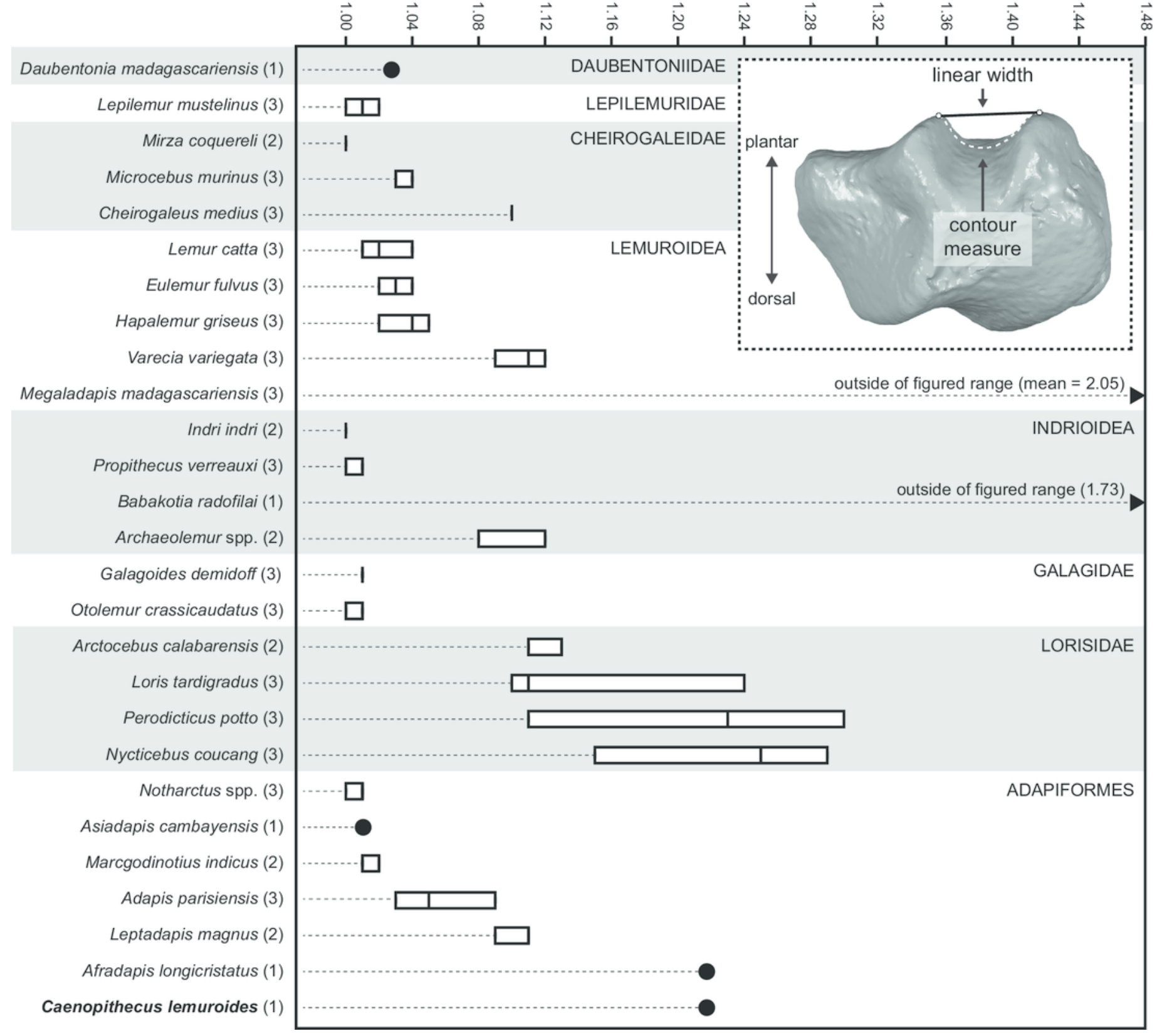




\section{Table 4(on next page)}

Ratios of flexor fibularis groove contour measures versus flexor fibularis groove linear width in living and extinct strepsirrhines. 
Taxon

Adapis parisiensis

Adapis parisiensis

Adapis parisiensis

Afradapis longicristatus

Archaeolemur sp.

Archaeolemur sp.

Arctocebus calabarensis

Arctocebus calabarensis

Asiadapis cambayensis

Babakotia radofilai

Caenopithecus lemuroides

Cheirogaleus medius

Cheirogaleus medius

Cheirogaleus medius

Daubentonia madagascariensis

Eulemur fulvus albifrons

Eulemur fulvus albifrons

Eulemur fulvus fulvus

Galagoides demidoff

Galagoides demidoff

Galagoides demidoff

Hapalemur griseus

Hapalemur griseus

Hapalemur griseus

Indri indri
Specimen

MaPhQ 1390

ROS 106

ROS 2708

DPC 21445C

DPC 7849

DPC 7900

AMNH 207949

AMNH 212576

GU 747

DPC 11000

NMB En.270

DPC 0142

DPC 031

DPC 1023

AMNH 119694

AMNH 170708

AMNH 170728

AMNH 31254

AMNH 212956

AMNH 241121

AMNH 215180

AMNH 170680

AMNH 170689

AMNH 61589

AMNH 208992
1.02

1.04

1.05

Flexor fibularis groove contour/flexor fibularis groove linear

1.03

1.05

1.09

1.22

1.08

1.12

1.11

1.13

1.01

1.73

1.22

1.10

1.10

1.10

1.03

1.03

1.04

1.02

1.01

1.01

1.01

1.00 
Indri indri

Lemur catta

Lemur catta

Lemur catta

Lepilemur mustelinus

Lepilemur mustelinus

Lepilemur mustelinus

Leptadapis magnus

Leptadapis magnus

Loris tardigradus

Loris tardigradus

Loris tardigradus

Marcgodinotius indicus

Marcgodinotius indicus

Megaladapis madagascariensis

Megaladapis madagascariensis

Megaladapis madagascariensis

Microcebus murinus

Microcebus murinus

Microcebus murinus

Mirza coquereli

Mirza coquereli

Notharctus sp.

Notharctus sp.

Notharctus sp.

Nycticebus coucang

Nycticebus coucang
AMNH 100504

1.00

AMNH 170739

1.02

AMNH 170740

1.04

AMNH 170765

1.01

AMNH 170556

1.01

AMNH 170560

1.02

AMNH 170565

1.00

NMB QE 261

1.11

NMB QE 496

1.09

AMNH 150038

1.24

AMNH 165931

1.10

AMNH 34257

1.11

GU 748

1.02

GU 749

1.01

DPC 18936

1.92

DPC 17176

1.81

DPC 7821

2.43

AMNH 174428

1.03

AMNH 174430

1.04

$\begin{array}{ll}\text { AMNH } 174431 & 1.03\end{array}$

DPC 0137

1.00

DPC 1139

1.00

AMNH 12000

1.01

AMNH 11474

1.00

AMNH 129382

1.01

AMNH 90381

1.29

AMNH 102027 
Nycticebus coucang

Otolemur crassicaudatus

Otolemur crassicaudatus

Otolemur crassicaudatus

Perodicticus potto

Perodicticus potto

Perodicticus potto

Propithecus verreauxi

Propithecus verreauxi

Propithecus verreauxi

Varecia variegata

Varecia variegata

Varecia variegata
AMNH 212953

1.15

AMNH 187364

1.00

AMNH 150413

1.01

AMNH 216240

AMNH 184579

AMNH 269851

AMNH 86898

AMNH 170474

AMNH 170463

AMNH 208991

AMNH 201384

DPC 049

AMNH 100512
1.00

1.23

1.11

1.30

1.00

1.01

1.00

1.11

1.12

1.09 
12

Peroneal tubercle position in living and extinct primates, and comparisons of the Caenopithecus calcaneus NMB Eh 719 with those of other adapiforms.

A) Box and whisker plots of [(natural log of proximal segment length) - (natural log of the position of peroneal tubercle midpoint)] measured on the calcanei of 50 Eocene adapiforms, 21 Eocene omomyiforms, four Eocene stem anthropoids, five Oligocene parapithecids, five Paleocene plesiadapiforms, and 15 extant non-primate euarchontans. Note that the range of Caenopithecus is intermediate between those of adapines and other adapiforms, but the broad range is largely driven by a single specimen. B) Calcanei of various adapiforms scaled to the same approximate proximal segment length, illustrating differences in peroneal tubercle position (peroneal tubercles are delimited by opaque overlays). Also note the very short distal calcaneal segments of Adapis and Leptadapis relative to those of Caenopithecus and other adapiforms, and the different shapes and orientations of the long axes of the cuboid facets in distal view (margins of the cuboid facets are also delimited by opaque overlays). Scale bar $=10 \mathrm{~mm}$. 


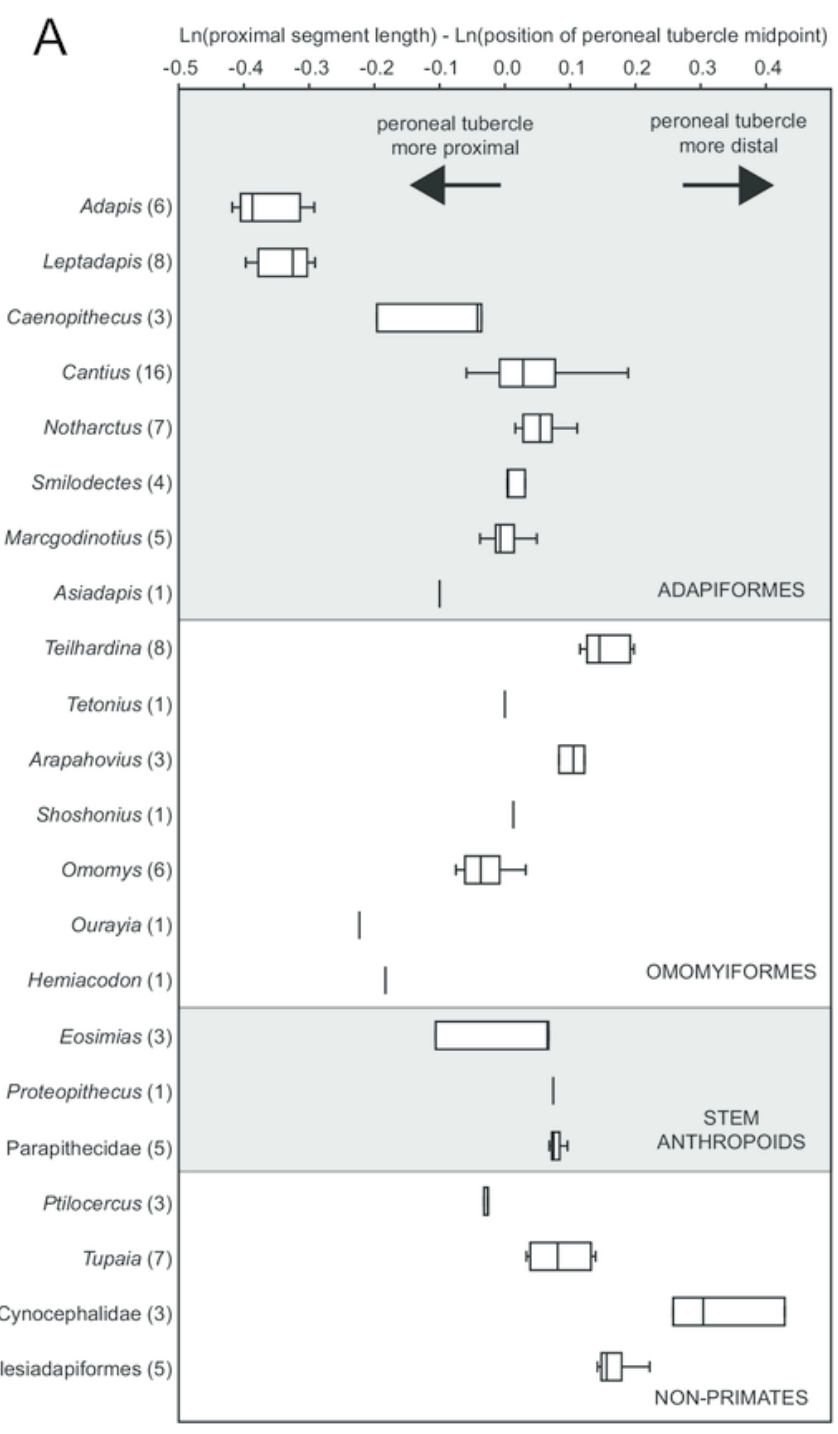

B
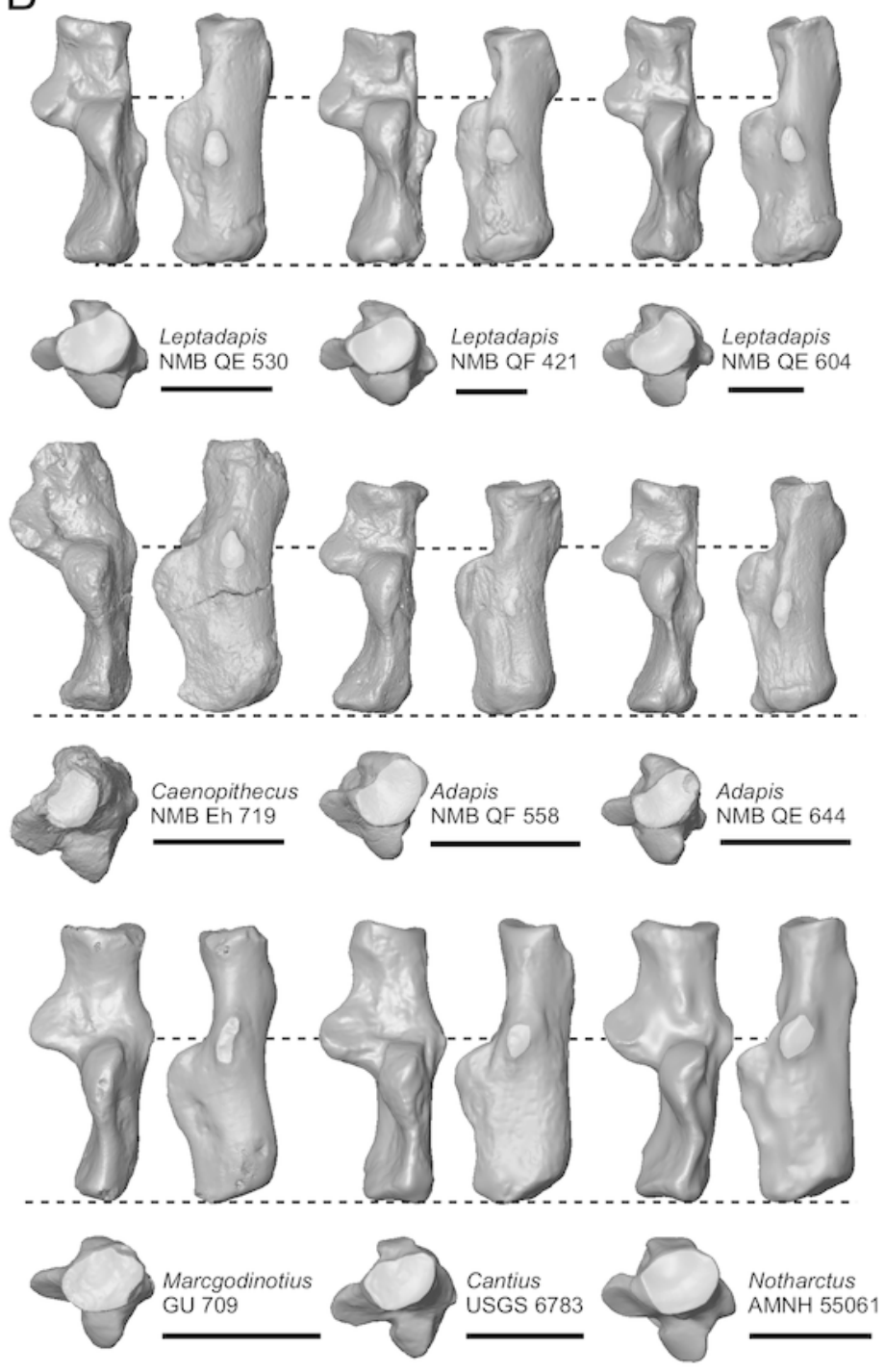


\section{Table 5(on next page)}

Measurements of peroneal tubercle position and size taken on calcanei of living and extinct euarchontans.

"ProxL" = length of the proximal segment; "DistPT" = distance from the proximal-most aspect of the calcaneal tuber to the distal-most projection of the peroneal tubercle; "MidPT" $=$ distance from the proximal-most aspect of the calcaneal tuber to the midpoint of the peroneal tubercle; "(3-1)" = MidPT - ProxL; “(2-1)" = DistPT - ProxL; "[(2-3) - 1]" = [(DistPTMidPT) - ProxL]. 


\begin{tabular}{|c|c|c|c|c|c|c|c|c|}
\hline Higher taxon & Genus/species & Specimen & 1) ProxL & 2) DistPT & 3) MidPT & 4) $(3-1)$ & 5) $(2-1)$ & 6) $[(2-3)-1]$ \\
\hline Adapinae & Adapis parisiensis & NMB QE 530 & 14.74 & 11.82 & 9.95 & -0.393 & -0.221 & -2.065 \\
\hline Adapinae & Adapis parisiensis & NMB QE 644 & 12.33 & 9.62 & 8.22 & -0.405 & -0.248 & -2.176 \\
\hline Adapinae & Adapis parisiensis & NMB QE 741 & 11.95 & 10.25 & 7.87 & -0.418 & -0.153 & -1.614 \\
\hline Adapinae & Adapis parisiensis & NMB QE 779 & 13.3 & 12.05 & 9.72 & -0.314 & -0.099 & -1.742 \\
\hline Adapinae & Adapis parisiensis & NMB QF 558 & 10.88 & 8.02 & 7.39 & -0.387 & -0.305 & -2.849 \\
\hline Adapinae & Adapis parisiensis & NMB QH 640 & 12.81 & 10.55 & 9.57 & -0.292 & -0.194 & -2.570 \\
\hline Adapinae & Leptadapis magnus & NMB QW 1676 & 22.56 & 19.7 & 16.55 & -0.310 & -0.136 & -1.969 \\
\hline Adapinae & Leptadapis magnus & PQ 1746 & 23.49 & 19.58 & 15.8 & -0.397 & -0.182 & -1.827 \\
\hline Adapinae & Leptadapis magnus & ACQ 266 & 24.74 & 22.05 & 16.95 & -0.378 & -0.115 & -1.579 \\
\hline Adapinae & Leptadapis magnus & ACQ 267 & 24.63 & 22.09 & 17.97 & -0.315 & -0.109 & -1.788 \\
\hline Adapinae & Leptadapis magnus & NMB QE 920 & 24.56 & 19.94 & 17.4 & -0.345 & -0.208 & -2.269 \\
\hline Adapinae & Leptadapis magnus & NMB QE 604 & 21.13 & 17.9 & 15.61 & -0.303 & -0.166 & -2.222 \\
\hline Adapinae & Leptadapis magnus & NMB QF 421 & 23.15 & 19.02 & 16.73 & -0.325 & -0.197 & -2.313 \\
\hline Adapinae & Leptadapis magnus & NMB QE 830 & 21.61 & 18.6 & 16.15 & -0.291 & -0.150 & -2.177 \\
\hline Asiadapinae & Asiadapis cambayensis & GU 716 & 5.76 & 5.89 & na & na & 0.022 & na \\
\hline Asiadapinae & Asiadapis cambayensis & GU 760 & 6.64 & 6.71 & 6.01 & -0.100 & 0.010 & -2.250 \\
\hline Asiadapinae & Marcgodinotius indicus & GU 1644 & 4.19 & 4.98 & 4.13 & -0.014 & 0.173 & -1.595 \\
\hline Asiadapinae & Marcgodinotius indicus & GU 709 & 4.55 & 5.33 & 4.52 & -0.007 & 0.158 & -1.726 \\
\hline Asiadapinae & Marcgodinotius indicus & GU 751 & 4.82 & 5.71 & 5.06 & 0.049 & 0.169 & -2.004 \\
\hline
\end{tabular}




\begin{tabular}{|c|c|c|c|c|c|c|c|c|}
\hline Asiadapinae & Marcgodinotius indicus & GU 1642 & 4.59 & 4.9 & 4.42 & -0.038 & 0.065 & -2.258 \\
\hline Asiadapinae & Marcgodinotius indicus & GU 1643 & 4.33 & 5.21 & 4.39 & 0.014 & 0.185 & -1.664 \\
\hline Caenopithecinae & Caenopithecus lemuroides? & NMB Eh 719 & 13.12 & 14.39 & 12.58 & -0.042 & 0.092 & -1.981 \\
\hline Caenopithecinae & Caenopithecus lemuroides? & NMB En.268 & 14.12 & 14.46 & 11.61 & -0.196 & 0.024 & -1.600 \\
\hline Caenopithecinae & Caenopithecus lemuroides? & NMB En.269 & 13.76 & 15.31 & 13.27 & -0.036 & 0.107 & -1.909 \\
\hline Carpolestidae & Carpolestes simpsoni & UM 101963 & 4.12 & 6.85 & 5.89 & 0.357 & 0.508 & -1.457 \\
\hline Cynocephalidae & Cynocephalus volans & UNSM 11501 & 7.92 & 12.37 & 10.25 & 0.258 & 0.446 & -1.318 \\
\hline Cynocephalidae & Cynocephalus volans & AMNH 207001 & 9.08 & 14.37 & 12.3 & 0.304 & 0.459 & -1.479 \\
\hline Cynocephalidae & Galeopterus variegatus & USNM 317118 & 7.5 & 13.25 & 11.52 & 0.429 & 0.569 & -1.467 \\
\hline Eosimiidae & Eosimias sp. & IVPP 11851 & 3.59 & 4.51 & 3.84 & 0.067 & 0.228 & -1.679 \\
\hline Eosimiidae & Eosimias sp. & IVPP 12313 & 4.33 & 5.98 & 4.62 & 0.065 & 0.323 & -1.158 \\
\hline Eosimiidae & Eosimias sp. & IVPP 12281 & 4.08 & 4.73 & 3.67 & -0.106 & 0.148 & -1.348 \\
\hline Notharctinae & Cantius mckennai & USGS 5897 & 10.45 & 12.72 & 11.4 & 0.087 & 0.197 & -2.069 \\
\hline Notharctinae & Cantius & USGS 6791 & 11.76 & 12.89 & 11.71 & -0.004 & 0.092 & -2.299 \\
\hline Notharctinae & Cantius & USGS 21768 & 13.96 & 16.13 & 14.2 & 0.017 & 0.144 & -1.979 \\
\hline Notharctinae & Cantius abditus & USGS 21771 & 14.04 & 16.91 & 15.23 & 0.081 & 0.186 & -2.123 \\
\hline Notharctinae & Cantius abditus & USGS 21774 & 13.52 & 15.12 & 13.41 & -0.008 & 0.112 & -2.068 \\
\hline Notharctinae & Cantius & USGS 21778 & 12.24 & 13.98 & 12.71 & 0.038 & 0.133 & -2.266 \\
\hline Notharctinae & Cantius abditus & USGS 21825 & 13.53 & 15.06 & 13.66 & 0.010 & 0.107 & -2.268 \\
\hline Notharctinae & Cantius abditus & USGS 21827 & 14.25 & 16.34 & 13.99 & -0.018 & 0.137 & -1.802 \\
\hline Notharctinae & Cantius frugivorus & USGS 21828 & 11.28 & 12.69 & 11.11 & -0.015 & 0.118 & -1.966 \\
\hline
\end{tabular}




\begin{tabular}{|c|c|c|c|c|c|c|c|c|}
\hline Notharctinae & Cantius mckennai & USGS 25029a & 11.28 & 13.25 & 12.04 & 0.065 & 0.161 & -2.232 \\
\hline Notharctinae & Cantius mckennai & USGS 25029b & 11.28 & 13.1 & 11.73 & 0.039 & 0.150 & -2.108 \\
\hline Notharctinae & Cantius abditus & AMNH 16852 & 13.05 & 15.09 & 13.75 & 0.052 & 0.145 & -2.276 \\
\hline Notharctinae & Cantius abditus & USGS 6783 & 13.67 & 15.95 & 14.06 & 0.028 & 0.154 & -1.979 \\
\hline Notharctinae & Cantius ralstoni & UF 252980 & 8.63 & 11.12 & 10.43 & 0.189 & 0.254 & -2.526 \\
\hline Notharctinae & Cantius sp. & USGS 21829 & 12.41 & 14.61 & 13.41 & 0.077 & 0.163 & -2.336 \\
\hline Notharctinae & Cantius trigonodus & USGS 6774 & 14.98 & 15.21 & 14.12 & -0.059 & 0.015 & -2.621 \\
\hline Notharctinae & Notharctus tenebrosus & AMNH 13766 & 15.46 & 18.42 & 16.35 & 0.056 & 0.175 & -2.011 \\
\hline Notharctinae & Notharctus tenebrosus & AMNH 55061 & 13.27 & 16.17 & 13.65 & 0.028 & 0.198 & -1.661 \\
\hline Notharctinae & Notharctus tenebrosus & AMNH 129382 & 13.56 & 16.07 & 14.28 & 0.052 & 0.170 & -2.025 \\
\hline Notharctinae & Notharctus tenebrosus & AMNH 11474 & 13.25 & 15.01 & 13.46 & 0.016 & 0.125 & -2.146 \\
\hline Notharctinae & Notharctus tenebrosus & AMNH 131945 & 14.26 & 17.66 & 15.05 & 0.054 & 0.214 & -1.698 \\
\hline Notharctinae & Notharctus tenebrosus & AMNH 131955 & 14.79 & 18.07 & 16.53 & 0.111 & 0.200 & -2.262 \\
\hline Notharctinae & Notharctus tenebrosus & AMNH 11478 & 15.57 & 18.57 & 16.73 & 0.072 & 0.176 & -2.136 \\
\hline Notharctinae & Smilodectes gracilis & USNM 21815 & 14.5 & 16.85 & 14.95 & 0.031 & 0.150 & -2.032 \\
\hline Notharctinae & Smilodectes gracilis & USNM 25686 & 14.76 & 16.38 & 14.82 & 0.004 & 0.104 & -2.247 \\
\hline Notharctinae & Smilodectes gracilis & AMNH 131763 & 15.02 & 17.46 & 15.45 & 0.028 & 0.151 & -2.011 \\
\hline Notharctinae & Smilodectes gracilis & AMNH 131774 & 14.85 & 16.96 & 14.93 & 0.005 & 0.133 & -1.990 \\
\hline Omomyiformes & Arapahovius & UCMP 118498 & 3.59 & 4.33 & 3.9 & 0.083 & 0.187 & -2.122 \\
\hline Omomyiformes & Arapahovius & UCMP 118499 & 3.39 & 4.43 & 3.83 & 0.122 & 0.268 & -1.732 \\
\hline Omomyiformes & Arapahovius & UCMP 173038 & 3.79 & 4.76 & 4.21 & 0.105 & 0.228 & -1.930 \\
\hline
\end{tabular}




\begin{tabular}{|c|c|c|c|c|c|c|c|c|}
\hline Omomyiformes & Hemiacodon gracilis & AMNH 12613 & 7.61 & 8.01 & 6.34 & -0.183 & 0.051 & -1.517 \\
\hline Omomyiformes & Omomys carteri & UCM 67678 & 6.93 & 7.79 & 6.52 & -0.061 & 0.117 & -1.697 \\
\hline Omomyiformes & Omomys carteri & UCM 68745 & 7.23 & 8.61 & 6.97 & -0.037 & 0.175 & -1.484 \\
\hline Omomyiformes & Omomys carteri & UCM 69065 & 7.52 & 9.69 & 7.13 & -0.053 & 0.254 & -1.078 \\
\hline Omomyiformes & Omomys carteri & UCM 67679 & 7.04 & 8.82 & 6.53 & -0.075 & 0.225 & -1.123 \\
\hline Omomyiformes & Omomys carteri & UCM 69303 & 7.88 & 9.08 & 8.14 & 0.032 & 0.142 & -2.126 \\
\hline Omomyiformes & Omomys carteri & UM 98604 & 6.45 & 7.01 & 6.4 & -0.008 & 0.083 & -2.358 \\
\hline Omomyiformes & Ourayia uintensis & $\begin{array}{l}\text { SDNM 4020- } \\
60933\end{array}$ & 10.96 & 12.58 & 8.77 & -0.223 & 0.138 & -1.057 \\
\hline Omomyiformes & Shoshonius cooperi & CM 69765 & 4.43 & 5.3 & 4.49 & 0.013 & 0.179 & -1.699 \\
\hline Omomyiformes & Teilhardina belgica & IRSNB M1236 & 3.49 & 4.99 & 4.03 & 0.144 & 0.358 & -1.291 \\
\hline Omomyiformes & Teilhardina belgica & IRSNB M1237 & 3.09 & 4.2 & 3.63 & 0.161 & 0.307 & -1.690 \\
\hline Omomyiformes & Teilhardina belgica & IRSNB M1247 & 3.2 & 4.47 & 3.9 & 0.198 & 0.334 & -1.725 \\
\hline Omomyiformes & Teilhardina belgica & IRSNB 16786-06 & 3.27 & 4.28 & 3.67 & 0.115 & 0.269 & -1.679 \\
\hline Omomyiformes & Teilhardina belgica & IRSNB 26857-05 & 3.19 & 4.12 & 3.62 & 0.126 & 0.256 & -1.853 \\
\hline Omomyiformes & Teilhardina belgica & IRSNB 26857-04 & 3.48 & 4.77 & 4.15 & 0.176 & 0.315 & -1.725 \\
\hline Omomyiformes & Teilhardina belgica & IRSNB M0061 & 3.13 & 4.35 & 3.62 & 0.145 & 0.329 & -1.456 \\
\hline Omomyiformes & Teilhardina belgica & IRSNB 16786-03 & 3.31 & 4.63 & 4.01 & 0.192 & 0.336 & -1.675 \\
\hline Omomyiformes & Tetonius sp. & AMNH 88821 & 4.49 & 6.7 & 4.49 & 0.000 & 0.400 & -0.709 \\
\hline Parapithecidae & Apidium phiomense? & DPC 1003B & 14.12 & 17.39 & 15.22 & 0.075 & 0.208 & -1.873 \\
\hline Parapithecidae & Apidium phiomense? & DPC 8810 & 13.45 & 17.52 & 14.81 & 0.096 & 0.264 & -1.602 \\
\hline Parapithecidae & Apidium phiomense? & DPC 2381 & 13.79 & 17.41 & 15 & 0.084 & 0.233 & -1.744 \\
\hline
\end{tabular}




\begin{tabular}{|c|c|c|c|c|c|c|c|c|}
\hline Parapithecidae & Apidium phiomense? & DPC 15679 & 14.06 & 17.4 & 15.05 & 0.068 & 0.213 & -1.789 \\
\hline Parapithecidae & Apidium phiomense? & DPC 20576 & 9.72 & 12.4 & 10.45 & 0.072 & 0.244 & -1.606 \\
\hline Paromomyidae & Ignacius graybullianus & USNM 442240 & 4.82 & 7.04 & 6.02 & 0.222 & 0.379 & -1.553 \\
\hline Plesiadapidae & Nannodectes gidleyi & AMNH 17379 & 6.49 & 8.95 & 7.48 & 0.142 & 0.321 & -1.485 \\
\hline Plesiadapidae & Plesiadapis churchilli & UM XXX & 7.71 & 10.53 & 9.01 & 0.156 & 0.312 & -1.624 \\
\hline Plesiadapidae & Plesiadapis cookei & UM 87990 & 11.13 & 16.05 & 12.91 & 0.148 & 0.366 & -1.265 \\
\hline Plesiadapidae & Plesiadapis tricuspidens & MNHN R 414 & 12.25 & 17.23 & 14.65 & 0.179 & 0.341 & -1.558 \\
\hline Proteopithecidae & Proteopithecus sylviae & DPC 24776 & 7.19 & 8.45 & 7.74 & 0.074 & 0.161 & -2.315 \\
\hline Ptilocercidae & Ptilocercus lowii & USNM 488067 & 3.13 & 3.74 & 3.05 & -0.026 & 0.178 & -1.512 \\
\hline Ptilocercidae & Ptilocercus lowii & USNM 488069 & 3.13 & 3.73 & 3.03 & -0.032 & 0.175 & -1.498 \\
\hline Ptilocercidae & Ptilocercus lowii & USNM 488072 & 3.13 & 3.66 & 3.05 & -0.026 & 0.156 & -1.635 \\
\hline Tupaiidae & Tupaia belangeri & AMNH 113135 & 5.3 & 7.16 & 5.51 & 0.039 & 0.301 & -1.167 \\
\hline Tupaiidae & Tupaia glis & SBU Tg01 & 5.09 & 7.72 & 5.26 & 0.033 & 0.417 & -0.727 \\
\hline Tupaiidae & Tupaia glis & AMNH 215175 & 4.9 & 7.58 & 5.63 & 0.139 & 0.436 & -0.921 \\
\hline Tupaiidae & Tupaia glis & AMNH 215176 & 4.62 & 6.96 & 4.91 & 0.061 & 0.410 & -0.813 \\
\hline Tupaiidae & Tupaia glis & AMNH 215177 & 5.23 & 7.9 & 5.92 & 0.124 & 0.412 & -0.971 \\
\hline Tupaiidae & Tupaia glis & AMNH 215178 & 5.18 & 7.63 & 5.91 & 0.132 & 0.387 & -1.102 \\
\hline Tupaiidae & Tupaia glis & AMNH 215179 & 4.99 & 6.93 & 5.41 & 0.081 & 0.328 & -1.189 \\
\hline
\end{tabular}


13

Calcanei of extant and subfossil strepsirrhines compared to NMB Eh 719, attributed here to Caenopithecus lemuroides.

A) Varecia variegata (AMNH 201384); B) Daubentonia madagascariensis (AMNH 185643); C) Perodicticus potto (AMNH 184597); D) Nycticebus coucang (AMNH 102027); E) Babakotia radofilai (DPC 11818); F) Caenopithecus lemuroides (NMB Eh 719). Views in, from left to right, medial, dorsal, lateral, and plantar; and, on the far right, proximal (above) and distal (below). Scale bars are equal to $5 \mathrm{~mm}$. 


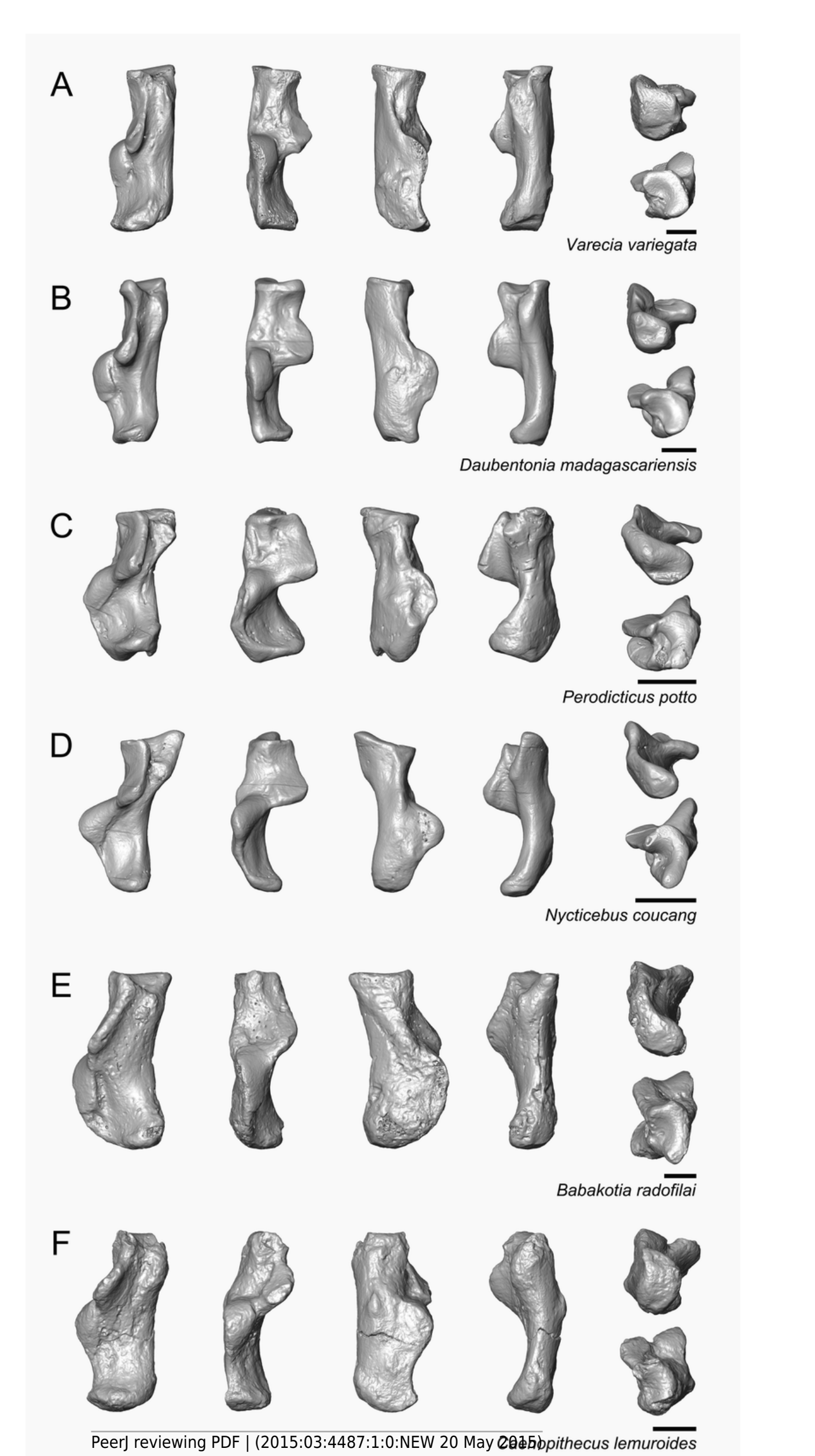




\section{4}

Multidimensional scaling plot derived from automated geometric morphometric analysis of euarchontan calcanei, based on 1200 points.

The position of Caenopithecus lemuroides (based on NMB Eh 719) is marked by a white star enclosed in a red circle. Abbreviations: "Asiad." = Asiadapinae; "Daub." = Daubentonia; "Noth." = Notharctinae; "Proteo." = Proteopithecus.

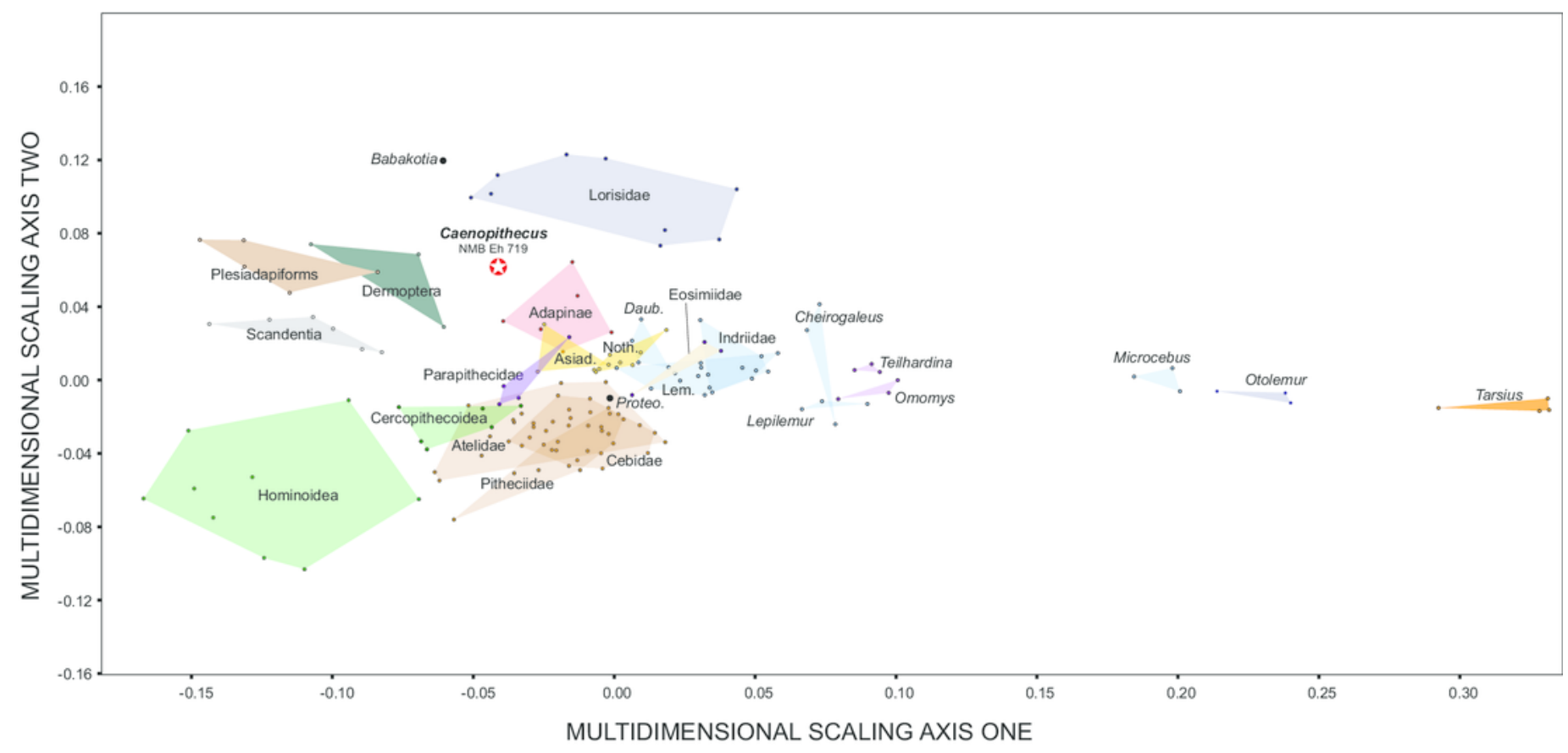


15

Phylogenetic analysis with some multistate characters ordered.

Strict consensus of two equally parsimonious trees of length 4330.5 recovered following parsimony analysis (10,000 heuristic search replicates) of the 291 character matrix in PAUP* 4.10b, with 256 of the characters ordered and transitions between "fixed" and "polymorphic" states in ordered morphoclines weighted as 0.5 . See text for tree statistics; numbers above or below branches are bootstrap values, following 1000 pseudoreplicates. Relationships among extant species were constrained by a molecular "scaffold" following Springer et al. (2012). 


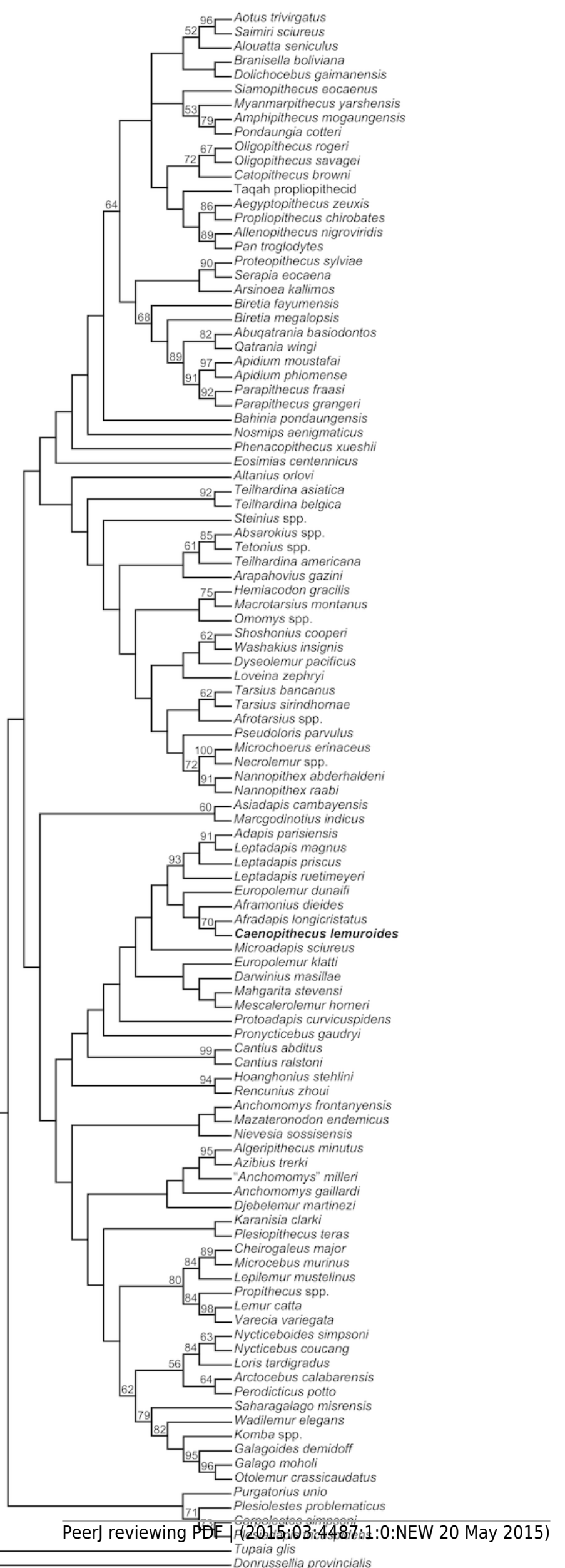




\section{6}

Phylogenetic analysis with all characters unordered.

A) Strict consensus of 342 equally parsimonious trees of length 4638 following parsimony analysis (10,000 heuristic search replicates) of the 291 character matrix in PAUP* 4.10b, with all characters unordered and equally weighted. See text for tree statistics; numbers above or below branches are bootstrap values, following 1000 pseudoreplicates. Relationships among extant species were constrained by a molecular "scaffold" following Springer et al. (2012). Note that, unlike the consensus tree with some characters ordered and scaled, adapines form a clade with Microadapis, Pronycticebus, and Protoadapis rather than with any caenopithecine, though Caenopithecus still forms a clade with Afradapis to the exclusion of all other species. B) "Halfcompat" (majority-rule) consensus tree following 50 million MCMC generations in MrBayes (first 25\% discarded as "burn-in"). Numbers above or below branches are posterior probabilities. Relationships among extant species were constrained by a molecular "scaffold" following Springer et al. (2012). Note that caenopithecines are paraphyletic with respect to adapines given this topology, unambiguously implying reacquisition of the upper and lower first premolar in the latter clade. 
A

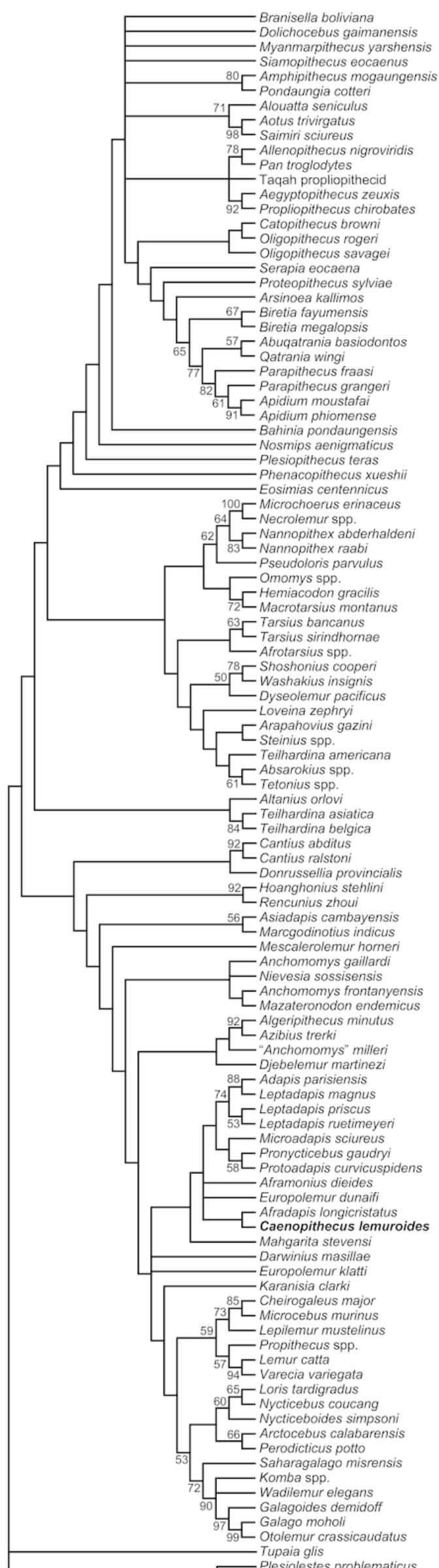

B

$100-$ Parapithecus fraasi

C Parapithecus grangeri

75- Abuqatrania basiodontos

- Qatrania wingi

$100 \square 74$ Biretia fayumensis

${ }^{4}$ - Biretia megalopsis - Arsinoea kallimos

90 Proteopithecus sylviae

L Serapia eocaena

98 Oligopithecus savagei

5 ᄃ Catopithecus browni

100 Aegyptopithecus zeuxis

62 - Propliopithecus chirobates

98 Taqah propliopithecid

Allenopithecus nigroviridis

100 - Pan troglodytes

4 Dolichocebus gaimanensis

- Alouatta seniculus

${ }_{100}$ - Aotus trivirgatus

Siamopithecus eocaenus

96 Myanmarpithecus yarshensis

$100-$ Amphipithecus mogaungensis

daungia cotteri

- Nosmips aenigmaticus

- Bahinia pondaungensis

- Phenacopithecus xueshi

- Eosimias centennicus

25- Tarsius bancanus

Larsius sirindhornae

${ }_{100}$ Microchoerus erinaceus

58 - Necrolemur spp.

100 - Nannopithex abderhaldeni

${ }_{97} \leftarrow$ Nannopithex raabi

- Pseudoloris parvulus

$100-$ Shoshonius cooper

- Washakius insignis

- Loveina zephryi

Dyseolemur pacificus

- Omomys spp.

- Hemiacodon gracilis

$100-$ Macrotarsius montanus

- Arapahovius gazir

6 - Absarokius spp.

- Tetonius spp.

- Steinius spp.

- Temardina americana

91 Teilhardina asiatica

- Teilhardina belgica

- Donrussellia provincialis

99

Cantius abditus

00 Asiadapis cambayensis

- Marcgodinotius indicus

$100-$ Hoanghonius stehlini

Lencunius zhoui

94-Adapis parisiensis

100 L Leptadapis magnus

- Leptadapis priscus

ruetimeyeri

97 - Alradapis longicristatus

Aframonius dieides

- Mahgarita stevensi

- Darwinius masillae

Europolemur dunaifi

- Europolemur klatti

- Microadapis sciureus

99 Pronycticebus gaudryi

L Protoadapis curvicuspidens

- Anchomomys frontanyensis

78 - Mazateronodon endemicus

L Nievesia sossisensis

- Anchomomys gaillardi

"Anchomomys" milleri

68 Algeripithecus minutus

100 - Azibius trerki

- Djebelemur martinezi

- Plesiopithecus teras

${ }_{100}^{100}-$ Cheirogaleus major

100 Lepilemur mustelinus

_ Propithecus spp.

Lemur catta

100 L Varecia variegata

52 - Arctocebus calabarensis

L Karanisia clarki

- Nycticeboides simpsoni

- Nycticebus coucang

L Loris tardigradus

Saharagalago misrensis

Komba spp.

Wadilemur elegans

22 Galago moholi

${ }_{100}$ Otolemur crassicaudatus

- Altanius orlovi Tupaia glis - Tupaia glis 


\section{7}

Phylogenetic analysis with standard polymorphic scoring and 256 multistate characters treated as ordered.

A) Strict consensus of 783 equally parsimonious trees of length 3796 following parsimony analysis (10,000 heuristic search replicates) of the 291 character matrix in PAUP* 4.10b, with all characters equally weighted, "standard" scoring of polymorphisms, and 256 multistate characters treated as ordered. See text for tree statistics; numbers above or below branches are bootstrap values, following 1000 pseudoreplicates. Relationships among extant species were constrained by a molecular "scaffold" following Springer et al. (2012). B) "Halfcompat" (majority-rule) consensus tree following 50 million MCMC generations of the same matrix in MrBayes (first 25\% discarded as "burn-in"). Numbers above or below branches are posterior probabilities. Relationships among extant species were constrained by a molecular "scaffold" following Springer et al. (2012). Note that, as in the Bayesian analysis of unordered characters caenopithecines are paraphyletic with respect to adapines given this topology, unambiguously implying re-acquisition of the upper and lower first premolar in the latter clade. 
A

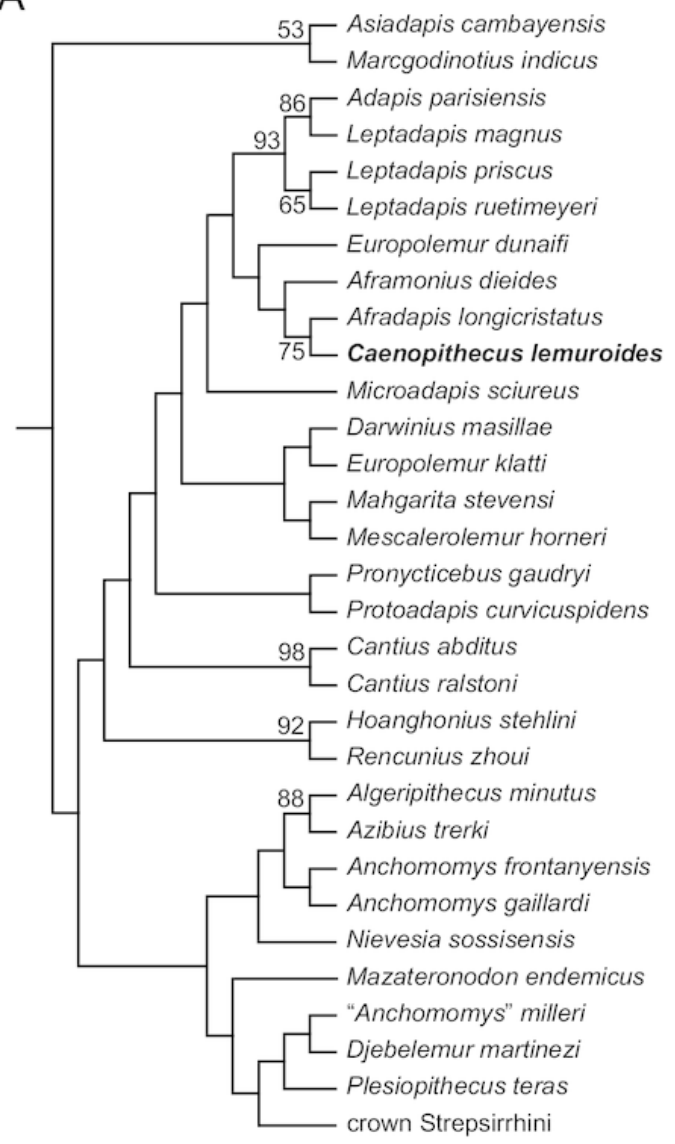

B

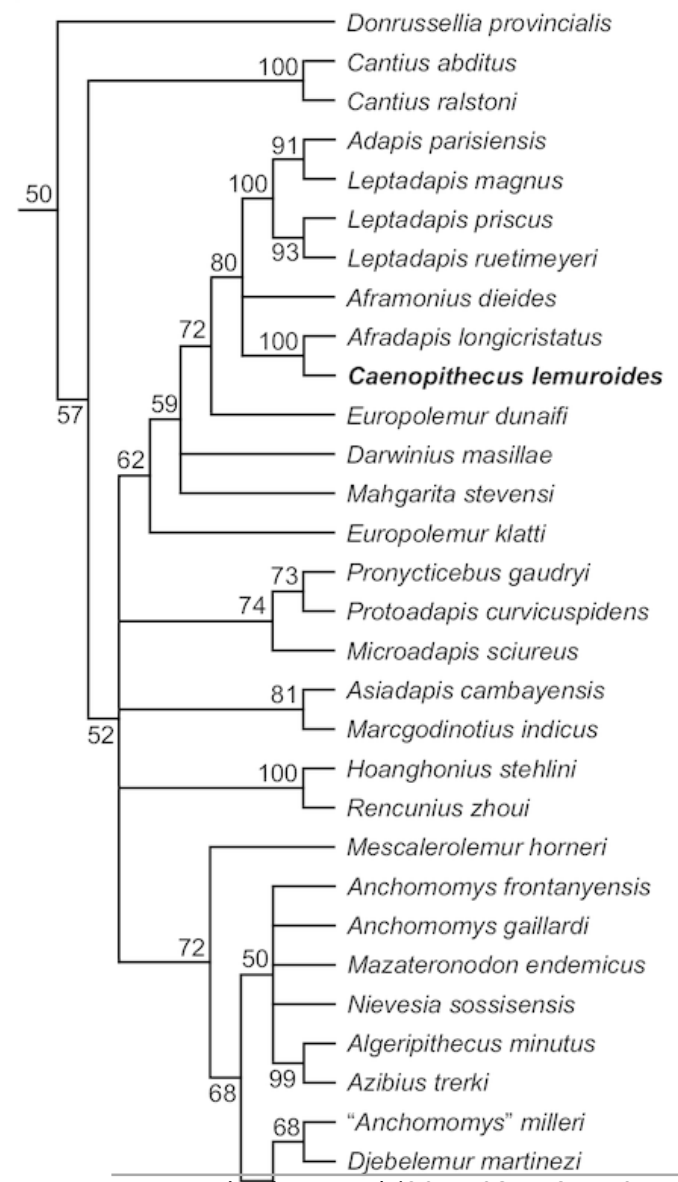

PeerJ reviewing PDFids(30175:03:44:87:1:0:NEW 20 May 2015)

$74 \leftarrow$ crown Strepsirrhini 


\section{8}

Sustentacular facet morphology and flexor fibularis groove depth in Caenopithecus and other adapiforms.

Stereopairs of A) Caenopithecus (NMB En.270, reversed); B) Afradapis (DPC 21445C, reversed); C) Adapis (ECA 7377); and Asiadapis (GU 747) in distal view, showing 1) the laterally expanded convexity of the sustentacular facet in Afradapis and particularly Caenopithecus, and 2) the deep flexor fibularis grooves of Afradapis and Caenopithecus when compared with Adapis and Asiadapis.
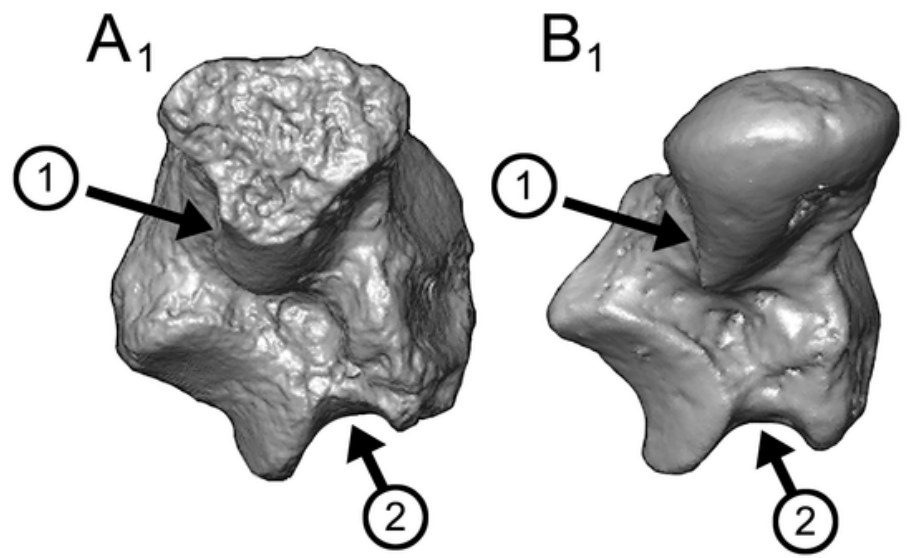

$\mathrm{A}_{2}$

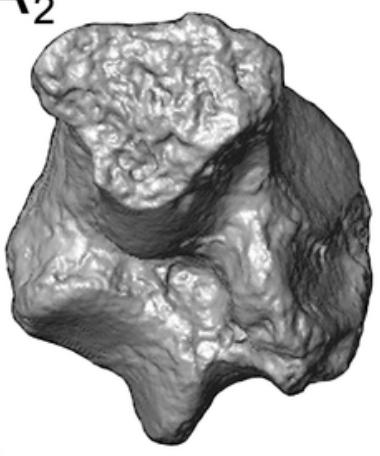

$\mathrm{D}_{1}$
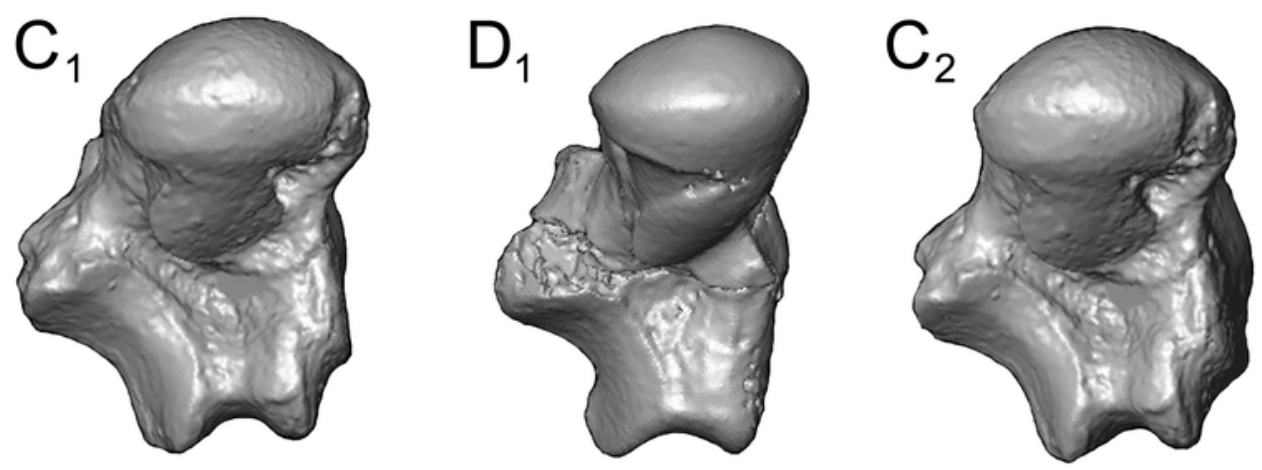
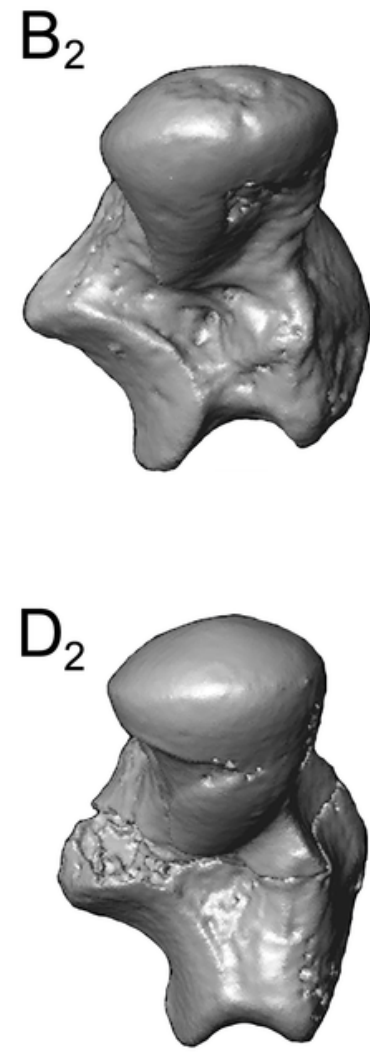
19

Articulation of the unassociated Caenopithecus astragalus NMB En.270 and and calcaneus NMB Eh 719 in inversion and eversion.

Articulated astragalus and calcaneus in A) lateral view, inverted; B) lateral view, everted; C) medial view, inverted; D) medial view, everted; E) dorsal view, inverted; F) dorsal view, everted; G) distal view, inverted; H) distal view, everted. In each unique view, from top to bottom the astragalus is rendered as solid (e.g., $A_{1}$ ), translucent (e.g., $A_{2}$ ), or is not shown (e.g., $A_{3}$ ). 

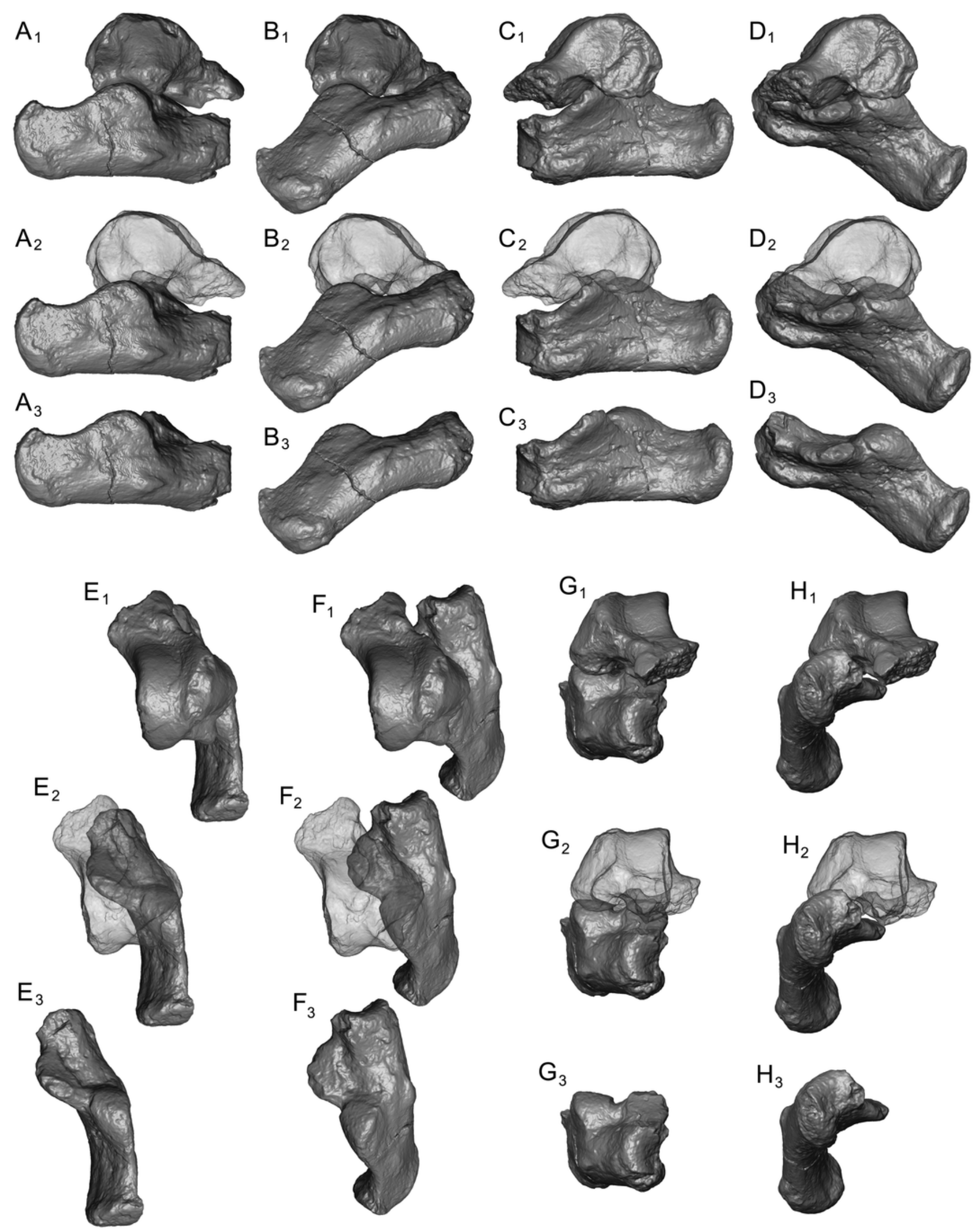